\title{
Molecular alterations during insulinoma tumorigenesis
}

Citation for published version (APA):

Jonkers, Y. M. H. (2007). Molecular alterations during insulinoma tumorigenesis. [Doctoral Thesis, Maastricht University]. Universiteit Maastricht. https://doi.org/10.26481/dis.20070614yj

Document status and date:

Published: 01/01/2007

DOI:

10.26481/dis.20070614yj

Document Version:

Publisher's PDF, also known as Version of record

\section{Please check the document version of this publication:}

- A submitted manuscript is the version of the article upon submission and before peer-review. There can be important differences between the submitted version and the official published version of record.

People interested in the research are advised to contact the author for the final version of the publication, or visit the DOI to the publisher's website.

- The final author version and the galley proof are versions of the publication after peer review.

- The final published version features the final layout of the paper including the volume, issue and page numbers.

Link to publication

\footnotetext{
General rights rights.

- You may freely distribute the URL identifying the publication in the public portal. please follow below link for the End User Agreement:

www.umlib.nl/taverne-license

Take down policy

If you believe that this document breaches copyright please contact us at:

repository@maastrichtuniversity.nl

providing details and we will investigate your claim.
}

Copyright and moral rights for the publications made accessible in the public portal are retained by the authors and/or other copyright owners and it is a condition of accessing publications that users recognise and abide by the legal requirements associated with these

- Users may download and print one copy of any publication from the public portal for the purpose of private study or research.

- You may not further distribute the material or use it for any profit-making activity or commercial gain

If the publication is distributed under the terms of Article $25 \mathrm{fa}$ of the Dutch Copyright Act, indicated by the "Taverne" license above, 
(c) YMH Jonkers, Maastricht 2007

Printed by: Graphic \& Mail, Venlo ISBN 978-90-9021769-7

Cover Illustration by Silvie Helmes 


\title{
MOLECULAR ALTERATIONS DURING INSULINOMA TUMORIGENESIS
}

\author{
PROEFSCHRIFT \\ ter verkrijging van de graad van doctor \\ aan de Universiteit Maastricht \\ op gezag van de Rector Magnificus Prof. mr. G.P.M.F. Mols \\ volgens het besluit van het College van Decanen, \\ in het openbaar te verdedigen op \\ donderdag 14 juni om 12.00 uur
}

door

Yvonne Margaretha Hendrika Jonkers geboren op 15 januari 1979 te Tegelen 


\section{Promotor:}

Prof. Dr. F.C.S. Ramaekers

\section{Co-promotor:}

Dr. E.J.M. Speel

\section{Beoordelingscommissie:}

Prof. Dr. A.P. de Bruïne (voorzitter)

Dr. C.H.C. Dejong

Prof. Dr. J.P.M. Geraedts

Prof. Dr. G. Klöppel (University of Kiel, Germany)

Prof. Dr. Em. C.J.M. Lips (UMC Utrecht)

The research presented in this thesis was performed at the department of Molecular Cell Biology, University of Maastricht, Maastricht, The Netherlands, and was supported by the Netherlands Foundations Vanderes and Sacha Swarttouw-Hijmans, and the Association for International Cancer Research (AICR), St. Andrews, UK.

The publication of this thesis was financially supported by: Abbott B.V., BD biosciences, Greiner bio-one, Ipsen Farmaceutica B.V., and Novartis Oncology. 


\section{CONTENTS}

$\begin{array}{lll}\text { Chapter } 1 & \text { General Introduction } & 7\end{array}$

Chapter 2 Chromosomal instability predicts metastatic disease 23 in patients with insulinomas

Chapter 3 Novel candidate tumor suppressor gene loci on chromosomes 11q23-24 and 22q13 involved in human insulinoma tumorigenesis

Chapter 4 Molecular parameters associated with insulinoma progression: chromosomal instability versus p53 and CK19 status

Chapter 5 DNA copy number status is a powerful predictor of poor survival in insulinoma patients

Chapter 6 General Discussion

Chapter 7 Summary

Chapter 8 Samenvatting

Color Figures

List of abbreviations

Dankwoord

Publications

Curriculum Vitae 


\section{CHAPTER 1}

\section{GENERAL INTRODUCTION}

Adapted in part from:

Molecular alterations during insulinoma tumorigenesis

Yvonne M.H. Jonkers, Frans C.S. Ramaekers, Ernst-Jan M. Speel Accepted for publication in BBA Reviews on Cancer

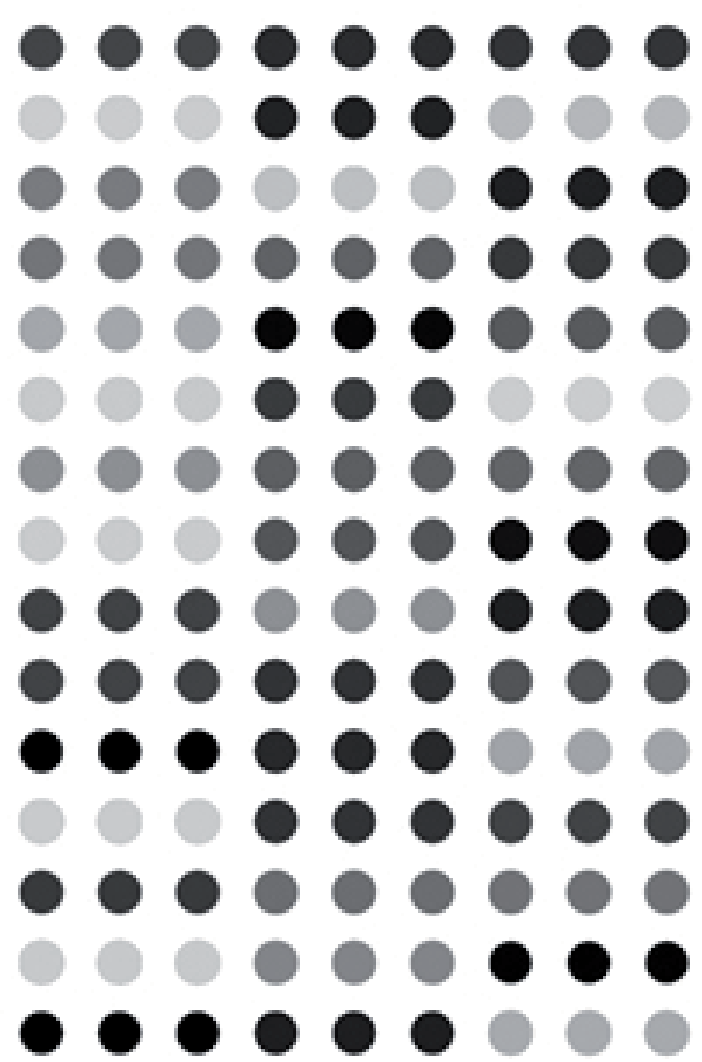




\subsection{The human pancreas and its cancers}

The pancreas is an organ with a role in both the digestive as well as the endocrine system. Its exocrine part produces pancreatic juice containing digestive enzymes, whereas its endocrine part produces several important hormones (Fig. 1.1). Under the microscope these two different tissue types can be distinguished, i.e. the endocrine pancreas visualized as the islets of Langerhans and the exocrine pancreas as the surrounding tissue (Fig. 1.2A, p.119). In the islets of Langerhans four main cell types are found, although these different cells are difficult to distinguish using standard staining techniques. They can be classified by their secretion as $\alpha$-cells producing glucagon (Fig. 1.2B, p.119), $\beta$-cells producing insulin (Fig. 1.2B, p.119), $\delta$-cells producing somatostatin, and PP cells producing pancreatic polypeptide. The exocrine pancreas is comprised of duct cells and acinar cells that produce a combination of pancreatic enzymes needed for digestion.

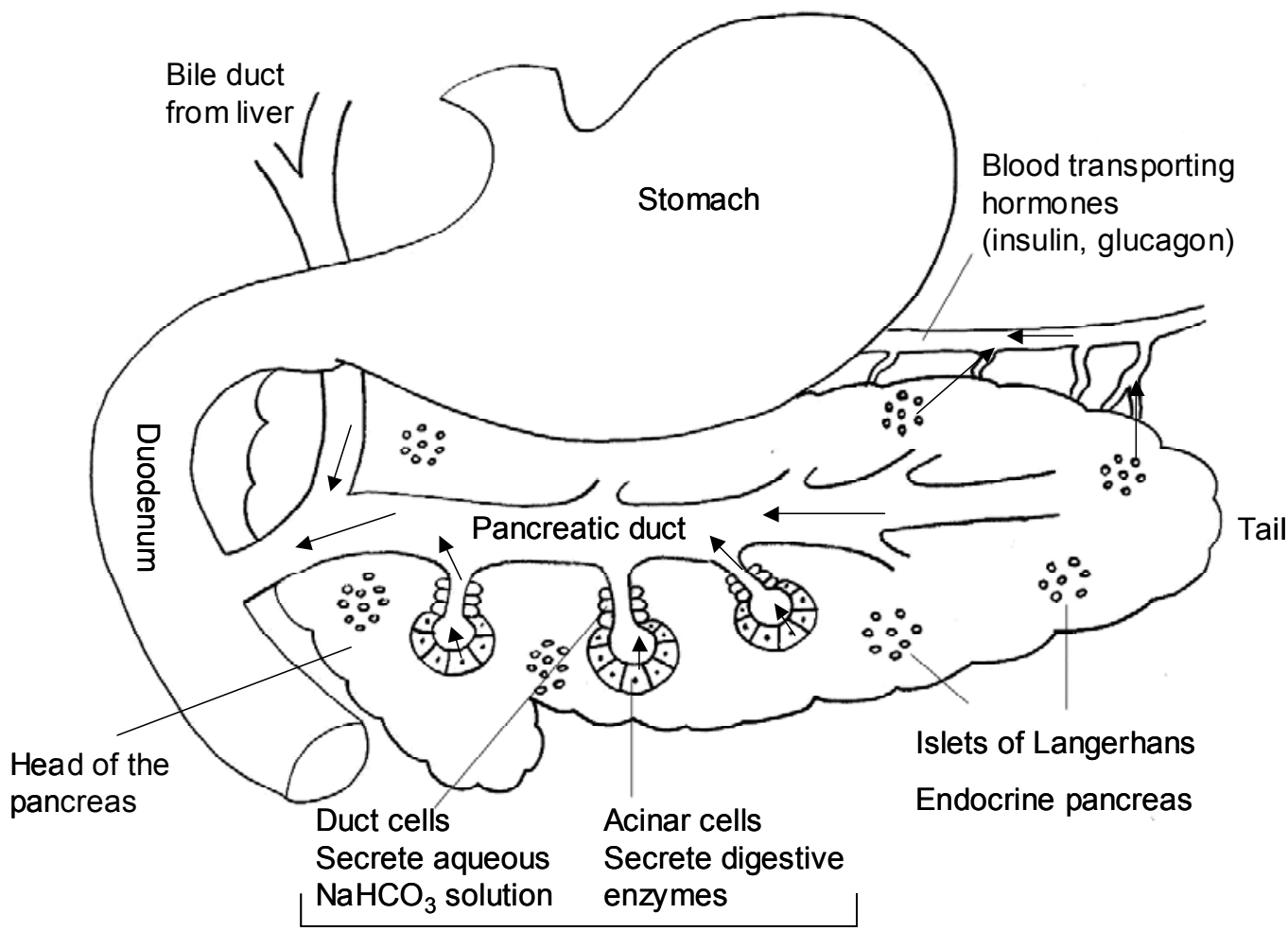

Exocrine pancreas

Figure 1.1. Illustration of the pancreas, showing the endocrine part comprising of the islets of Langerhans and the exocrine part comprising of duct and acinar cells. 
As in many organs, also in the pancreas benign or malignant tumors may develop during life time. The majority of exocrine pancreatic cancers are ductal adenocarcinomas. These tumors originate in the epithelial cells lining the pancreatic ducts and account for $\sim 90 \%$ of all pancreatic cancers [1]. It is the fourth most common cause of cancer mortality with the worst prognosis and a 5-year survival of $8 \%$. There are a few established environmental risk factors, but a previous history of chronic pancreatitis and exposure to tobacco and salted food appear to be the most important. In these tumors, frequent gene mutations have been found in TP53, p16INK4A, SMAD4 and K-Ras [2]. In endocrine pancreatic tumors (EPTs) mutations in these genes only seldomly occur. At present, no environmental risk factors have been identified as being significantly associated with the development of EPTs, most likely due to the rare nature of these tumors. Therefore, no clear clues are present that may prevent its occurrence. Individuals with multiple endocrine neoplasia type 1 (MEN1) or von Hippel Lindau (VHL) syndrome, however, have a genetic predisposition to developing EPTs and should be screened regularly in an effort to detect the disease early. The molecular pathogenesis of EPTs, as well as their histogenesis is not well understood. Therefore, these tumors have been studied in further detail in this thesis.

\subsection{Endocrine pancreatic cancer}

EPTs have a better prognosis as compared to exocrine pancreatic tumors, and the incidence of EPTs is $0.4-1$ in 100.000 as compared to 8-10 in 100.000 for the exocrine tumors. Originally EPTs were thought to evolve from the islets of Langerhans, although recently it has been suggested they develop from pluripotent stem cells in the ductal epithelium [2-3].

The gross and microscopic appearances of EPTs are well characterized. They are similar to endocrine tumors at other sites, and most are solitary and well demarcated. They vary in size upon detection, ranging from less than $1 \mathrm{~cm}$ to more than 15 $\mathrm{cm}$ in diameter. Their growth-pattern can be solid, nested, trabecular, ribbon-like, tubulo-acinar, or glandular, while mixed patterns are also common. In general the histological pattern does not discriminate between EPTs with different functioning state or type of hormone production. However, there are two exceptions to this, i.e. amyloid deposits which are indicative of insulinomas, and glandular structures containing psammoma bodies are commonly observed in somatostatin-producing tumors [4]. EPTs can clearly be identified by using antibodies to markers common to all or most neuroendocrine cells, i.e. chromogranin A, synaptophysin, neuronspecific enolase, and protein gene product 9.5 . They may also contain cytokeratins 8, 18 and 19, and neurofilaments [3-5].

Based on their clinical manifestation, EPTs are subdivided into functioning and non-functioning tumors. Functioning tumors are associated with clinical syndromes with life-threatening symptoms caused by inappropriate secretion of hormones. This group of tumors comprises insulinomas, glucagonomas, somatostatinomas, 
gastrinomas, vipomas, and other less common tumors. The non-functioning tumors are not associated with a distinct hormonal syndrome but may still show elevated hormone levels in the blood or immunoreactivity for hormones in tissue sections (Table 1.1).

Table 1.1. Phenotyping and clinical features of the different types of EPTs

\begin{tabular}{|c|c|c|c|}
\hline Tumortype & Hormone & Syndrome & Frequency \\
\hline \multicolumn{4}{|l|}{ Functioning tumors } \\
\hline Insulinoma & Insulin & Hypoglycemia & $27.2 \%$ \\
\hline Gastrinoma & Gastrin & $\begin{array}{l}\text { Zollinger Ellison syn- } \\
\text { drome }\end{array}$ & $12.5 \%$ \\
\hline Glucagonoma & Glucagon & $\begin{array}{l}\text { Glucagonoma } \\
\text { syndrome }\end{array}$ & $8.0 \%$ \\
\hline Vipoma & $\begin{array}{l}\text { Vasoactive Intesti- } \\
\text { nal Polypeptide }\end{array}$ & $\begin{array}{l}\text { Verner-Morrison } \\
\text { syndrome }\end{array}$ & $6.4 \%$ \\
\hline Somatostatinoma & Somatostatin & $\begin{array}{l}\text { Somatostatinoma } \\
\text { syndrome }\end{array}$ & $3.8 \%$ \\
\hline ACTH producing tumor & ACTH & Cushing syndrome & $2.4 \%$ \\
\hline Serotonin producing tumor & Serotonin & Carcinoid syndrome & $<1 \%$ \\
\hline Non-functioning tumors & $\begin{array}{l}\text { Different hormones, } \\
\text { slightly elevated }\end{array}$ & No syndrome & $39.7 \%$ \\
\hline
\end{tabular}

Interestingly, EPTs can occur in association with several syndromes, such as MEN1, VHL, neurofibromatosis type 1 (NF1), and tuberosclerosis (TSC), caused by germ line alterations in the MEN1 (11q13), VHL (3p25), NF1 (17q11), or TSC1/2 (9q34/16p13) genes, respectively. It is therefore expected that these genes will also be altered in a proportion of sporadic EPTs. The VHL gene does not appear to be involved in the development of sporadic EPTs [6-7]. NF1 and TSC1/2 have to be examined further to determine a possible role in sporadic EPTs. MEN1 mutations have been found in sporadic EPTs, but in different frequencies per subtype, i.e. in $8 \%$ of non-functioning tumors, and in $28 \%$ of the functioning tumors with $8 \%$ of insulinomas, $37 \%$ of gastrinomas, $44 \%$ of vipomas, and $67 \%$ of glucagonomas [8].

Because EPTs are a very heterogeneous group of tumors with different clinical behavior and genetic makeup, it is essential to study these tumors per subtype, rather than as one group, as has often been done in studies described in literature (Table 1.2). As insulinomas are the most frequently detected functioning EPTs, this subtype has been chosen for further examination in this thesis. 
Table 1.2. Genetic alterations described to occur in EPTs. Results modified from [3]

\begin{tabular}{|c|c|c|c|c|c|}
\hline $\begin{array}{l}\text { Chromosomal } \\
\text { locus }\end{array}$ & $\mathrm{CGH}^{*}$ & LOH & Gene & Mutation & Reference \\
\hline 1p36- & $21 / 102(21 \%)$ & $10 / 29(34 \%)$ & & & 9 \\
\hline 1q32- & $16 / 102(16 \%)$ & $8 / 29(28 \%)$ & & & 10 \\
\hline $3 p 23-$ & $19 / 102(19 \%)$ & $23 / 31(74 \%)$ & & & 11 \\
\hline 3p25-26- & 19/102 (19\%) & $31 / 73(42 \%)$ & VHL & $1 / 75(1 \%)$ & $6,10,12,13$ \\
\hline 6q22- & $29 / 102(28 \%)$ & $43 / 69(62 \%)$ & & & 10,14 \\
\hline $9 p-$ & $0 / 102(0 \%)$ & $12 / 37(32 \%)$ & $\begin{array}{l}\text { CDKN2A/ } \\
\text { p16 }\end{array}$ & $1 / 44(2 \%)$ & 15,16 \\
\hline $9 q+$ & $29 / 102(28 \%)$ & & & & 17 \\
\hline 10q23- & $14 / 102(14 \%)$ & $8 / 16(50 \%)$ & PTEN & $1 / 31(3 \%)$ & 18 \\
\hline 11p14- & $28 / 102(27 \%)$ & & & & 19 \\
\hline 11q13- & $31 / 102(30 \%)$ & $75 / 111(67 \%)$ & MEN1 & $33 / 155(21 \%)$ & $12,13,20-22$ \\
\hline 11q22-23- & $31 / 102(30 \%)$ & $20 / 37(54 \%)$ & SDHD & $0 / 20(0 \%)$ & 23 \\
\hline $12 \mathrm{p} 12+$ & $23 / 102(23 \%)$ & & K-Ras & $1 / 39(3 \%)$ & 15 \\
\hline $15 q-$ & $6 / 102(6 \%)$ & & SMAD3 & $0 / 18(0 \%)$ & 24 \\
\hline 17p13- & $2 / 102(2 \%)$ & $15 / 40(38 \%)$ & TP53 & $1 / 40(3 \%)$ & 10,15 \\
\hline $17 p+$ & $32 / 102(31 \%)$ & & & & 25 \\
\hline $18 q 21-$ & $6 / 102(6 \%)$ & $23 / 68(34 \%)$ & DPC4 & $0 / 41(0 \%)$ & 12,26 \\
\hline 22q12.1- & $4 / 102(4 \%)$ & $9 / 12(75 \%)$ & & & 27 \\
\hline Xq- & 14/46 (30\%) & $11 / 23(48 \%)$ & & & 28 \\
\hline Y- & $14 / 56(25 \%)$ & $5 / 14(36 \%)$ & & & 28 \\
\hline
\end{tabular}

${ }^{*}$ Results from reference 17, 19, 25, 29. 


\subsection{Insulinomas}

\subsubsection{Clinical features}

Insulinomas have been diagnosed in all age groups, with a median patient age of about 50 years at first diagnosis. Patients associated with MEN1 are usually younger, i.e. 20-30 years of age. In most series, females seem to be slightly more frequently affected than males (1-1.5: 1 ratio). Malignant insulinomas occur more frequently in males than in females [30]. Collective data indicate that tumors are equally distributed between the head, body, and tail of the pancreas with a slight predominance of the head and tail region. Virtually all functioning insulinomas manifest with symptoms of hypoglycemia due to their uncontrolled insulin production. Insulinoma patients learn to avoid symptoms by eating frequent small meals and sugary snacks, with resultant weight gain. Symptoms of hypoglycemia become apparent during a fasting state or after exercise which sets this diagnosis apart from the far more common postprandial or reactive hypoglycemia. To differentiate insulinoma from other causes of hypoglycemia can, however, be quite difficult. Nesidioblastosis is a rare disorder characterized by replacement of normal pancreatic islets with diffuse hyperplasia of the islet, which may require intra-operative biopsy to differentiate it from insulinoma [31]. Patients with multiple myeloma or systemic lupus erythematosus and hypoglycemia may have anti-insulin antibodies that bind and release insulin in an unregulated manner, resulting in hypoglycemia. These patients can be distinguished from patients with insulinoma by an anti-insulin antibody test [4]. Patients with non-insulinoma pancreatogenic hypoglycemia syndrome (NIPHS) present with hypoglycemia, but with negative pancreatic imaging results. However, approximately $30 \%$ of patients with a single insulinoma also fail to show a pancreatic tumor preoperatively. Attempts have been made to preoperatively differentiate NIPHS from insulinomas in order to prevent failure of surgical intervention. Service et al. [32] characterized patients with NIPHS by postprandial neuroglycopenia and a negative 72-h fasting test, although recently Starke et al. [33] described that only a few cases of NIPHS showed these signs. They described rather low serum insulin levels at the time of postprandial and / or fasting hypoglycemia in most patients with NIPHS compared to patients with an insulinoma.

Diagnosis of insulinoma is made by fasting provocation demonstrating a serum glucose concentration of less than $3.0 \mathrm{mmol} / \mathrm{l}$, together with an inappropriately high serum insulin level. The hypoglycemia typically presents with a gradual onset of sweating and palpitations. More than $80 \%$ of patients have transient symptoms of central nervous system dysfunction, ranging from drowsiness to coma and epilepsia. Neuroglycopenia is nearly always the presenting symptom in insulinoma patients and includes confusion, personality change or bizarre behavior, and amnesia for the hypoglycemic episode. The symptoms of hypoglycemia are unrelated to the size or grade of the tumor. Insulinomas are diagnosed using subsequent clinical tests as schematically represented in Fig. 1.3. 


\subsubsection{Detection}

Insulinomas may be quite small and the risk of missing a small tumor remains, because they are difficult to localize radiologically. Somatostatin is a small cyclic peptide that inhibits the secretion of pancreatic and intestinal hormones, including insulin. This peptide may also control cell proliferation in tissues and tumors [34], and acts through high-affinity $G$ protein-coupled membrane receptors. Five somatostatin receptor subtype genes have been cloned and characterized, i.e. SSTR1, SSTR2, SSTR3, SSTR4, and SSTR5. Neuroendocrine tumors in general and EPTs in particular contain frequently SSTR2. This has been exploited for their detection by using somatostatin analogues that are radio-labeled to perform somatostatin receptor scintigraphy. However, the method has problems in localizing small tumors and tumors that lack SSTR2, which is the case in $50 \%$ of insulinomas [4].

Traditionally, intra-operative ultrasound imaging with manual palpation was the gold standard for localizing insulinoma once a biochemical diagnosis had been confirmed [35]. Preoperative imaging enables accurate surgery, which may prevent unnecessary total pancreatectomy and its associated morbidities, and facilitates the detection of metastases. It also avoids prolonging the duration of surgery and potential intra-operative damage to major structures such as the splenic vein [35]. With recent advances in non-invasive imaging giving rise to a detection rate approaching that of intra-operative imaging, the present consensus is that preoperative imaging is advised. Technical advances have improved the quality of computed tomography (CT) as a preoperative imaging technique, with a recent study using dual-phase, thin-section multidetector CT visualizing $94.4 \%$ of insulinomas as compared with $28.6 \%$ with sequential CT [36]. CT is therefore currently accepted as the first-line investigation method for insulinomas. Magnetic resonance imaging (MRI) has recently been described as being the more sensitive tool, being able to also detect lymphadenopathy and metastatic disease. Drawbacks include costs and more limited availability of equipment as compared to CT. In current practice MRI is a second-line investigation, but potentially it could take over from $\mathrm{CT}$ in the future as it becomes more widely available and expertise improves [35].

\subsubsection{Histopathology}

Insulinomas exhibit four main histological patterns including a solid, trabecular, gland-like (tubular or acinar) tumor growth and mixed forms. Larger tumors are encapsulated but the capsule is usually incomplete. Smaller tumors and microadenomas are rarely encapsulated. Tumor cells frequently exhibit a bland cytology and cells with large pleomorphic nuclei are rare. If present, these features are not predictive of malignant behavior.

A relatively uncommon, but characteristic finding in insulinomas is the deposition of amyloid. Its major component is islet amyloid polypeptide or amylin that can be visualized by immunohistochemistry [37]. Calcifications and intracytoplasmic pigment may rarely be seen in insulinomas [38-39]. 


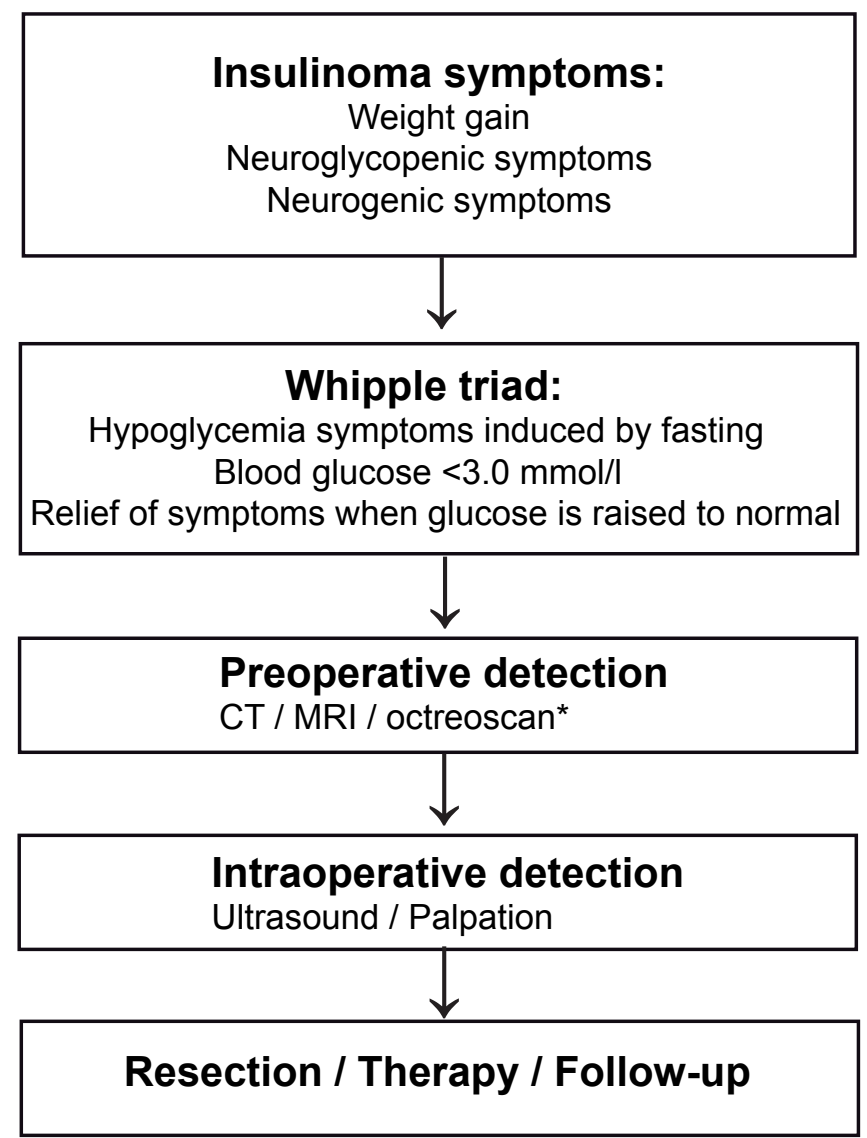

Figure 1.3. Scheme outlining the diagnosis and the subsequent clinical tests for the detection of insulinomas. * Can only be used in patients with somatostatin-receptor type 2. CT, computed tomography; MRI, magnetic resonance imaging.

Almost all insulinomas exhibit immunoreactivity for insulin and proinsulin. The biosynthesis of insulin takes place in the endoplasmic reticulum (ER). The preproinsulin becomes converted to proinsulin in the ER by the action of a signal peptidase. Two prohormone-converting endoproteases each cleave one of the two dibasic cleavage sites in proinsulin, followed by the removal of the C-terminal basic residue by carboxypeptidase $\mathrm{H}$ to generate mature insulin and $\mathrm{C}$-peptide. In normal pancreatic $\beta$-cells, proinsulin-insulin conversion occurs in acidic immature secretory granules of the trans-Golgi apparatus. In contrast to normal $\beta$-cells, the proinsulin-insulin conversion in insulinomas occurs already in the Golgi apparatus, but remains incomplete, resulting in the formation of secretory granules containing both proinsulin and insulin. This indicates that in insulinoma, sorting into secretory granules may not be a prerequisite for hormone conversion [40]. The distribution pattern of proinsulin and insulin has been investigated in 76 insulinomas. No correlation was found between a particular staining pattern, histological type, multihormonality or the degree of malignancy of insulinomas [41]. 
Approximately $10-15 \%$ of insulinomas are classified as malignant on the basis of the presence of organ and / or lymph node infiltration or distant metastases. The most common sites of metastases for insulinomas are the peripancreatic lymph nodes with occasional hepatic metastases. According to the WHO criteria, EPTs should be classified into four groups, i.e. well differentiated EPTs (in the absence of all adverse criteria), well differentiated EPTs of uncertain behavior (tumor diameter $\geq 2 \mathrm{~cm}, \geq 2$ mitoses $/ 10$ high power fields, angioinvasion or a proliferative index $>2 \%$ ), well differentiated endocrine pancreatic carcinomas (gross local invasion or metastasis), and poorly differentiated pancreatic endocrine carcinomas ( $\geq 10$ mitoses / 10 high power fields) [3]. Because these criteria are not always reliable, markers have to be detected to predict a possible malignant outcome of insulinomas in an earlier stage.

\subsubsection{Treatment}

Strategies for insulinoma treatment include surgical removal or debulking of tumor tissue, drug therapy aimed at palliation of symptoms referable to hypoglycemia, and chemotherapy in patients with metastatic disease. Liver transplantation may be justified in young patients with only hepatic metastases to provide immediate relief of otherwise intractable pain or hormone-related symptoms. Diazoxide is often used to control hypoglycemia. It acts on $\beta$-cells to decrease insulin secretion. In patients with metastatic insulinomas, symptoms of insulin hypersecretion will only completely disappear after complete resection of all metastases. About two-thirds of the patients can be cured by resection of the tumor [40]. However, resection of a large part of the pancreas may cause type 2 diabetes. Therefore it is important to resect the whole tumor without removing too much of the surrounding normal pancreatic tissue. A more than $60 \%$ risk of tumor recurrence within three years has been found even after complete resection [42]. Because the clinical outcome of patients is difficult to predict there is a need for prognostic indicators.

\subsubsection{The molecular pathogenesis}

No definite precursor lesion has been identified for insulinoma. Proliferation of $\beta$-cells ( $\beta$-cell hyperplasia, nesidioblastosis) in patients with persistent hyperinsulinemic hypoglycemia cannot be considered a precursor lesion of insulinoma because it is genetically different [43]. Ductal proliferation may sometimes be associated with insulinoma, suggesting a potential duct cell origin [44]. Alternatively, an islet origin of $\beta$-cell tumors is suggested by histology in MEN1 patients and is supported by observations that MEN1 transgenic mice consistently developed islet $\beta$ cell hyperplasia, dysplasia and insulinomas, in the absence of ductuloinsular proliferation [45-46].

Little is known about the molecular pathogenesis of insulinomas [47-48]. Mutations in important tumor suppressor genes, such as p16/CDKN2A, TP53, VHL, PTEN, $S M A D 3, S M A D 4, D C C$, and ZAC, or oncogenes, including $K$-ras, $R E T$, and $B R A F$ seem to be involved in the development of only a small proportion of EPT cases, including insulinomas $[3,8,49]$. 


\subsubsection{Early markers in insulinoma tumorigenesis}

So far, only limited numbers of predominantly benign insulinomas have been genetically analyzed, indicating the involvement of the MEN1 gene at $11 \mathrm{q} 13$, and gain of chromosome $9 q$ in early tumorigenesis [17, 20, 21, 50]. The MEN1 gene is a growth suppressor gene with nuclear localization. It is the susceptibility gene of the autosomal dominant familial MEN1 cancer syndrome [51]. Patients with an inherited mutation in this gene develop tumors in endocrine organs, including insulinomas in $10-35 \%$ of cases.

Homozygous loss of MEN1 causes death in mice in utero, as often seen by inactivation of tumor suppressor genes in mice [52]. Approximately $20-30 \%$ of the embryos exhibit delayed development and craniofacial abnormalities likely associated with defective neural tube closure, heart hypotrophy, and altered liver organization. Mice with heterozygous MEN1 loss gestate normally, but, 9-16 months after birth they develop amongst others endocrine tumors. Because of the embryonic lethality caused by germ line homozygous loss of MEN1, conditional knock-out mouse models have been developed for tissue selective homozygous MEN1 loss in the parathyroid, pancreatic islet $\beta$-cells, pituitary, or liver (a tissue not associated with MEN1 tumors). Mice with homozygous loss of MEN1 in the pancreatic islet $\beta$-cells developed multiple insulinomas with elevated serum insulin levels and decreased blood glucose levels [52-53]. However, a role for the MEN1 gene in human sporadic insulinomas is unclear, because its mutation rate is rather low, ranging from $0-17 \%$ in the different studies described so far $[20,21,47,49,50]$.

\subsubsection{Criteria of malignancy in insulinomas}

The only reliable criteria for malignancy of insulinomas are the infiltration of the tumor into adjacent organs, the presence of angioinvasion of lymph nodes, and / or distant metastases. It has been hypothesized that certain immunohistochemical markers can help to identify tumors with malignant behavior. However, most of these markers have been shown to be only of limited value. One of these markers is the $\alpha$-chain of human chorionic gonadotropin (HCG- $\alpha$ ) [54]. Immunoreactivity of HCG-a, studied in 17 insulinomas, revealed that it was only expressed in 2 benign tumors [55], and therefore this marker has been considered to be of limited value.

In a study on 53 EPTs it has been demonstrated that the expression of polysialylated NCAM, NCAM protein isoforms, and beta-1,6-branched, asparagines-linked oligosaccharides, which have been associated with increased aggressiveness, metastatic potential, and survival in other tumor types, are not suitable to distinguish between benign and malignant EPTs [56]. In another study on 27 EPTs, it was demonstrated that EPTs may express the glycoprotein CD44 and its isoforms, but this expression was also not associated with a malignant phenotype or tumor progression as reported for other tumors [57].

P53 has also been described as a prognostic marker. The TP53 tumor suppressor gene is mutated in more than $50 \%$ of all human neoplasms [58]. If the remaining 
wildtype TP53 gene is inactivated, predominantly by deletion, these mutations abrogate the negative growth regulatory functions of p53 and are often associated with chromosomal instability. Immunohistochemical detectability of p53 is normally associated with the presence of a TP53 mutation. Controversy exists with respect to the p53 status in EPTs. Lee suggested no role for p53, whereas Pavelic et al. identified p53 overexpression in 3 out of 3 cases of malignant insulinoma [59,60]. Mutations of TP53 have only been found in a few isolated EPT cases [61-62]. This gene also remains to be examined in a larger group of benign and malignant insulinomas. The p27 protein was also suggested to be a marker for malignant progression of insulinomas, because previous reports showed high levels of p27 in quiescent cells, while neoplastic and proliferating cells showed no detectable p27. However, Guo et al. did not find a difference in p27 level between benign and malignant EPTs [63]. Immunohistochemical analysis of cyclooxigenase (COX)-2 expression in EPTs did show an association with tumor progression and proliferation in a single study [64].

It may be obvious from the foregoing that proper molecular markers to reliably predict the progression of insulinomas are still to be developed. For this purpose we have determined whether chromosomal alterations can differentiate between benign and malignant tumors.

Several chromosomal markers for malignant or metastatic progression in EPTs have been indicated, in particular loss of chromosomes 1 [9], 3p [6, 11, 12], 3q [65, 66], 6q22-24 [14], 11q13 [12], 17p [67], 22q [27, 65] and X [28]. These do, however, require further validation in larger series of individual EPT subtypes, including insulinomas.

In a subset of 17 insulinomas (11 benign, 6 malignant) an accumulation of chromosomal aberrations and loss of chromosome $6 q$ was described to be associated with malignant behavior [25].

\subsection{Aim of the study and outline of the thesis}

The aim of the studies described in this thesis was to gain a better understanding of the molecular processes underlying the development of insulinomas and to detect molecular markers that can make a reliable distinction between benign and malignant tumors and predict the clinical behavior of these endocrine tumors.

More specifically, the following questions were addressed during this study:

1) Do MEN1 and TP53 mutations play a role in the tumorigenesis of sporadic insulinomas?

2) Which chromosomal alterations are involved in insulinoma development and metastatic progression?

3) Which are the best parameters to predict metastatic disease and clinical outcome in insulinoma patients? 


\subsection{References}

1. Cowgill SM, Muscarella P. The genetics of pancreatic cancer. Am. J. Surg. 2003; 186: 279-286.

2. Bardeesy N, DePinho RA. Pancreatic cancer biology and genetics. Nat. Rev. Cancer 2002; 2: 897909.

3. Heitz PU, Komminoth P, Perren A, Klimstra DS, Dayal Y. Tumours of the endocrine pancreas. In: DeLellis RA, Lloyd RV, Heitz PU, Eng C (Eds.):Pathology \& Genetics. Tumours of endocrine organs, IARC Press, Lyon 2004,pp. 177-208.

4. Oberg K, Eriksson B. Endocrine tumors of the pancreas. Best practice \& research. Clin. Gastroenterol. 2005; 19: 753-781.

5. Frankel WL. Update on pancreatic endocrine tumors. Arch. Pathol. Lab. Med. 2006; 130: 963-966.

6. Chung DC, Smith AP, Louis DN, Graeme-Cook F, Warshaw AL, Arnold AA. Novel pancreatic endocrine tumor suppressor gene locus on chromosome $3 p$ with clinical prognostic implications. J. Clin. Invest. 1997; 100: 404-410.

7. Lubensky IA, Pack S, Ault D, Vortmeyer AO, Libutti SK, Choyke PL, et al. Multiple neuroendocrine tumors of the pancreas in von Hippel-Lindau disease patients: histopathological and molecular genetic analysis. Am. J. Pathol. 1998; 153: 223-231.

8. Perren A, Komminoth P, Heitz PU. Molecular genetics of gastroenteropancreatic endocrine tumors. Ann. N. Y. Acad. Sci. 2004; 1014: 199-208

9. Ebrahimi SA, Wang EH, Wu A, Schreck RR, Passaro E Jr, Sawicki MP. Deletion of chromosome 1 predicts prognosis in pancreatic endocrine tumors. Cancer Res. 1999; 59: 311-315.

10. Rigaud G, Missiaglia E, Moore PS, Zamboni G, Falconi M, Talamini G, et al. High resolution allelotype of non-functional pancreatic endocrine tumors: identification of two molecular subgroups with clinical implications. Cancer Res. 2001; 61: 285-292.

11. Barghorn A, Komminoth P, Bachmann D, Rütimann K, Saremaslani P, Mulatta-Feurer S, et al. Deletion at 3p25.3-p23 is frequently encountered in endocrine pancreatic tumours and is associated with metastatic progression. J. Pathol. 2001; 94: 451-458.

12. Hessman O, Lindberg D, Einarsson A, Lillhager P, Carling T, Grimelius L, et al. Genetic alterations on $3 p, 11 q 13$, and 18q in nonfamilial and MEN1-associated pancreatic endocrine tumors. Genes Chromosomes Cancer 1999; 26: 258-264.

13. Moore PS, Missiaglia E, Antonello D, Zamo A, Zamboni G, Corleto V, et al. Role of disease-causing genes in sporadic pancreatic endocrine tumors: MEN1 and VHL. Genes Chromosomes Cancer 2001; 32: 177-181.

14. Barghorn A, Speel EJM, Farspour B, Saremaslani P, Schmid S, Perren A, et al. Putative tumor suppressor loci at $6 q 22$ and $6 q 23-q 24$ are involved in the malignant progression of sporadic endocrine pancreatic tumors. Am. J. Pathol. 2001; 158: 1903-1911.

15. Moore PS, Orlandini S, Zamboni G, Capelli P, Rigaud G, Falconi M, et al. Pancreatic tumors: molecular pathways implicated in ductal cancer are involved in ampullary but not in exocrine nonductal or endocrine tumorigenesis. Br. J. Cancer 2001; 84: 253-262.

16. Serrano J, Goebel SU, Peghini PL, Lubensky IA, Gibril F, Jensen RT. Alterations in the p16INK4a/CDKN2A tumor suppressor gene in gastrinomas. J. Clin. Endocrinol. Metab. 2000; 85: 4146-4156.

17. Speel EJM, Scheidweiler AF, Zhao J, Matter C, Saremaslani P, Roth J, et al. Genetic evidence for early divergence of small functioning and nonfunctioning endocrine pancreatic tumors: gain of 9q34 is an early event in insulinomas. Cancer Res. 2001; 61: 5186-5192.

18. Perren A, Komminoth P, Saremaslani P, Matter C, Feurer S, Lees JA, et al. Mutation and expression analyses reveal differential subcellular compartmentalization of PTEN in endocrine pancreatic tumors compared to normal islet cells. Am. J. Pathol. 2000; 157: 1097-1103.

19. Stumpf E, Aalto Y, Hoog A, Kjellman M, Otonkoski T, Knuutila S, et al. Chromosomal alterations in human pancreatic endocrine tumors, Genes Chromosomes Cancer 2000; 28: 83-87. 
20. Cupisti K, Hoppner W, Dotzenrath C, Simon D, Berndt I, Roher HD, et al. Lack of MEN1 gene mutations in 27 sporadic insulinomas. Eur. J. Clin. Invest. 2000; 30: 325-329.

21. Gortz B, Roth J, Krahenmann A, de Krijger RR, Muletta-Feurer S, Rutimann K, et al. Mutations and allelic deletions of the MEN1 gene are associated with a subset of sporadic endocrine pancreatic and neuroendocrine tumors and not restricted to foregut neoplasms. Am. J. Pathol. 1999; 154: 429-436.

22. Hessman O, Lindberg D, Skogseid B, Carling T, Hellman P, Rastad J, et al. Mutation of the multiple endocrine neoplasia type 1 gene in nonfamilial, malignant tumors of the endocrine pancreas. Cancer Res. 1998; 58: 377-379.

23. Perren A, Barghorn A, Schmid S, Saremaslani P, Roth J, Heitz PU, et al. Absence of somatic SDHD mutations in sporadic neuroendocrine tumors and detection of two germline variants in paraganglioma patients. Oncogene 2002; 21: 7605-7608.

24. Shattuck TM, Costa J, Bernstein M, Jensen RT, Chung DC, Arnold A. Mutational analysis of Smad3, a candidate tumor suppressor implicated in TGF-beta and menin pathways, in parathyroid adenomas and enteropancreatic endocrine tumors. J. Clin. Endocrinol. Metab. 2002; 87: 3911-3914.

25. Speel EJM, Richter J, Moch H, Egenter C, Saremaslani P, Rutimann K, et al. Genetic differences in endocrine pancreatic tumor subtypes detected by comparative genomic hybridization. Am. J. Pathol. 1999; 155: 1787-1794.

26. Perren A, Hurlimann S, Saremaslani P, Schmid S, Bonvin C, Roth J, et al. DPC4/Smad4 expression is lost in a subset of ductal adenocarcinomas of the pancreas but not in endocrine pancreatic tumors and chronic pancreatitis. Mod. Pathol. 2002; 15: 119A.

27. Wild A, Langer P, Celik I, Chaloupka B, Bartsch DK. Chromosome 22q in pancreatic endocrine tumors: identification of a homozygous deletion and potential prognostic associations of allelic deletions. Eur. J. Endocrinol. 2002; 147: 507-513.

28. Missiaglia E, Moore PS, Williamson J, Lemoine NR, Falconi M, Zamboni G, et al. Sex chromosome anomalies in pancreatic endocrine tumors. Int. J. Cancer 2002; 98: 532-538.

29. Zhao J, Moch H, Scheidweiler AF, Baer A, Schäffer AA, Speel EJM, et al. Genomic imbalances in the progression of endocrine pancreatic tumors. Genes Chromosomes Cancer 2001; 32: 364-372.

30. Danforth DN, Gorden P, Brennan MF. Metastatic insulin-secreting carcinoma of the pancreas: clinical course and the role of surgery. Surgery 1984; 96: 1027-1037.

31. Anlauf M, Wieben D, Perren A, Sipos B, Komminoth P, Raffel A, et al. Persistent hyperinsulinemic hypoglycaemia in 15 adults with diffuse nesidioblastosis. Am. J. Surg. Pathol. 2005; 29: 524-533.

32. Service FJ, Natt N, Thompson GB, Grant CS, van Heerden JA, Andrews JC, et al. Noninsulinoma pancreatogenous hypoglycaemia in adults independent of mutations in Kir6.2 and SUR1 genes. J. Clin. Endocrinol. Metab. 1999; 84: 1582-1589.

33. Starke A, Saddig C, Kirch B, Tschahargane C, Goretzki P. Islet hyperplasia in adults: challenge to preoperatively diagnose non-insulinoma pancreatogenic hypoglycaemia syndrome. World J. Surg. 2006; 30: $1-10$.

34. Lamberts SW, Krenning EP, Reubi JC. The role of somatostatin and its analogs in the diagnosis and treatment of tumors. Endocrine reviews 1991; 12: 450-482.

35. McAuley G, Delaney H, Colville J, Lyburn I, Worsley D, Govender P, et al. Multimodality preoperative imaging of pancreatic insulinomas. Clin. Radiol. 2005; 60: 1039-1050.

36. Gouya H, Vignaux O, Augui J, Dousset B. CT, endoscopic sonography and a combined protocol for preoperative evaluation of pancreatic insulinomas. Am. J. Roentgenol. 2003; 181: 987-992.

37. Williams AJ, Coates PJ, Lowe DG, McLean C, Gale EA. Immunochemical investigation of insulinomas for islet amyloid polypeptide and insulin: evidence for differential synthesis and storage. Histopathology 1992; $21: 215-223$.

38. Wolf EL, Sprayregen S, Frager D, Rifkin H, Gliedman ML. Calcification in an insulinoma of the pancreas. Am. J. Gastroenterol. 1984; 79: 559-561.

39. Illyes G, Bucsek MJ, Kadar A, Horanyi J, Flautner L. Ultrastructural study of a black insulinoma. UItrastruct. Pathol. 1993; 17: 495-501. 
40. Komminoth P, Heitz PU, Roth J. Human insulinoma: Clinical, cellular, and molecular aspects. Endocrine Pathol. 1999; 10: 269-281.

41. Roth J, Kloppel G, Madsen OD, Storch MJ, Heitz PU. Distribution patterns of proinsulin and insulin in human insulinomas: an immunohistochemical analysis in 76 tumors. Virchows Arch. 1992; 63: 51-61.

42. de Herder WW. Insulinoma. Neuroendocrinol. 2004; 80: 20-22.

43. Sempoux C, Guiot Y, Dahan K, Moulin P, Stevens M, Lambot V, et al. The focal form of persistent hyperinsulinemic hypoglycaemia of infancy: morphological and molecular studies show structural and functional differences with insulinoma. Diabetes 2003; 52: 784-794.

44. Kemp DM, Thomas MK, Habener JF. Developmental aspects of the endocrine pancreas. Rev. Endocr. Metab. Disord. 2003; 4: 5-17.

45. Hanahan D. Heritable formation of pancreatic beta-cell tumors in transgenic mice expressing recombinant insulin/simian virus 40 oncogenes. Nature 1985; 315: 115-122.

46. Rindi G, Candusso ME, Marchetti AL. Origin and genetic background of insulinomas. Endocr. Pathol. 1999; 10: 283-290.

47. Moore PS, Beghelli S, Zamboni G, Scarpa A. Genetic abnormalities in pancreatic cancer. Molecular Cancer 2003; 2: 7-12.

48. Leothela PD, Jauch A, Holtgreve-Grez H, Thakker RV. Genetics of Neuroendocrine and Carcinoid Tumours. Endocr. Relat. Cancer 2003; 10: 437-450.

49. Gumbs AA, Moore PS, Falconi M, Bassi C, Beghelli S, Modlin I, et al. Review of the clinical, histological, and molecular aspects of pancreatic endocrine neoplasms. J. Surg. Oncol. 2002; 81: 45-53.

50. Zhuang Z, Vortmeyer AO, Pack S, Huang S, Pham TA, Wang C, et al. Somatic mutations of the MEN1 tumor suppressor gene in sporadic gastrinomas and insulinomas. Cancer Res. 1997; 57: 4682-4686.

51. Schussheim DH., Skarulis MC, Agarwal SK, Simonds WF, Burns AL, Spiegel AM, et al. Multiple endocrine neoplasia type 1: new clinical and basic findings. Trends Endocrinol. Metab. 2001; 12: $173-178$.

52. Crabtree JS, Scacheri PC, Ward JM, McNally SR, Swain G.P., Montagna C, et al. Of mice and MEN1: Insulinomas in a conditional mouse knockout. Mol. Cell. Biol. 2003; 23: 6075-6085.

53. Bertolino $P$, Tong WM, Herrera PL, Casse $H$, Zhang CX, Wang ZQ. Pancreatic $\beta$-cell-specific ablation of the multiple endocrine neoplasia type 1 (MEN1) gene causes full penetrance of insulinoma development in mice. Cancer Res. 2003; 63: 4836-4841.

54. Heitz PU, Kasper M, Kloppel G, Polak JM, Vaitukaitis JL. Glycoprotein-hormone alpha-chain production by pancreatic endocrine tumors: a specific marker for malignancy. Immunocytochemical analysis of tumors of 155 patients. Cancer 1983; 51: 277-282.

55. Graeme-Cook F, Bell DA, Flotte TJ, Preffer F, Pastel-Levy C, Nardi G, et al. Aneuploidy in pancreatic insulinomas does not predict malignancy. Cancer 1990; 66: 2365-2368.

56. Li WP, Komminoth P, Zuber C, Klöppel G, Heitz PU, Roth J. Can malignancy in insulinoma be predicted by the expression patterns of beta 1,6 branching of asparagine-linked oligosaccharides and polysialic acid of the neural cell adhesion molecule? Virchows Arch. 1996; 429: 197-204.

57. Komminoth P, Seelentag WK, Saremaslani P, Heitz PU, Roth J. CD44 isoform expression in the diffuse neuroendocrine system. II Benign and malignant tumors. Histochem. Cell Biol. 1996; 106: 551-562.

58. Hollstein M, Sidransky D, Vogelstein B, Harris CC. P53 mutations in human cancers. Science 1991; 253: 49-53.

59. Lee CS. Lack of p53 immunoreactivity in pancreatic endocrine tumors. Pathology 1996; 28: 139-141.

60. Pavelic K, Hrascan R, Kapitanovic S, Karapandza N, Vranes Z, Belicza M, et al. Multiple genetic alterations in malignant metastatic insulinomas. J. Pathol. 1995; 177: 395-400.

61. Bartz C, Ziske C, Wiedenmann B, Moelling K. p53 tumor suppressor gene expression in pancreatic neuroendocrine tumor cells. Gut 1996; 38: 403-409.

62. Lin HJ, French SW, Reichenbach D, Wan YY, Passaro E, Sawicki MP. Novel p53 mutation in a malignant tumor secreting vasoactive intestinal peptide. Arch. Pathol. Lab. Med. 1997; 121: 125-128. 
63. Guo SS, Wu X, Shimoide AT, Wong J, Sawicki MP. Anomalous overexpression of p27(Kip1) in sporadic pancreatic endocrine tumors. J. Surg. Res. 2001; 96: 284-288.

64. Ohike N, Morohoshi T. Immunohistochemical analysis of cyclooxygenase (COX)-2 expression in pancreatic endocrine tumors: association with tumor progression and proliferation, Pathol. Int. 2001; 51: 770-777.

65. Chung DC, Brown SB, Graeme-Cook F, Tillotson LG, Warshaw AL, Jensen RT, et al. Localisation of putative tumor suppressor loci by genome-wide allelotyping in human pancreatic endocrine tumors. Cancer Res. 1998; 58: 3706-3711.

66. Guo SS, Arora C, Shimoide AT, Sawicki MP. Frequent deletion of chromosome 3 in malignant sporadic pancreatic endocrine tumors. Mol. Cell. Endocrinol. 2002; 190: 109-114.

67. Beghelli S, Pelosi G, Zamboni G, Falconi M, lacono C, Bordi C, et al. Pancreatic endocrine tumours: evidence for a tumour suppressor pathogenesis and for a tumour suppressor gene on chromosome 17p. J. Pathol. 1998; 186: 41-50. 


\section{Abstract}

Endocrine pancreatic tumors (EPTs) comprise a highly heterogeneous group of tumors with different clinical behavior and genetic makeup. Insulinomas represent the predominant syndromic subtype of EPTs. The metastatic potential of insulinomas can frequently not be predicted using histopathological criteria, and also molecular markers indicating malignant progression are unreliable because of the small number of cases per subtype studied so far. For the identification of reliable indicators of metastatic disease, we investigated 62 sporadic insulinomas (44 benign and 18 tumors with metastases) by means of comparative genomic hybridization (CGH). In addition, the role of MEN1 (multiple endocrine neoplasia type 1) gene mutations was determined to assess specific chromosomal alterations associated with dysfunction of this endocrine tumor-related tumor suppressor gene. Only one case with a somatic MEN1 mutation was identified (1527del7bp), indicating that the MEN1 gene plays a minor pathogenic role in sporadic insulinomas. CGH analysis revealed that the total number of aberrations per tumor differs strongly between the benign and the malignant group (4.2 vs $14.1 ; p<0.0001)$. Furthermore, chromosome 9q gain was found to be the most frequent aberration in both benign and malignant insulinomas, whereas chromosome $6 q$ losses and $12 q, 14 q$ and $17 p q$ gains are strongly associated with metastatic disease. Our study shows that chromosomal instability, as defined by $\geq 5$ gains together with $\geq 5$ losses, or total number of gains and losses $\geq 8$, rather than parameters such as tumor size and proliferation index, is the most powerful indicator for the development of metastatic disease in patients with sporadic insulinoma.

\subsection{Introduction}

Endocrine pancreatic tumors (EPTs) represent 1-2\% of all pancreatic neoplasms and are separated on the basis of their clinical manifestation into functioning (syndrome-related) and non-functioning tumors. Insulinomas are the most frequently detected functioning EPTs. They show evidence of $ß$-cell differentiation and clinical symptoms of hypoglycemia due to uncontrolled insulin production. Strategies for insulinoma treatment include surgical resection and, in the case of palliation, chemotherapy and anti-hypoglycemic medication [1-2]. The only feature that separates benign from malignant disease is organ and / or lymph node infiltration or distant metastases [2]. When only a primary lesion is identified, however, no reliable markers for malignancy are available. At best a tumor diameter $\geq 2 \mathrm{~cm}$, an increased mitotic index and necrosis seem to indicate an increased risk for malignancy [3]. It is obvious that new indicators that reliably determine prognosis of malignancy are urgently needed.

Little is known about the molecular pathogenesis of insulinomas [4-5]. So far, only limited numbers of predominantly benign insulinomas have been genetically analyzed, indicating the involvement of the MEN1 (multiple endocrine neoplasia type 
1) gene at $11 q 13$, and gain of chromosome $9 q$ in early tumorigenesis [6-9]. MEN1 is the susceptibility gene of the autosomal dominant familial MEN1 cancer syndrome [10]. Patients with an inherited mutation in this gene develop tumors in endocrine organs, including insulinomas in $10-35 \%$ of cases. Evidence for a direct involvement of the MEN1 tumor suppressor gene in early insulinoma development was provided by a transgenic mouse model with a hemizygous deletion of the MEN1 gene in pancreatic $\beta$-cells. Somatic deletion of the second allele resulted in insulinoma formation with multiple progression features [11]. However, a role for the MEN1 gene in human sporadic insulinomas is unclear. Its mutation rate seems to be rather low, ranging from $0-17 \%$ in the different studies described so far $[6-8$, and references therein]. On the other hand, we have recently shown that in a small series of predominantly benign insulinomas, gain of chromosome $9 q$ is the most common alteration identified by comparative genomic hybridization (CGH) in $50 \%$ of insulinomas with a diameter $<2 \mathrm{~cm}$, with the smallest region of gain being $9 q 34$ [9].

Chromosomal markers with high potential to discriminate malignant from benign insulinomas have not been described so far. DNA cytometry data suggest that DNA ploidy is unlikely to provide useful prognostic information for patients with insulinomas, because large ploidy changes are seldomly detected [12-13]. The few malignant insulinomas that have been genetically analyzed by molecular allelotyping and CGH were mainly part of larger studies on EPTs, including different functioning and non-functioning subtypes [9, 14-17]. Several markers for malignant or metastatic progression in EPTs have been indicated, in particular loss of chromosomes 1 [18], 3p [19-21], 3q [14, 22], 6q22-24 [23], 11q13 [20], 17p [24], $22 q[14,25]$ and $X[26]$. These do, however, require further validation in larger series of individual EPT subtypes, including insulinomas.

The objective of the present study was to determine by CGH the occurrence of DNA copy number losses and gains along all chromosome arms in benign and malignant insulinomas in order to asses the chromosomal markers with the highest potential to predict metastatic disease. These markers will be compared with the best indicators of increased risk for malignancy suggested by the WHO, i.e. tumor size and proliferation index. For this purpose we have extended our previously analyzed collection of mainly benign insulinomas [9] to a large group of 62 tumors, including 18 malignant cases. In addition, these tumors were examined for MEN1 mutations to assess the impact of this gene in insulinomas, and a possible association of such mutations with particular CGH profiles. 


\subsection{Material and methods}

\subsubsection{Tumor material and patient data.}

Sixty-two insulinomas (32 females, mean age $52.1 \pm 18.6$ years and 30 males, mean age $53.1 \pm 15.7$ years) were selected from the archives of the Departments of Pathology of the University Hospital Zurich, Switzerland and the University Medical Centers of Rotterdam, Utrecht and Nijmegen, The Netherlands. The study protocol was approved by the institutional ethical committee, and all of the patients gave informed consent. The samples included 59 frozen and 3 paraffin-embedded insulinomas which were all sporadic tumors and not associated with the inherited MEN1 syndrome. The tumors were classified according to the most recent WHO classification [2]. All insulinomas had hyperinsulinism followed by a hypoglycemia syndrome. Forty-four of the patients had localized disease, defined by (1) the absence of extra-pancreatic spread of the tumor as evidenced by computed tomography, magnetic resonance imaging or ultrasound scanning, and (2) a complete absence of hypoglycemia (even during $72 \mathrm{~h}$ fasting) after successful removal of the tumor by surgery. Moreover, during follow-up of at least 1 year, these cases showed neither evidence of recurrent hypoglycemia at follow-up, nor recurrence or metastases by radiology. No post-operative adjuvant therapy was given to these patients. Eighteen patients had advanced disease, with tumor spread into the surrounding soft tissue, lymph nodes or liver.

\subsubsection{DNA extraction.}

DNA extraction was performed as described before [9]. Genomic DNA from frozen samples was isolated by homogenizing approximately $5 \mathrm{~mm}^{3}$ of each sample prior to proteinase $\mathrm{K}$ treatment and DNA purification using the QIAamp DNA mini kit (Qiagen, Hilden, Germany). Genomic DNA from paraffin-embedded tumor material was isolated from 5-10 $\mathrm{nm}$-thick tissue sections by this procedure after deparaffination. DNA quality was checked with agarose gel electrophoresis and quantified by spectrophotometry.

\subsubsection{CGH and digital image analysis.}

CGH was performed with DNA isolated from the 62 insulinoma samples as previously described [9]. Briefly, $2 \mu \mathrm{g}$ tumor DNA were labeled with Spectrum GreendUTP (Vysis, Downers Grove, IL, USA) by nick translation (BioNick labeling kit; Life Technologies, Breda, The Netherlands). Spectrum Red-labeled normal and sex-matched reference DNA (Life technologies) was used for co-hybridization. The hybridization mixture consisted of $800 \mathrm{ng}$ Spectrum Green-labeled tumor DNA, $800 \mathrm{ng}$ Spectrum-Red labeled reference DNA and $10 \mu \mathrm{g}$ of human Cot-1 DNA (Life Technologies) dissolved in $12 \mu \mathrm{l}$ hybridization buffer ( $50 \%$ formamide, 2xSSC, $10 \%$ dextran sulfate, $\mathrm{pH} 7.0$ ). Hybridization was carried out for 3 days at $37^{\circ} \mathrm{C}$ to denatured $\left(5 \mathrm{~min}\right.$ at $75^{\circ} \mathrm{C}$ in $70 \%$ formamide/2xSSC, pH 7.0 ) normal male human metaphase spreads (Vysis). Slides were washed twice at $42^{\circ} \mathrm{C}$ for 5 
min in $50 \%$ formamide/2xSSC, $\mathrm{pH} 7.0$ and dehydrated. The chromosomes were counterstained with $0.2 \mu \mathrm{g}$ 4,6-diamidino-2-phenylindole per ml Vectashield (Vector laboratories, Burlingame, CA) for identification.

Digital images were collected from at least ten metaphases using the Metasystems Image Pro System black and white CCD camera (Altlussheim, Germany) mounted on top of a Leica DMRE fluorescence microscope, equipped with DAPI, Spectrum Green, and Spectrum Red filter sets. The software Metasystems ISIS 4.4.25 program was used to calculate average green-to-red ratio profiles for each chromosome. At least ten observations per autosome and five observations per sex chromosome were included in each analysis. Gains and losses of DNA sequences were defined as chromosomal regions where the mean green-to-red fluorescence ratio was above 1.20 and below 0.80 respectively. Over-representations were considered amplifications when the fluorescence ratio values in a subregion of a chromosomal arm exceeded 1.5. In negative control hybridizations, the mean green-to-red ratio occasionally exceeded the fixed 1.2 cut-off level at the following chromosomal regions: 1p32-pter, 16p, 19, and 22. Gains of these G-C-rich regions were therefore excluded from all analyses.

\subsubsection{Statistical analysis of $\mathrm{CGH}$ results.}

The relationship between genomic alterations and malignancy was analyzed by using the chi-square test or the Fisher exact test, as appropriate. ANOVA was applied to compare the number of genomic alterations between benign and malignant insulinomas. A significance level of $p \leq 0.05$ was chosen.

\subsubsection{Confirmation of CGH data by fluorescence in situ hybridization (FISH) analysis.}

To validate $\mathrm{CGH}$ data independently, touch preparations of 15 insulinomas were subjected to FISH as described previously [7, 9]. The following probe combinations were applied: 1) centromere 9 (pMR9a) and a cosmid probe (c-ABL-8) containing the $c A b /$ gene on chromosome $9 q 34,2)$ centromere 6 (p308) and a PAC probe $(66 \mathrm{H} 14)$ mapping to the $6 \mathrm{q} 21$ region, and 3$)$ centromere $11(\mathrm{pLC} 11 \mathrm{~A})$ and a cosmid probe (c10B11) containing the MEN1 gene at 11q13. Digoxigenin-labeled probes were detected by sheep anti-digoxigenin fluorescein (Roche) and biotinlabeled probes by two layers of avidin-rhodamine connected by a biotinylated goat anti-avidin antibody (Vector). Probe visualization and nuclear counterstaining were carried out as described for $\mathrm{CGH}$, and signal scoring and evaluation was performed as described previously [7, 21]. 
Table 2.1. Primers used for MEN1 mutation analysis (exons 2-10): modified from a previous study [7]

\begin{tabular}{|c|c|c|c|c|}
\hline Primer & Sequence & $\begin{array}{l}\text { Length } \\
\text { (bp) }\end{array}$ & Technique & $\begin{array}{l}\text { Annealing } \\
\text { Temperature. }\left({ }^{\circ} \mathrm{C}\right)\end{array}$ \\
\hline M2cnewF & 5'-CCCGCTTCACCGCCCAGAT-3' & 272 & DGGE & 55 \\
\hline M2cnewR & 5'-TGGAGGGTTTTGAAGAAGTGGGTCA-3' & & & \\
\hline M2newF & 5'-CCTTAGCGGACCCTGGGA-3' & 365 & SSCP & 58 \\
\hline M2newR & 5'-ATAGAGGGCGGCGATGATAGA-3' & & & \\
\hline M2NNF & 5'-TCAACCGCGTCATCCCTACC-3' & 405 & SSCP & 62 \\
\hline M2NR & 5'-CACCTGCCGAACCTCACAAG-3' & & & \\
\hline M3F & 5'-GCACAGAGGACCCTCTTTCAT-3' & 335 & DGGE & 55 \\
\hline M3R & 5'-CTACAGTATGAAGGGGACAAGG-3' & & & \\
\hline M4F & 5'-TGGGCCATCATGAGACATAA-3' & 272 & DGGE & 55 \\
\hline M4R & 5'-CCCACAGCAAGTCAAGTCTG-3' & & & \\
\hline M5F & 5'-CCTGTTCCGTGGCTCATAAC-3' & 148 & DGGE & 55 \\
\hline M5R & 5'-CCTGGCCACTTCCСТCTA-3' & & & \\
\hline M6F & 5'-GGTGGCAGCCTGAATTATGA-3' & 213 & DGGE & 55 \\
\hline M6R & 5'-TTAGGGTCTCCCTTCTGCAC-3' & & & \\
\hline M7F & 5'-GGTGGGAGTGGAGATGGAGAGG-3' & 398 & DGGE & 55 \\
\hline M7R & 5'-GGACGAGGGTGGTTGGAAACTG-3' & & & \\
\hline M8NF & 5'-AGACCCCTTCAGACCCTACAGAG-3' & 273 & SSCP & 67 \\
\hline M8R & 5'-ССАТСССТААТCCCGTACATGC-3' & & & \\
\hline M9F & 5'-CTGCTAAGGGGTGAGTAAGAGAC-3' & 334 & DGGE & 55 \\
\hline M9R & 5'-AAAAGTCTGACAAGCCCGTG-3' & & & \\
\hline M10NF & 5'-TTGCTCTCACCTTGCTCTCC-3' & 409 & SSCP & 56 \\
\hline M10NNR & 5'-CTTGATGGCGCTCGAGTT-3' & & & \\
\hline M10aF & 5'-CCTTGCTCTCACСTTGCTCT-3' & 392 & DGGE & 55 \\
\hline M10aR & 5'-TCTGGAAAGTGAGCACTGGA-3' & & & \\
\hline M10bF & 5'-GAGGGTCCAGTGCTCACTTT-3' & 423 & DGGE & 55 \\
\hline M10bR & 5'-GGGTTCTGAGCTGGAGAAAA-3' & & & \\
\hline
\end{tabular}

\subsubsection{MEN1 mutation analysis.}

MEN1 is a $9 \mathrm{~kb}$ gene which encompasses ten exons (first exon untranscribed). The remaining nine coding exons were examined in 43 insulinomas, 31 benign and 12 malignant tumors, by denaturing gradient gel electrophoresis (DGGE) and single-strand confirmation polymorphism (SSCP), as previously used in several studies (see Table 2.1) [7, 27]. PCR amplifications were carried out using a programmable thermal cycler (DNA thermal cycler 9600, Perkin Elmer, Norwalk, CT, USA). After initial denaturation at $94^{\circ} \mathrm{C}$ for $5-10$ minutes, the DGGE PCR procedure comprises 40 cycles of denaturation at $94^{\circ} \mathrm{C}$ for $1 \mathrm{~min}$, annealing at $55-67^{\circ} \mathrm{C}$ 
(see Table 2.1) for $1 \mathrm{~min}$ and extension at $72^{\circ} \mathrm{C}$ for $1 \mathrm{~min}$. Finally, PCR tubes were incubated at $72^{\circ} \mathrm{C}$ for $10 \mathrm{~min}$, at $98^{\circ} \mathrm{C}$ for $8 \mathrm{~min}$, at $55^{\circ} \mathrm{C}$ for $30 \mathrm{~min}$, at $37^{\circ} \mathrm{C}$ for 30 $\mathrm{min}$, and than at $0^{\circ} \mathrm{C}$. The SSCP PCR procedure used the following incubations: 35 cycles of denaturation at $94^{\circ} \mathrm{C}$ for $75 \mathrm{~s}$, annealing at $55-67^{\circ} \mathrm{C}$ (Table 2.1) for 90 $\mathrm{s}$ and extension at $72^{\circ} \mathrm{C}$ for $2 \mathrm{~min}$. Finally, PCR tubes were incubated at $72^{\circ} \mathrm{C}$ for $5 \mathrm{~min}$ and than at $4^{\circ} \mathrm{C}$. PCR amplifications were performed in $50 \mu \mathrm{l}$ reactions with $1 \mathrm{ng}$ genomic DNA, 1x PCR buffer (Roche), $1.5 \mathrm{mM} \mathrm{MgCl}$ 2, $0.2 \mathrm{mM}$ dNTPs, 50 pmol of each forward and reverse primer and $1 \cup$ Amplitaq Gold (Roche). For the DGGE analysis, $10 \%$ polyacrylamide gels with a $20-80 \%$ (in the case of exon $10 a$ : $50-90 \%$ ) denaturing gradient were used. A solution of $100 \%$ chemical denaturant consists of $7 \mathrm{M}$ urea and $40 \%$ formamide. The gels polymerized by adding $1 \%$ ammonium persulfate and $0.05 \%$ tetramethylethylene-diamine. Once the gradient gel has polymerized, a $10 \%$ polyacrylamide stacking gel is layered on top of this gradient gel. $10 \mu \mathrm{l} \mathrm{PCR}$-amplified DNA was mixed with $3 \mu \mathrm{l}$ PCR-amplified non-mutated DNA, denatured, annealed, and loaded on the gel together with $5 \mu$ Ficoll loading buffer. Electrophoresis was performed at $100 \mathrm{~V}$ for $15 \mathrm{~h}$. After electrophoresis the DNA was visualized by silver staining as previously described [7]. Patient DNAs with an altered migration pattern on the DGGE gel were amplified again with primers without a GC-clamp, purified using the QIAquick PCR purification kit (Qiagen), and subjected to DNA cycle sequencing in sense and antisense direction using the TaqDyeDeoxy Terminator Cycle Sequencing kit (Applied Biosystems, Weiterstadt, Germany). This was followed by gel electrophoresis, data collection, and analysis on an automated DNA sequencer (Model 373A; Applied Biosystems).

For SSCP analysis, $10 \mu$ denatured PCR products in stop buffer (95\% formamide, $20 \mathrm{mM}$ EDTA, $0.05 \%$ xylene cyanol, $0.05 \%$ bromophenol blue) were loaded onto non-denaturing $6 \%$ polyacrylamide and $5 \%$ glycerin gels. Electrophoresis was carried out for $16 \mathrm{~h}$ at $8 \mathrm{~W}$ and $500-700 \mathrm{~V}$ at room temperature. After electrophoresis the DNA was visualized by silver staining. PCR products with an altered migration pattern on a SSCP gel were further purified and sequenced as described above for DGGE.

\subsubsection{Ki67 Immunohistochemistry.}

Ki67 antigen staining was performed on $4 \mu \mathrm{m}$ thick paraffin-embedded tissue sections of 35 insulinomas (22 benign and 13 malignant) as described previously [28]. Briefly, sections were deparaffinized and treated with $10 \mathrm{mM}$ citrate buffer ( $\mathrm{pH}$ 6.0) in a microwave oven at $600 \mathrm{~W}$ for $15 \mathrm{~min}$ (antigen retrieval). Endogenous peroxidase was inactivated by treatment with $2 \% \mathrm{H}_{2} \mathrm{O}_{2}$ in methanol, followed by incubation in 3\% BSA / PBS to block non-specific binding of antibody conjugates. The sections were incubated for 30 minutes at $37^{\circ} \mathrm{C}$ with the mouse monoclonal antibody MIB-1 directed against Ki67 (DAKO A/S, Denmark) at a 1:100 dilution in $1 \%$ BSA/PBS, biotin-labeled horse anti-mouse antibody at a 1:200 dilution, and avidin-biotinylated peroxidase complex (Vector laboratories, Burlingame, CA, USA) at a 1:50 dilution in 4x SSC. Peroxidase activity was visualized using diami- 
nobenzidine/ $\mathrm{H}_{2} \mathrm{O}_{2}$ (Sigma Chemical Co.) and sections were counterstained with hematoxylin and mounted in Entellan (Merck, Darmstadt, Germany). Positive and negative control tissues were included. Positive nuclei were scored in at least 500 cells per sample. The Ki67 labeling index was expressed as the percentage of total cells that were immunopositive.

\subsection{Results}

\subsubsection{General CGH findings.}

Figure 2.1 summarizes the DNA copy number changes detected by $\mathrm{CGH}$ in the 62 insulinomas. Genomic aberrations were found in 33 of the 44 benign and all malignant insulinomas. The average number of chromosomal aberrations per tumor was $7.2 \pm 7.0$ (range 0-28). Chromosomal gains (mean 3.9) were more common than chromosomal losses (mean 2.8), and in two tumors amplifications were identified, i.e. at 9q34 (2x) and 4p16 (1x). The most frequently involved specific genomic changes (in $>20 \%$ of insulinomas) included loss of $X q$ in female patients (smallest region of interest (SRI): Xq21) (34\%) and $Y$ in male patients (43\%), and gains of chromosomes $5 q, 7 p q, 9 q, 17$, and $20 q$, with the highest frequency of gains for chromosome 9q (58\%). Interestingly, gain of chromosome 9q was detected at approximately the same frequency in both benign and malignant tumors (57 vs $61 \%$ respectively) with $9 \mathrm{q} 34$ most commonly included. When these tumors are compared with those without $9 q$ alterations, the total number of aberrations and gains per tumor were significantly higher in the former group (9.1 \pm 6.2 vs $4.6 \pm$ $7.3, p=0.001$; and $5.5 \pm 4.3$ vs $1.7 \pm 3.1, p<0.0001$ respectively), with gains of $7 p q$, $9 p$ and $20 q$ and loss of Xpq more frequently detected. The obtained CGH results were validated in 15 insulinomas by FISH using chromosome 6-, 9- and 11-specific probe sets (Table 2.2 and Fig. 2.2, p.119). In general, the FISH results confirmed our CGH findings. Tumors without $\mathrm{CGH}$ alterations exhibited two or sometimes three copies of chromosome targets, indicating a diploid and triploid DNA content respectively (patients 1-7, 11-13), or showed alterations in small subpopulations $(\sim 20 \%)$ of cells (e.g. 11q13 loss in patients 2,14 and 15$)$. In the case of $9 q$ alterations, always $\geq 3$ copies of the 9q34-specific region were observed including two cases with an amplification (patients 10 and 15). Four cases showed tumor subpopulations with aberrant copy numbers of chromosome 9 targets indicating genetic heterogeneity (patients 10-12, 15).

\subsubsection{CGH findings, tumor size and proliferation index in relation to meta- static disease.}

The total number of chromosomal changes, gains, and losses all are strongly associated with malignancy $(P<0.0001$; Table 2.3A). In addition, marked differences in chromosome-specific alterations were observed between benign and malignant tumors (Fig. 2.1 and Table 2.3A). Particularly, losses of 2q, 3q, 6pq and 10q and gains of $4 q, 7 q, 12 p q, 14 q, 15 q, 17 p q$ and $20 p q$ were detected significantly more 
frequent in malignant insulinomas, with $6 q$ loss (SRI: $6 q 14$ and $21-22)(0 \%$ in benign vs $67 \%$ in malignant insulinomas), $12 q$ gain (SRI: $12 q 24)(2 \%$ vs $50 \%), 14 q$ gain ( $5 \%$ vs $50 \%$ ), and $17 \mathrm{pq}$ gain ( 5 and $9 \%$ vs 56 and $61 \%$ respectively) correlating most evidently (in all cases $p<0.0001$ ). If the tumors are grouped according to the presence of $9 q$ gains, the best common markers for malignancy are $6 q$ loss and $7 q, 14 q$ and $17 q$ gains (Table 2.3B).

In addition, a number of genomic changes were exclusively identified in one or the other insulinoma group. Interestingly, the group with 9q gain shows gains and the group without $9 q$ gain predominantly losses as parameters associated with malignancy (Table 2.3B).

Table 2.2. Double-target FISH results in 14 benign (cases 1-14) and one malignant (case 15) insulinomas

\begin{tabular}{lllllll}
\hline Tumor & $\begin{array}{l}\text { CGH } \\
\text { chr }\end{array}$ & 6C:6q21a & $\begin{array}{l}\text { CGH } \\
\text { chr 9 }\end{array}$ & 9C:9q34 & $\begin{array}{l}\text { CGH } \\
\text { chr 11 }\end{array}$ & 11C:11q13 \\
\hline 1 & 0 & $2: 2$ & 0 & $2: 2$ & 11 pq- & $1: 1$ \\
2 & 0 & $2: 2$ & 0 & $2: 2$ & 0 & $2: 1(26 \%)$ \\
3 & 0 & $2: 2$ & 0 & $2: 2$ & 0 & $2: 2$ \\
4 & 0 & $2: 2$ & 0 & $2: 2$ & 0 & $2: 2$ \\
5 & 0 & $2: 2$ & 0 & $2: 2(41 \%), 3: 3(30 \%)$ & 0 & $2: 2$ \\
6 & 0 & $2: 2$ & 0 & $2: 2,2:>2(27 \%)$ & 0 & $2: 2$ \\
7 & 0 & $2: 2$ & 0 & $2: 2$ & 0 & $2: 2$ \\
8 & 0 & $2: 2$ & $9 q r g+$ & $2: 3$ & 0 & $2: 2$ \\
9 & 0 & $2: 2$ & $9 q 34+$ & $3: 3$ & 0 & $2: 2$ \\
10 & 0 & $2: 2$ & $9 p q+$, & Area 1; 3:3 & $11 q 13+$ & $2: 3$ \\
& & & $9 q 34++$ & Area 2; 3:5, 3:>5 amp & & \\
11 & 0 & $3: 3$ & $9 q 34+$ & $3: 3(37 \%), 4: 4(37 \%)$ & 0 & $2: 2$ \\
12 & 0 & $3: 3$ & $9 q 32-34+$ & $3: 3(42 \%), 3: 4(24 \%)$ & $11 p q-$ & $2: 2$ \\
13 & 0 & $3: 3$ & $9 q 34+$ & $3: 6$ & 0 & $3: 3$ \\
14 & $6 p q+$ & $3: 3$ & 0 & $2: 2$ & 0 & $2: 1(20 \%)$ \\
15 & $6 q-$ & $2: 1$ & $9 q+$, & $4: 4(44 \%), 4: 8(25 \%)$ & 0 & $2: 1(22 \%)$ \\
& & $(34 \%)$ & $9 q 34++$ & $2: 12(5 \%$, amp $)$ & & \\
\hline
\end{tabular}

aFISH results 2:1 ( $n \%), 2$ copies of the centromere probe and 1 copy of the locus-specific probe in $n \%$ of nuclei (in the case of subpopulation of cells); amp, amplification. 
Table 2.3. Parameters associated with malignancy and tumor size (A) or 9q gain (B)

\begin{tabular}{|c|c|c|c|c|c|c|}
\hline A. & $B(n=44)$ & $M(n=18)$ & $\mathbf{P}$ & $\begin{array}{l}\text { Size }<2 \mathrm{~cm} \\
(\mathrm{n}=40)\end{array}$ & $\begin{array}{l}\text { Size } \geq 2 \mathrm{~cm} \\
(n=22)\end{array}$ & $\mathbf{P}$ \\
\hline $\begin{array}{l}\text { Total } \\
\text { aberrations }\end{array}$ & $4.2 \pm 4.6$ & $14.1 \pm 6.7$ & $<0.0001^{a}$ & $4.7 \pm 4.8$ & $11.9 \pm 8.0$ & $<0.0001^{a}$ \\
\hline Losses & $1.7 \pm 2.5$ & $5.7 \pm 4.5$ & $<0.0001^{a}$ & $1.7 \pm 2.5$ & $5.0 \pm 4.5$ & $<0.0001^{a}$ \\
\hline Gains & $2.5 \pm 3.3$ & $7.3 \pm 4.4$ & $<0.0001^{a}$ & $2.8 \pm 3.1$ & $6.1 \pm 5.2$ & $<0.0001^{a}$ \\
\hline Mean size $(\mathrm{cm})$ & $1.5 \pm 0.5$ & $3.8 \pm 2.3$ & $<0.0001^{\mathrm{a}}$ & - & - & - \\
\hline $2 q$ loss & $5 \%$ & $39 \%$ & $0.002^{c}$ & $8 \%$ & $27 \%$ & $N S^{b}$ \\
\hline $3 q$ loss & $0 \%$ & $33 \%$ & $<0.0001^{c}$ & $3 \%$ & $23 \%$ & $0.010^{\mathrm{b}}$ \\
\hline $4 q$ gain & $0 \%$ & $22 \%$ & $0.005^{c}$ & $0 \%$ & $18 \%$ & $0.025^{b}$ \\
\hline $5 p$ gain & $11 \%$ & $28 \%$ & $N^{c}$ & $8 \%$ & $32 \%$ & $0.033^{b}$ \\
\hline $5 q$ gain & $16 \%$ & $39 \%$ & $\mathrm{NS}^{\mathrm{c}}$ & $13 \%$ & $41 \%$ & $0.025^{b}$ \\
\hline $6 p$ loss & $0 \%$ & $28 \%$ & $0.001^{c}$ & $0 \%$ & $23 \%$ & $0.008^{b}$ \\
\hline $6 q$ loss & $0 \%$ & $67 \%$ & $<0.0001^{c}$ & $5 \%$ & $45 \%$ & $<0.0001^{b}$ \\
\hline $7 q$ gain & $18 \%$ & $67 \%$ & $0.001^{c}$ & $20 \%$ & $55 \%$ & $0.012^{b}$ \\
\hline $10 q$ loss & $0 \%$ & $22 \%$ & $0.005^{c}$ & $0 \%$ & $18 \%$ & $0.025^{b}$ \\
\hline $12 p$ gain & $0 \%$ & $22 \%$ & $0.005^{c}$ & $0 \%$ & $18 \%$ & $0.025^{b}$ \\
\hline $12 q$ gain & $2 \%$ & $50 \%$ & $<0.0001^{c}$ & $8 \%$ & $32 \%$ & $0.033^{b}$ \\
\hline $14 q$ gain & $5 \%$ & $50 \%$ & $<0.0001^{c}$ & $5 \%$ & $41 \%$ & $0.001^{\mathrm{b}}$ \\
\hline $15 q$ gain & $7 \%$ & $33 \%$ & $0.014^{c}$ & $8 \%$ & $27 \%$ & $N^{b}$ \\
\hline $17 p$ gain & $5 \%$ & $56 \%$ & $<0.0001^{c}$ & $10 \%$ & $36 \%$ & $0.029^{b}$ \\
\hline $17 q$ gain & $9 \%$ & $61 \%$ & $<0.0001^{c}$ & $13 \%$ & $45 \%$ & $0.010^{\mathrm{b}}$ \\
\hline $20 p$ gain & $7 \%$ & $28 \%$ & $0.039^{c}$ & $8 \%$ & $23 \%$ & $N S^{b}$ \\
\hline $20 q$ gain & $11 \%$ & $50 \%$ & $0.002^{c}$ & $18 \%$ & $32 \%$ & $N S^{b}$ \\
\hline $21 q$ gain & $9 \%$ & $17 \%$ & $\mathrm{NS}^{\mathrm{c}}$ & $3 \%$ & $27 \%$ & $0.011^{\mathrm{b}}$ \\
\hline $22 q$ loss & $5 \%$ & $22 \%$ & $\mathrm{NS}^{\mathrm{c}}$ & $3 \%$ & $23 \%$ & $0.033^{b}$ \\
\hline
\end{tabular}

\begin{tabular}{|c|c|c|c|c|c|c|c|}
\hline \multirow[t]{2}{*}{ B. } & \multicolumn{3}{|c|}{ Insulinomas with 9q gain } & & \multicolumn{3}{|c|}{ Insulinomas without 9q gain } \\
\hline & $B(n=25)$ & $M(n=11)$ & $\mathbf{P}$ & & $B(n=19)$ & $M(n=7)$ & $\mathbf{P}$ \\
\hline \multicolumn{8}{|c|}{ Common parameters } \\
\hline $6 q$ loss & $0 \%$ & $64 \%$ & $<0.0001^{c}$ & $6 q$ loss & $0 \%$ & $71 \%$ & $<0.0001^{c}$ \\
\hline $7 q$ gain & $32 \%$ & $73 \%$ & $0.034^{c}$ & 7q gain & $0 \%$ & $57 \%$ & $0.002^{c}$ \\
\hline $14 q$ gain & $8 \%$ & $45 \%$ & $0.018^{c}$ & $14 q$ gain & $0 \%$ & $57 \%$ & $0.002^{\mathrm{c}}$ \\
\hline $17 q$ gain & $16 \%$ & $73 \%$ & $0.002^{\mathrm{c}}$ & $17 q$ gain & $0 \%$ & $43 \%$ & $0.013^{c}$ \\
\hline \multicolumn{8}{|c|}{ Group-specific parameters } \\
\hline $12 p$ gain & $0 \%$ & $27 \%$ & $0.023^{c}$ & $1 p$ loss & $5 \%$ & $57 \%$ & $0.010^{c}$ \\
\hline $12 q$ gain & $4 \%$ & $64 \%$ & $<0.0001^{\mathrm{c}}$ & $2 q$ loss & $0 \%$ & $43 \%$ & $0.013^{c}$ \\
\hline $13 q$ gain & $0 \%$ & $27 \%$ & $0.023^{c}$ & $3 q$ loss & $0 \%$ & $57 \%$ & $0.002^{c}$ \\
\hline $17 p$ gain & $8 \%$ & $73 \%$ & $<0.0001^{c}$ & $5 q$ gain & $5 \%$ & $57 \%$ & $0.010^{c}$ \\
\hline
\end{tabular}




\begin{tabular}{|c|c|c|c|c|c|c|c|}
\hline \multirow[t]{2}{*}{ B. } & \multicolumn{3}{|c|}{ Insulinomas with $9 q$ gain } & & \multicolumn{3}{|c|}{ Insulinomas without 9q gain } \\
\hline & $B(n=25)$ & $M(n=11)$ & $\mathbf{P}$ & & $B(n=19)$ & $M(n=7)$ & $\mathbf{P}$ \\
\hline \multirow[t]{4}{*}{$20 q$ gain } & $20 \%$ & $64 \%$ & $0.020^{c}$ & $6 p$ loss & $0 \%$ & $57 \%$ & $0.002^{c}$ \\
\hline & & & & $21 q$ loss & $0 \%$ & $43 \%$ & $0.013^{c}$ \\
\hline & & & & $22 q$ loss & $5 \%$ & $57 \%$ & $0.010^{c}$ \\
\hline & & & & Y loss & $5 \%$ & $57 \%$ & $0.010^{\circ}$ \\
\hline
\end{tabular}

aANOVA analysis, ${ }^{\circ} \mathrm{Chi}$-square test, "Fisher exact test,

B, Benign; M, Malignant; NS, not significant.

Apart from differences in genomic alterations, benign insulinomas were found to be significantly smaller than malignant ones (diameter $=1.5$ vs $3.8 \mathrm{~cm}$ respectively, $\mathrm{p}<0.0001$ ). Because a diameter of $2 \mathrm{~cm}$ is an important parameter in insulinoma classification, we compared tumors with a size $<2 \mathrm{~cm}$ with tumors $\geq 2 \mathrm{~cm}$ in diameter. This comparison revealed that an increase in the total number of aberrations, gains, and losses was significantly correlated with a size $\geq 2 \mathrm{~cm}$ (Table 2.3A). Loss of $3 q, 6 p q$ and $22 q$ and gains of $5 p q, 7 q, 12 q, 14 q, 17 p q$ and $21 q$ were also significantly correlated with a tumor size $\geq 2 \mathrm{~cm}$ (Table $2.3 \mathrm{~A}$ ).

Another indicator of risk of malignancy is a proliferation index of $\geq 2 \%$ measured by immunohistochemistry of Ki67 (MIB-1 monoclonal antibody). Comparison of 22 benign and 13 malignant insulinomas revealed only one benign and four malignant insulinomas showing a proliferation index $\geq 2 \%$. This finding did not reach statistical significance when comparing benign and malignant tumors. Gain of chromosome $12 q$ was the only parameter significantly correlated with a proliferative rate of $\geq 2$ $\%$ (60 vs $13 \%$ in the group with a proliferation index $<2 \%$ respectively, $p=0.044$ ). Table 2.4 shows these parameters as markers in univariate and bivariate analysis with the percentages of correctly classified tumors (sensitivity and specificity) and their odds ratios. The best classification markers for malignant behavior according to sensitivity in univariate analysis are the total number of aberrations $(\geq 8)$, gains $(\geq 5)$ and the size of the tumor ( $\geq 2 \mathrm{~cm}$ in diameter). A combination of the total number of gains $(\geq 5)$ and losses $(\geq 5)$ provides an even better sensitivity as shown by bivariate analysis with two independent markers. 
Table 2.4. Parameters for assessing malignant behavior

\begin{tabular}{llll}
\hline Parameter & Sensitivity & Specificity & OR (95\% Cl) \\
\hline Univariate analysis & & & \\
\hline Total aberrations $\geq 8$ & $83 \%$ & $82 \%$ & $22.5(5.2-96.6)$ \\
Total gains $\geq 5$ & $78 \%$ & $89 \%$ & $27.3(6.4-116.3)$ \\
Total losses $\geq 5$ & $50 \%$ & $89 \%$ & $7.8(2.1-29.0)$ \\
$6 q$ loss & $67 \%$ & $100 \%$ & $>86.0(9.4-785.2)$ \\
$14 q$ gain & $50 \%$ & $95 \%$ & $21.0(3.9-114.1)$ \\
$17 q$ gain & $61 \%$ & $91 \%$ & $15.7(3.9-63.6)$ \\
Size $\geq 2$ cm & $76 \%$ & $82 \%$ & $15.8(4.1-60.7)$ \\
Proliferative index (Ki67) $\geq 2 \%$ & $31 \%$ & $95 \%$ & $9.3(0.9-95.6)$ \\
\hline Bivariate analysis & & & $20.9(4.5-96.0)$ \\
\hline Total gains and total losses $\geq 5$ & $89 \%$ & $77 \%$ & $15.8(4.0-61.6)$ \\
$17 q$ gain and total losses $\geq 5$ & $83 \%$ & $80 \%$ & \\
OR, odds ratio; 95\% Cl, 95\% confidence interval, apercent of malignant tumors with the parameter, ${ }^{\text {pPercent of }}$ \\
benign tumors without the parameter.
\end{tabular}

\subsubsection{MEN1 mutation analysis.}

MEN1 mutation analysis was performed on 43 sporadic insulinomas from which sufficient DNA was available. Only one insulinoma (male, 42 years old) showed a somatic 7 bp deletion in exon 10 (position 1527) of the MEN1 gene, as shown in Fig. 2.2 D-F (p.119) CGH analysis of this benign tumor showed gains of 5pq, $6 \mathrm{pq}$ and $21 \mathrm{q}$. Although loss of chromosome 11q was not identified by $\mathrm{CGH}, \mathrm{FISH}$ analysis revealed loss of the MEN1 gene in $20 \%$ of cells (see above and Table 2.2, patient 14) suggesting deletion of the wild type locus. A known polymorphism in exon 2 (S145S) was found in an additional tumor. 


\section{Benign insulinomas $(n=44)$}


10

11

12

13

15

$17 \quad 18$

19

20

21

22

$\mathrm{X}$

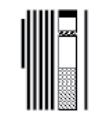

Y

\section{Malignant insulinomas $(n=18)$}

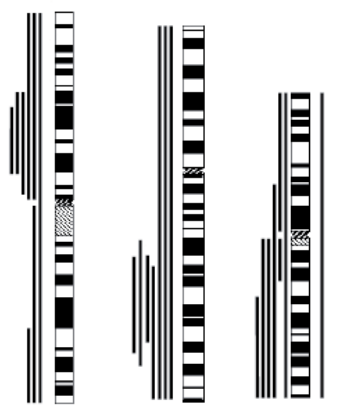

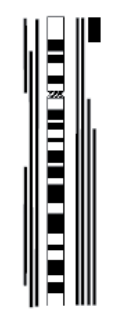

4

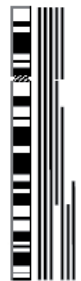

5

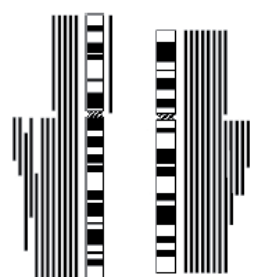

7

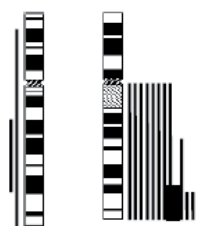

9

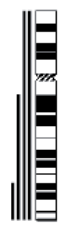

10

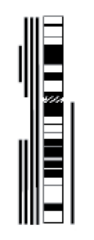

11

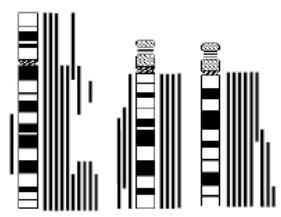

12

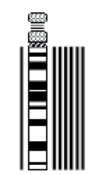

15

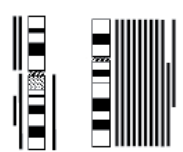

$\begin{array}{ll}16 & 17\end{array}$

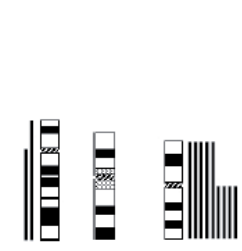

$\begin{array}{lll}18 & 19 & 20\end{array}$

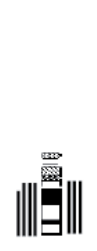

21

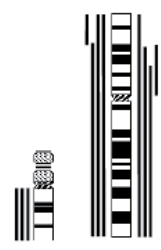

$22 \mathrm{X}$

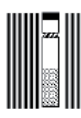

Y

Figure 2.1. Summary of all DNA copy number changes detected by CGH in 44 benign and 18 malignant insulinomas. Vertical lines on the left of the chromosome ideograms indicate the number of cases showing losses of the corresponding chromosomal regions; vertical lines on the right indicate the number of cases showing gains. The bold lines represent amplifications at $4 p 16$ and $9 q 34$. Gains on 1p32-pter, 16p, 19, and 22 were not analyzed (see text). 


\subsection{Discussion}

We have performed a comprehensive genome-wide survey of DNA copy number changes in a series of 62 human sporadic insulinomas with the goal to identify genetic alterations that discriminate benign tumors from cases with metastatic progression. Particularly the CGH detection of a high number of confined chromosomal alterations per tumor was found to strongly correlate with metastatic disease in this EPT subtype. In addition, this study provides further evidence that gain and/or amplification of chromosome 9q, rather than MEN1 mutations, is a frequent event in sporadic insulinomas that may be of pathogenetic importance.

Our data strongly indicate that insulinoma progression is driven by the accumulation of genetic changes, as is also known to occur in other types of human carcinomas [29-31]. A marked distinction between benign and malignant insulinomas can be made on the basis of the number of genomic alterations per tumor as identified by $\mathrm{CGH}$. The most prominent DNA copy number changes enabling this differentiation include loss of chromosome $6 q$ (SRI $6 q 14$ and $6 q 21-22)$ and gains of $7 q$, $12 q$ (SRI 12q24), 14q and 17pq. In comparison with currently used indicators of malignancy, including tumor size $\geq 2 \mathrm{~cm}$ and proliferative index $\geq 2 \%$, high numbers of chromosomal alterations are significantly more powerful for this purpose (Table 2.4). The most potential indicators for metastatic progression detected in our study include: (1) a combination of gains and losses (both $\geq 5$ per tumor), (2) the total number of aberrations ( $\geq 8$ per tumor), (3) a combination of losses ( $\geq 5$ per tumor) and $17 q$ gain, and (4) the total number of gains ( $\geq 5$ per tumor). Thus, our data implicate that chromosomal instability (CIN), an abnormal cell state with elevated chromosomal gains and losses, is the optimal predictor for malignant progression in sporadic insulinomas. It will be interesting to identify the target genes that might be involved in the development of CIN [31].

The identified chromosomal regions altered in insulinomas point to loci containing putative oncogenes and tumor suppressor genes. The most frequent aberration identified by $\mathrm{CGH}$ in about $60 \%$ of both benign and malignant insulinomas is the increase of chromosome $9 q$ copy numbers. This extends our previous findings in a small group of benign insulinomas and endorses the importance of this genetic event in early tumor development [9]. Moreover, insulinomas with 9q gain harbored a significantly higher number of aberrations, especially gains, than the remaining tumors, and this difference in genetic makeup suggests the evolution along two different genetic pathways in insulinoma development. The SRI is located at 9q34 and this region was found amplified in two insulinomas. Gain and/or amplification of this region have been reported in other neoplasms, including neuroendocrine tumors [32-34], schwannomas [35], and enteropathy-type T-cell lymphomas [36]. There are several candidate genes localized in this region, i.e. the oncogene VAV2 [37], CDK9, a co-regulator of the progression through the cell cycle [38], Notch-1, a transmembrane receptor promoting differentiation of T-cells [39], LMX1B, a LIMhomeodomain-containing protein involved in a variety of developmental events 
[40], TSC1, the tuberous sclerosis gene 1, and $c A b l$, playing a role in chronic myeloid leukemia [41]. In TSC patients, insulinomas are occasionally detected. In these tumors, mutations in TSC1 or TSC2 (at 16p13.3) in combination with loss of the wildtype allele result in stimulation of cell growth and proliferation via dysregulation of mTOR activity [42-43]. In our series of insulinomas we noticed often $\geq 3$ copies of 9q34 instead of loss. The intriguing finding that duplication / amplification of mutated alleles may also lead to tumorigenesis [44] should be examined in this respect. The oncogenic significance of the $c A b /$ gene in insulinomas is unknown, although we identified two cases with amplification of this locus by FISH analysis, and cAbl overexpression has been reported in two rat insulinoma cell lines [45]. Additional research is needed to clarify its possible role in the development of insulinomas.

Despite the importance of MEN1 gene mutations in EPTs, we only identified one case with a MEN1 mutation in a group of 43 insulinomas. In this tumor the wildtype allele was also lost. This finding is in agreement with other studies suggesting a minor role for MEN1 in human insulinomas [4, 6-8, 46]. However, other mechanisms of gene inactivation may be involved in insulinoma development. Promotor hypermethylation of the MEN1 gene has not been detected so far [47]. The many different candidate proteins found to interact with menin may also implicate that other mechanisms can lead to down-regulation of the MEN1 protein [48]. This needs to be further investigated using, for example, RT-PCR or immunohistochemistry [49]. The high frequency of loss of heterozygosity in EPTs, including insulinomas, may also point to additional tumor suppressor gene loci at 11q [50-51].

Chromosome $6 q$ loss proved to be the strongest chromosome-specific marker to classify the metastatic potential of insulinomas, because it was only detected in the malignant tumors. This is in agreement with a previous study, in which we mapped the SRI to 6q22-24 in sporadic EPTs in general [23]. Several candidate tumor suppressor genes are located in the common region of deletion, including AIM1 (absent in melanoma 1), a beta-gamma-crystallin superfamily member inhibiting cellular growth by possible interactions with the cytoskeleton [52], CCNC (Cyclin C) [53], PTPRK (receptor-type protein-tyrosine phosphatase kappa), possibly involved in the regulation of cell contact and adhesion via dephosphorylation of catenins or cadherins [54], CX43 (connexin 43), a gap junction protein involved in intercellular communication [55], and LOT1 (PLAGL1/ZAC1). LOT1 is a zinc-finger nuclear transcription factor that regulates the type 1 receptor for pituitary adenylate cyclase-activating polypeptide, an important mediator of autocrine control of insulin secretion in the pancreatic islet. Furthermore, it possesses anti-proliferative effects and appears to be epigenetically silenced in different types of cancer, including parathyroid adenomas [56-57]. Future studies will determine if these genes are involved in insulinoma oncogenesis.

Deletions of other chromosomal regions that were reported to be associated with malignant behavior of EPTs, such as $1 p, 3 p, 3 q, 11 q, 17 p, 22 q$ and $X[14,18-26]$, were only occasionally observed in this CGH study on insulinomas. Losses of 
chromosome $3 p$ and $3 q$ were identified significantly more frequent in the malignant insulinomas, but only at low frequencies of 17 and $33 \%$, respectively. This holds also true for the association of $1 p$ and $22 q$ losses with malignancy in the group of insulinomas without $9 q$ gain. These results indicate that the reported alterations are infrequent in insulinomas. However, it can not be excluded that small deletions and gains are missed by $\mathrm{CGH}$ analysis due to the resolution of $\sim 5-10 \mathrm{Mb}$. This might also underscore to some extent the frequency of alterations yet identified in this study. Gains of chromosomes 7pq, 12q, 14q and 17pq have been frequently reported in many types of cancer and are also commonly observed in sporadic gastrointestinal neuroendocrine tumors, including EPTs [16-17, 58-60]. However, so far no convincing evidence has been presented of specific genes on these chromosomes playing a role in EPTs in general or insulinomas in particular [15, 61]. In summary, our data show that benign insulinomas can be efficiently distinguished from tumors with metastatic progression on basis of the chromosomal profile of the tumors. Furthermore, because these alterations are recurrently detected by $\mathrm{CGH}$, the identified chromosomal regions may harbor candidate cancer genes that are important in insulinoma pathogenesis. Whereas the presence of $9 q$ gain and/or amplification appears to be an important genetic event in insulinoma development, the MEN1 gene is unlikely to be involved in this process.

\subsection{Acknowledgements}

We thank V.M. Cuijpers (Department of Pathology, UMC Nijmegen, The Netherlands), M. Verdaasdonk (Department of Pathology, UMC Utrecht, The Netherlands), and T. Locher (Department of Pathology, University Hospital Zurich, Switzerland) for expert technical assistance; P.U. Heitz, J. Roth (Department of Pathology, University Hospital Zurich, Switzerland), A.H.N. Hopman (Department of Molecular Cell Biology, University of Maastricht, The Netherlands), and A.C. Voogd (Department of Epidemiology, University of Maastricht, The Netherlands) for helpful discussions.

This study was supported by the Netherlands Foundations Vanderes and Sacha Swarttouw-Hijmans, and the Association for International Cancer Research (AICR), St. Andrews, UK and in part by the National Science Foundation (31-618845.0), Swiss Cancer Research Foundation (997-02-2000). We declare that there is no conflict of interest that would prejudice its impartiality.

\subsection{References}

Chun J, Doherty GM. Pancreatic endocrine tumors. Curr. Opin. Oncol. 2001; 13: 52-56.

Komminoth P, Perren A, Öberg K, Rindi G, Heitz PU, Klöppel G. Insulinoma. In Pathology \& Genetics. Tumours of endocrine organs. 2004: pp 183-186. Eds RA DeLellis, RV Lloyd, PU Heitz, C Eng. Lyon: IARC Press.

Hochwald SN, Zee S, Conlon KC, Colleoni R, Louie O, Brennan MF, et al. Prognostic factors in pancreatic endocrine neoplasms: an analysis of 136 cases with a proposal for low-grade and intermediategrade groups. J. Clin. Oncol. 2002; 20: 2633-2642. 2003; 2: 7-12. 
Zhuang Z, Vortmeyer AO, Pack S, Huang S, Pham TA, Wang C, et al. Somatic mutations of the MEN1 tumor suppressor gene in sporadic gastrinomas and insulinomas. Cancer Res. 1997; 57: 4682-4686.

Görtz B, Roth J, Krähenmann A, De Krijger RR, Muletta-Feurer S, Rütimann K, et al. Mutations and allelic deletions of the MEN 1 gene are associated with a subset of sporadic endocrine pancreatic and neuroendocrine tumors and not restricted to foregut neoplasms. Am. J. Pathol. 1999; 154: 429-436.

Cupisti K, Höppner W, Dotzenrath C, Simon D, Berndt I, Röher HD, et al. Lack of MEN1 gene mutations in 27 sporadic insulinomas. Eur. J. Clin. Invest. 2000; 30: 325-329.

Speel EJM, Scheidweiler AF, Zhao J, Matter C, Saremaslani P, Roth J, et al. Genetic evidence for early divergence of small functioning and nonfunctioning endocrine pancreatic tumors: gain of 9q34 is an early event in insulinomas. Cancer Res. 2001; 61: 5186-5192.

Schussheim DH, Skarulis MC, Agarwal SK, Simonds WF, Burns AL, Spiegel AM, et al. Multiple endocrine neoplasia type 1: new clinical and basic findings. Trends Endocrinol. Metab. 2001; 12: 173-178.

Bertolino P, Tong WM, Herrera PL, Casse H, Zhang CX, Wang ZQ. Pancreatic $\beta$-cell-specific ablation of the multiple endocrine neoplasia type 1 (MEN1) gene causes full penetrance of insulinoma development in mice. Cancer Res. 2003; 63: 4836-4841.

Graeme-Cook F, Bell DA, Flotte TJ, Preffer F, Pastel-Levy C, Nardi G, et al. Aneuploidy in pancreatic insulinomas does not predict malignancy. Cancer 1990; 66: 2365-2368.

Böttger T, Seidl C, Seifert JK, Heintz A, Bretz B, Junginger T. Value of quantitative DNA analysis in endocrine tumors of the pancreas. Oncology 1997; 54: 318-323.

Chung DC, Brown SB, Graeme-Cook F, Tillotson LG, Warshaw AL, Jensen RT, et al. Localisation of putative tumor suppressor loci by genomewide allelotyping in human pancreatic endocrine tumors. Cancer Res. 1998; 58: 3706-3711.

Speel EJM, Richter J, Moch H, Egenter C, Saremaslani P, Rütimann K, et al. Genetic differences in endocrine pancreatic tumor subtypes detected by comparative genomic hybridization. Am. J. Pathol. 1999; 155: 1787-1794.

Stumpf E, Aalto Y, Höög A, Kjellman M, Otonkoski T, Knuutila S, et al. Chromosomal alterations in human pancreatic endocrine tumors. Genes Chromosomes Cancer 2000; 29: 83-87.

Zhao J, Moch H, Scheidweiler AF, Baer A, Schäffer AA, Speel EJM, et al. Genomic imbalances in the progression of endocrine pancreatic tumors. Genes Chromosomes Cancer 2001; 32: 364-372.

Ebrahimi SA, Wang EH, Wu A, Schreck RR, Passaro Jr E, Sawicki MP. Deletion of chromosome 1 predicts prognosis in pancreatic endocrine tumors. Cancer Res. 1999; 59: 311-315.

Chung DC, Smith AP, Louis DN, Graeme-Cook F, Warshaw AL, Arnold AA. Novel pancreatic endocrine tumor suppressor gene locus on chromosome $3 p$ with clinical prognostic implications. J. Clin. Invest. 1997; 100: 404-410.

Hessman O, Lindberg D, Einarsson A, Lillhager P, Carling T, Grimelius L, et al. Genetic alterations on $3 p, 11 q 13$, and 18q in nonfamilial and MEN1-associated pancreatic endocrine tumors. Genes Chromosomes Cancer 1999; 26: 258-264.

Barghorn A, Komminoth P, Bachmann D, Rütimann K, Saremaslani P, Mulatta-Feurer S, et al. Deletion at 3p25.3-p23 is frequently encountered in endocrine pancreatic tumours and is associated with metastatic progression. J. Pathol. 2001; 194: 451-458.

Guo SS, Arora C, Shimoide AT, Sawicki MP. Frequent deletion of chromosome 3 in malignant sporadic pancreatic endocrine tumors. Mol. Cell. Endocrinol. 2002; 190: 109-114.

Barghorn A, Speel EJM, Farspour B, Saremaslani P, Schmid S, Perren A, et al. Putative tumor suppressor loci at 6q22 and 6q23-q24 are involved in the malignant progression of sporadic endocrine pancreatic tumors. Am. J. Pathol. 2001; 158: 1903-1911.

Beghelli S, Pelosi G, Zamboni G, Falconi M, lacono C, Bordi C, et al. Pancreatic endocrine tumours: evidence for a tumour suppressor pathogenesis and for a tumour suppressor gene on chromosome 17p. J. Pathol. 1998; 186: 41-50. 
Wild A, Langer P, Celik I, Chaloupka B, Bartsch DK. Chromosome 22q in pancreatic endocrine tumors: identification of a homozygous deletion and potential prognostic associations of allelic deletions. Eur. J. Endocrinol. 2002; 147: 507-513.

Missiaglia E, Moore PS, Williamson J, Lemoine NR, Falconi M, Zamboni G, et al. Sex chromosome anomalies in pancreatic endocrine tumors. Int. J. Cancer 2002; 98: 532-538.

Perren A, Barghorn A, Schmid S, Saremaslani P, Roth J, Heitz PU, et al. Absence of somatic SDHD mutations in sporadic neuroendocrine tumors and detection of two germline variants in paraganglioma patients. Oncogene 2002; 21: 7605-7608.

Wessels PH, Twijnstra A, Kubat B, Ummelen MIJ, Claessen SMH, Sciot R, et al. 10q25.3 (DMBT1) copy number changes in astrocytoma grades II and IV. Genes Chromosomes Cancer 2004; 39: 2228.

Nowak MA, Komarova NL, Sengupta A, Jallepalli PV, Shih LM, Vogelstein B, et al. The role of chromosomal instability in tumor initiation. PNAS 2002; 99: 16226-16231.

Vogelstein B, Kinzler KW. Cancer genes and the pathways they control. Nat. Med. 2004; 10: 789-799.

Draviam VM, Xie S, Sorger PK. Chromosome segregation and genomic stability. Curr. Opin. Genet. Dev. 2004; 14: 120-125.

Figueiredo BC, Ribeiro RC, Zambetti G, Haddad B, Pianovsky MD, Pereira RM, et al. Amplification of 9q34 in childhood adrenocortical tumors: a specific feature unrelated to ethnic origin or living conditions. Braz. J. Med. Biol. Res. 2000; 33: 1217-1224.

Dannenberg H, Speel EJ, Zhao J, Saremaslani P, van der Harst E, Roth J, et al. Losses of chromosome $1 p$ and $3 q$ are early genetic events in the development of sporadic pheochromocytomas. Am. J. Pathol. 2000; 157: 353-359.

Garcia JL, Tardio JC, Gutierrez NC, Gonzalez MB, Polo JR, Hernandez JM, et al. Chromosomal imbalances identified by comparative genomic hybridization in sporadic parathyroid adenomas. Eur. J. Endocrinol. 2002; 146: 209-213.

Warren C, James LA, Ramsden RT, Wallace A, Baser ME, Varley JM, et al. Identification of recurrent regions of chromosome loss and gain in vestibular schwannomas using comparative genomic hybridization. J. Med. Genet. 2003; 40: 802-806.

Baumgärtner AK, Zettl A, Chott A, Ott G, Müller-Hermelink HK, Starostik P. High frequency of genetic aberrations in enteropathy-type T-cell lymphoma. Lab. Invest. 2003; 83:1509-1516.

Booden MA, Campbell SL, Der CJ. Critical but distinct roles for the pleckstrin homology and cysteinerich domains as positive modulators of Vav2 signaling and transformation. Mol. Cell. Biol. 2002; 22: 2487-2497.

Napolitana G, Majello B, Lania L. Role of cyclin / Cdk9 complex in basal and regulated transcription (review). Int. J. Oncol. 2002; 21: 171-177.

Aster JC, Xu L, Karnell FG, Patriub V, Pui JC, Pear WS. Essential roles for ankyrin repeat and transactivation domains in induction of T-cell leukemia by Notch-1. Mol. Cell. Biol. 2000; 20: 7505-7515.

Hobert O, Westphall H. Functions of LIM-homeobox genes. Trends Genet. 2000; 16: 75-83.

Goldman JM, Melo JV. Chronic myeloid leukemia-advances in biology and new approaches to treatment. New Engl. J. Med. 2003; 349: 1451-1464.

Davoren PM, Epstein MT. Insulinoma complicating tuberous sclerosis. J. Neurol. Neurosurg. Psychiatry 1992; 55: 1209-1212.

43 Yong L, Corradetti MN, Inoki K, Guan KL. TSC2: filling the GAP in the mTOR signalling pathway. Trends Biochem. Sci. 2004; 29: 32-38.

Zhuang Z, Park WS, Pack S, Schmidt L, Vortmeyer AO, Pak E, et al. Trisomy 7-harbouring non-random duplication of the mutant MET allele in hereditary papillary renal carcinomas. Nat. Genet. 1998; 20:66-69. 
DeAizpurua HJ, Cram DS, Naselli G, Devereux L, Dorow DS. Expression of mixed lineage kinase-1 in pancreatic $\beta$-cell lines at different stages of maturation and during embryonic pancreas development. J. Biol. Chem. 1997; 272:16364-16373.

Gumbs AA, Moore PS, Falconi M, Bassi C, Beghelli S, Modlin I, et al. Review of the clinical, histological, and molecular aspects of pancreatic endocrine neoplasms. J. Surg. Oncol. 2002; 81: 45-53.

Chan AO, Kim SG, Bedeir A, Issa JP, Hamilton SR, Rashid A. CpG island methylation in carcinoid and pancreatic endocrine tumors. Oncogene 2003; 22: 924-934.

Chandrasekharappa SC, Teh BT. Functional studies of the MEN1 gene. J. Int. Med. 2003; 253: 606615.

Cavallari I, D'agostino DM, Ferro T, Rosato A, Barzon L, Pasquali C, et al. In situ analysis of human menin in normal and neoplastic pancreatic tissues: evidence for differential expression in exocrine and endocrine cells. J. Clin. Endocrinol. Metab. 2003; 88: 3893-3901.

Chakrabarti R, Srivatsan ES, Wood TF, Eubanks PJ, Ebrahimi SA, Gatti RA, et al. Deletion mapping of endocrine tumors localizes a second tumor suppressor gene on chromosome band 11q13. Genes Chromosomes Cancer 1998; 22: 130-137.

Speel EJM, Meier D, Zhao J, Matter C, Muletta-Feurer S, Perren A, et al. Chromosome 11q losses in sporadic endocrine pancreatic and neuroendocrine tumors indicate the presence of another tumor suppressor gene telomeric of MEN1. Proc. AACR 2002; 43: 636.

Ray ME, Wistoow G, Su YA, Meltzer PS, Trent JM. AIM1, a novel non-lens member of the beta-gammacrystallin superfamily, is associated with the control of tumorigenicity in human malignant melanoma. PNAS 1997; 94: 3229-3234.

Polly P, Danielsson C, Schrader M, Carlberg C. Cyclin C is a primary 1alpha,25-dihydroxyvitamin $D(3)$ responding gene. J. Cell. Biochem. 2000; 77: 75-81.

Yang Y, Gil M, Byun SM, Choi I, Pyun KH, Ha H. Transforming growth factor-beta 1 inhibits human keratinocyte proliferation by upregulation of a receptor-type tyrosine phosphatase R-PTP-kappa gene expression. Biochem. Biophys. Res. Commun. 1996; 228: 807-812.

Mesnil M. Connexins and cancer. Biol. Cell 2002; 94: 493-500.

Pagotto U, Arzberger T, Theodoropoulou M, Grubler Y, Pantaloni C, Saeger W, et al. The expression of the antiproliferative gene ZAC is lost or highly reduced in non-functioning pituitary adenomas. Cancer Res. 2000; 60: 6794-6799.

Abdollahi A, Pisarcik D, Roberts D, Weinstein J, Cairns P, Hamilton TC. LOT1 (PLAGL1/ZAC1), the candidate tumor suppressor gene at chromosome $6 \mathrm{q} 24-25$, is epigenetically regulated in cancer. $\mathrm{J}$. Biol. Chem. 2003; 278: 6041-6049.

Knuutila S, Björkqvist AM, Autio K, Tarkkanen M, Wolf M, Monni O, et al. DNA copy number amplifications in human neoplasms: review of comparative genomic hybridization studies. Am. J. Pathol. 1998; 152: $1107-1123$.

59 Terris B, Meddeb M, Marchio A, Danglot G, Fléjou JF, Belghiti J, et al. Comparative genomic hybridization analysis of sporadic neuroendocrine tumors of the digestive system. Genes Chromosomes Cancer 1998; 22: 50-56.

Tönnies H, Toliat MR, Ramel C, Pape UF, Neitzel H, Berger W, et al. Analysis of sporadic neuroendocrine tumors of the enteropancreatic system by comparative genomic hybridization. Gut $2001 ; 48$ : 536-541.

Goebel SU, Iwamoto M, Raffeld M, Gibril F, Hou W, Serrano J, et al. HER-2/neu expression and gene amplification in gastrinomas: correlations with tumor biology, growth, and aggressiveness. Cancer Res. 2002; 62: 3702-3710. 


\section{CHAPTER 3}

Novel candidate tumor suppressor gene loci on chromosomes 11q23-24 and 22q13 involved in human insulinoma tumorigenesis

Yvonne M.H. Jonkers, Sandra M.H. Claessen, Ton Feuth, Ad Geurts van Kessel, Frans C.S. Ramaekers, Joris A. Veltman, Ernst-Jan M. Speel

Published in Journal of Pathology 210: 450-458 (2006) 


\section{Abstract}

Insulinomas represent the predominant syndromic subtype of endocrine pancreatic tumors. Previous molecular studies have shown that gain of chromosome $9 q$ rather than MEN1 gene mutation is an important early event in tumor development and that chromosomal instability is associated with metastatic disease. In order to identify new gene loci and to define further the critical genetic events in insulinoma tumorigenesis, 27 insulinomas were investigated by array-based comparative genomic hybridization (array CGH) on $3.7 \mathrm{k}$ genomic BAC arrays (resolution $\leq 1 \mathrm{Mb}$ ). Fluorescence in situ hybridization was used to validate alterations in a subset of tumors. Array CGH most frequently detected loss of chromosomes $11 q$ and $22 q$ and gains of chromosome 9q. The chromosomal regions of interest (CRI) included $11 q 24.1$ (56\%), 22q13.1 (67\%), 22q13.31 (56\%), and 9q32 (63\%). Evaluation of the simultaneous occurrence of these aberrations in the individual tumors revealed that gain of 9q32 and loss of 22q13.1 are early genetic events in insulinomas, occurring independently of the other alterations. In tumors with increased genomic complexity, these alterations were often detected simultaneously, occurring in the same tumor cells. Losses of 11q24.1 and 22q13.31 were also associated with these more advanced tumor cases. The CRIs identified most likely harbor crucial candidate genes important in insulinoma tumorigenesis.

\subsection{Introduction}

Insulinomas are the most frequently occurring functioning endocrine pancreatic tumors (EPTs). They show $\beta$-cell differentiation and may cause clinical symptoms of hypoglycemia due to uncontrolled insulin production already early in tumor development. On the basis of the presence of organ and / or lymph node infiltration or distant metastases, approximately $10 \%$ of insulinomas are classified as malignant. Primary tumors with a diameter $\geq 2 \mathrm{~cm}$, an increased mitotic index, and / or necrosis may indicate an increased risk for malignancy and are classified as tumors of uncertain behavior according to WHO criteria [1]. Recently, we have shown that chromosomal instability, as defined by an accumulation of chromosomal gains and losses, can be used as a reliable parameter to predict metastatic disease in insulinomas (Chapter 2).

Genomic alterations are believed to contribute to tumorigenesis by altering the expression levels of critical oncogenes and tumor suppressor genes. Insulinomas clearly differ from other EPT subtypes with respect to their clinical behavior and low mutation frequency in the susceptibility gene for the multiple endocrine neoplasia type 1 (MEN1) syndrome at 11q13. Molecular genetic studies have revealed that early events in insulinoma development comprise $9 q$ gain in approximately $60 \%$ of cases and sporadic mutations in the CDKN2A and VHL genes (Chapter 2) [2,3]. The objective of the present study was to perform a genome-wide search for new loci of interest by array-based comparative genomic hybridization (array CGH). 
This technology can improve the resolution of conventional $\mathrm{CGH}$ on metaphase chromosomes from 5-10 Mb to $\leq 1 \mathrm{Mb}$ on arrayed DNA clones [4,5]. Moreover, array CGH allows a more reliable analysis of DNA copy number changes at chromosomes 1p32-pter, 16p, 19, and 22 than the conventional CGH technology, because in the latter these regions often show gains in negative control experiments [6]. An increasing number of studies have shown the usefulness of this technique in identifying new loci with genes of interest in the area of clinical and cancer genetics [7-10]. Here we identified new loci of interest in insulinomas by analyzing a series of 27 cases with array CGH and verified these genomic alterations in a subset of cases with targeted fluorescence in situ hybridization (FISH) analysis.

\subsection{Materials and Methods}

\subsubsection{Patient data}

Twenty-seven cases of insulinoma (15 females, mean age $55.6 \pm 13.0$ years and 12 males, mean age $49.4 \pm 13.4$ years) from which enough good quality DNA was available were selected from the archives of the Departments of Pathology of the University Hospital Zurich, Switzerland and the University Medical Centers Rotterdam, Utrecht and Nijmegen, The Netherlands. All of the institutions gave approval for the use of tissues and the patients gave informed consent. The insulinomas selected for this study were all sporadic tumors and not associated with the inherited MEN1 syndrome. The tumors were classified according to the most recent WHO classification [1]. The samples included 15 benign tumors, six tumors of uncertain behavior, and six malignant tumors. All insulinomas exhibited hyperinsulinism followed by a hypoglycemia syndrome.

\subsubsection{DNA extraction}

Genomic DNA isolated from the blood lymphocytes of four cytogenetically normal, healthy individuals (two males and two females) was used for array validation and as normal reference DNA. Genomic DNA from frozen insulinoma samples was extracted as described before (Chapter 2).

\subsubsection{Array CGH analysis}

Array $\mathrm{CGH}$ was performed on microarrays containing $3700 \mathrm{FISH}$-verified bacterial artificial chromosome (BAC) clones at a resolution of $\leq 1 \mathrm{Mb}[11,12]$. Array preparation, labeling, hybridization, and scanning procedures were performed as described elsewhere [13]. In brief, tumor and reference DNA was labeled by random priming in a total volume of $80 \mu \mathrm{l}$. For labeling, $500 \mathrm{ng}$ of DNA was mixed with $50 \mathrm{mM}$ Tris- $\mathrm{HCl}$ (pH 6.8), 5mM MgCl, $10 \mathrm{mM}$ 2-mercaptoethanol, and $300 \mu \mathrm{g} / \mathrm{ml}$ random octamers (Bioprime DNA labeling system; $1 \mathrm{x}$ random Primers solution, Invitrogen) and was denatured for $10 \mathrm{~min}$ at $100^{\circ} \mathrm{C}$. After cooling to $4^{\circ} \mathrm{C}$, tumor DNA was incubated with $4 \mathrm{nmol}$ Cy3-dUTP, and control DNA with $4 \mathrm{nmol}$ of Cy5-dUTP (Amersham Pharmacia Biotech), in combination with 2 mM dGTP, 2mM dCTP, 
$2 \mathrm{mM}$ dATP, $1 \mathrm{mM}$ dTTP, and $64 \mathrm{U}$ of Klenow enzyme (Invitrogen). Labeling was performed overnight. The labeled probes were purified over a QIAquick column (Qiagen) to remove unincorporated fluorescent nucleotides. The Cy3- and Cy5-labeled DNA probes were mixed together with $120 \mu \mathrm{g}$ of Cot-1 DNA (Roche) and coprecipitated for at least $2 \mathrm{~h}$ at $-20^{\circ} \mathrm{C}$. Pellets were air-dried and resolved in a total volume of $130 \mu \mathrm{l}$ of hybridization solution containing $50 \%$ formamide, $10 \%$ dextran sulphate, $4 \%$ SDS, $100 \mu \mathrm{g}$ of yeast tRNA, and $2 x$ saline sodium citrate (SSC). This probe mix was denatured for $15 \mathrm{~min}$ at $70^{\circ} \mathrm{C}$ and pre-annealed for $30 \mathrm{~min}$ at $37^{\circ} \mathrm{C}$. After pre-annealing, the sample was applied to a pretreated and denatured array [13]. Hybridization and post-hybridization washing procedures were performed using a GeneTac hybridization station (Genomic Solutions, Cambridgeshire, UK) according to the manufacturer's instructions.

\subsubsection{Image analysis and processing}

Fluorescence intensity images were acquired using an Affymetrix 428 scanner and analyzed using GenePix Pro 6.0 (Axon Instruments Inc., Foster City, CA, USA), as described elsewhere [13]. To obtain a genomic copy number ratio for each spot, the median local background was subtracted from the median pixel intensity of both dyes. Data normalization was performed by using the SAS software package version 8.0 (SAS institute, Cary, NC, USA) for each array sub-grid, by applying loess curve fitting with a smoothing factor of 0.3 to predict the $\log _{2}$-transformed test-over-reference values. This smoothing factor was shown to result in the lowest percentage of false-positive results while not increasing false-negative results in the validation experiments. To utilize the spatial coherence between nearby clones, we used an unsupervised Hidden Markov Models (HMM) approach [14]. The clones are partitioned into the states which represent the underlying copy number of the group of clones. A chromosomal region of gain or loss is defined by at least five adjacent BAC clones showing gain or loss by HMM analysis. These regions may contain intermediate clones without aberrations. A maximum of two intermediate 'normal' clones per region is allowed. Amplifications were defined as regions containing two or more adjacent clones displaying $\log _{2}$ chromosome copy number ratios $\geq 1.0$. The chromosome copy number at $\log _{2}=0$ was validated by $\mathrm{FISH}$ analysis with centromeric probes. All mapping information regarding clone locations, cytogenetic bands, and genomic content was retrieved from the UCSC genome browser (May 2004 freeze).

\subsubsection{Confirmation of array CGH data by FISH analysis}

To verify the array CGH data, dual-color FISH was performed with probes for chromosomes 4p15 (RP11-79N22), 9q22 (RP11-89K14), 9q32 (RP11-95J4), 11q23.3 (RP11-8K10), 22q13.1 (RP11-108C6) and 22q13.31 (RP11-1038H9 and 106H23), in some cases together with a centromere-specific probe for chromosome 9 , 11, or 22. The latter probes, as well as the centromere-specific probes for chromosomes 1,7 , and 10 were used to obtain an indication of the chromosome copy number 
at $\log _{2}=0$. Briefly, isolated BAC DNA was labeled with either biotin- or digoxigeninconjugated dUTP. FISH on five touch preparations and nine paraffin-embedded tissue sections was performed as described previously [15]. Biotin-labeled probes were detected by two layers of avidin-rhodamin connected by a biotinylated goat anti-avidin antibody (Vector laboratories, Burlingame, CA, USA), and digoxigenin-labeled probes were detected by mouse anti-digoxigenin fluorescein (Roche), followed by rabbit-anti-mouse FITC and swine-anti-rabbit FITC. Probe visualization, nuclear counterstaining, signal scoring and evaluation were performed as described previously [15]. For each tumor, hybridization signals of 100 interphase nuclei were scored.

\subsection{Results}

\subsubsection{Genomic copy number alterations identified by array CGH}

Genomic DNA extracted from 27 insulinomas was analyzed by array CGH for the presence of copy number alterations. Chromosomal changes, defined as regions containing at least five adjacent BAC clones gained or lost in the HMM analysis, were found in 13 out of 15 benign tumors, six out of six tumors with uncertain behavior, and six out of six malignant tumors. Chromosomal losses were more common than chromosomal gains. Figures 3.1A and $B$ show representative array $\mathrm{CGH}$ profiles of a benign and a malignant tumor showing an accumulation of DNA copy number changes with increasing malignant potential. In the benign group, the average number of chromosomal aberrations was $13.3 \pm 13.1$ (average number

of 4.9 gains and 8.4 losses), whereas the tumors with uncertain and malignant behavior showed an average number of $25.5 \pm 15.3$ (10.3 gains and 15.2 losses) and $33.2 \pm 7.9$ chromosomal changes (14.0 gains and 19.2 losses), respectively. This finding is in agreement with our previous study using conventional $\mathrm{CGH}$, in which genomic instability was identified as an important discriminator of metastatic disease in insulinomas (Chapter 2).

\subsubsection{Identification of novel regions of interest}

Figure 3.1C and Table 3.1A show the chromosomal regions encompassing at least five adjacent BAC clones, gained or lost in at least $25 \%$ of the insulinoma cases. The regions ranged from 1.16 to $136.7 \mathrm{Mb}$ in size. The most frequent aberrations shown here are gain of chromosome 9 and loss of 11q23.2-q25, and 22q11.1q13.33. Interestingly, when taking only those regions that were aberrant in $\geq 50 \%$ of cases, four smaller regions were found, i.e. 11q23.3-q24.3, 22q13.1-q13.31, and 22q13.31-q13.32, which were lost, and 9q22.2-q33.2, which was gained. In the latter region, an amplification of 9q22.2 was observed in one malignant tumor. In Figure 3.2, these four regions are visualized in detail per tumor. The dark horizontal bars in this figure show the minimal regions of gain or loss, i.e. 9q32, 11q24.1, $22 q 13.1$ and 22q13.31. In order to indicate if copy number changes of these regions of interest are early or late events in insulinoma tumorigenesis, we com- 
pared their alteration frequencies in the tumors with benign, uncertain and malignant behavior (Table 3.1B). Gain of 9q22.2-33.2 already occurred in nine out of 15 benign tumors, including two tumors with none of the three other aberrations. Loss of 22q13.1-q13.31 occurred in ten out of 15 benign tumors and in two tumors as a single event. This suggests that these aberrations are independent critical genetic events in early tumor development. Loss of 22q13.31-q13.32 was almost always detected together with loss of 22q13.1-q13.31, particularly in the more advanced tumors, indicating losses of larger parts or the entire chromosome 22 during tumor progression. Loss of 11q23.3-q24.3 always coincided with one of the other alterations and also occurred more frequently in the more advanced tumors.

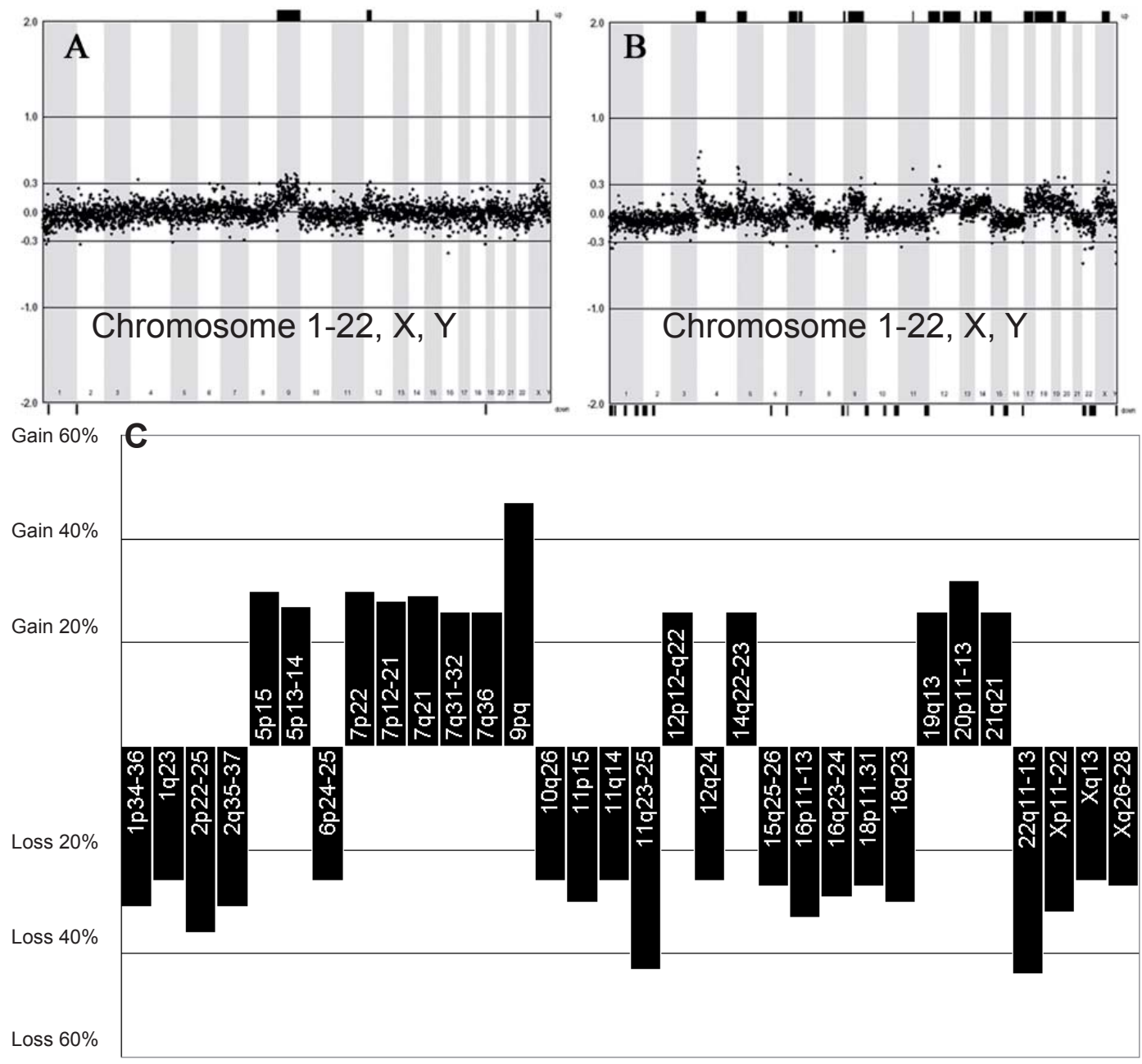

Figure 3.1. Representative examples of array CGH profiles of a benign $(A)$ and a malignant insulinoma (B). Bars above and below the figure are gains and losses, respectively, detected by HMM analysis. (C) Summary of chromosomal aberrations, defined as regions of $\geq 5$ adjacent BAC clones, with a maximum of 2 intermediate clones without the aberration in $\geq 25 \%$ of insulinomas. Regions above the $\mathrm{X}$-axis are gained and regions below are lost, defined by the percentage of insulinomas. 
Table 3.1. Chromosomal regions of gain or loss based on hidden Markov analysis in $\geq 25 \%$ of cases $(A)$, and the occurrence of the most frequently detected aberrations per classified tumor group (B)

\begin{tabular}{|c|c|c|c|}
\hline Cytogenetic region of gain ${ }^{a}$ & Mb position ${ }^{a}$ & Size $(M b)^{a}$ & $\%$ tumors $^{b}$ \\
\hline $5 p 15.1-p 15.33$ & 1.46 & 14.25 & 30 \\
\hline 5p13.2-p14.1 & 25.23 & 10.68 & 27 \\
\hline 7p22.1-p22.2 & 2.71 & 3.56 & 30 \\
\hline 7p12.3-p21.1 & 17.43 & 31.04 & 28 \\
\hline $7 q 21.11-q 21.3$ & 80.23 & 12.35 & 29 \\
\hline 7q31.33-q32.2 & 124.77 & 4.85 & 26 \\
\hline 7q36.1-q36.3 & 150.24 & 6.93 & 26 \\
\hline $9 p 24.3-q 34.3$ & 0.28 & 136.70 & 47 \\
\hline $12 p 12.3-q 22$ & 18.51 & 73.89 & 26 \\
\hline $14 q 22.1-q 23.1$ & 50.48 & 10.63 & 26 \\
\hline $19 q 13.31-q 13.32$ & 48.88 & 1.83 & 26 \\
\hline 20p11.23-p13 & 0.47 & 18.96 & 32 \\
\hline $21 q 21.3$ & 26.52 & 2.52 & 26 \\
\hline Cytogenetic region of loss ${ }^{a}$ & Mb position ${ }^{a}$ & Size $(\mathrm{Mb})^{\mathrm{a}}$ & $\%$ tumors $^{b}$ \\
\hline 1p34.2-p36.33 & 0.29 & 39.69 & 31 \\
\hline 1q23.2-q23.3 & 156.39 & 1.16 & 26 \\
\hline $2 p 22.3-p 25.3$ & 2.36 & 31.91 & 36 \\
\hline $2 q 35-q 37.2$ & 218.12 & 18.96 & 31 \\
\hline 6p24.3-p25.3 & 1.85 & 5.73 & 26 \\
\hline $10 q 26.2-q 26.3$ & 128.67 & 2.83 & 26 \\
\hline 11p15.1-p15.2 & 15.34 & 4.92 & 30 \\
\hline $11 q 14.1-q 14.2$ & 78.64 & 6.72 & 26 \\
\hline 11q23.2-q25 & 113.00 & 20.56 & 43 \\
\hline $12 q 24.31-q 24.33$ & 124.68 & 5.10 & 26 \\
\hline $15 q 25.3-q 26.3$ & 85.34 & 13.14 & 27 \\
\hline 16p11.2-p13.32 & 7.77 & 23.59 & 33 \\
\hline $16 q 23.1-q 24.1$ & 75.79 & 8.81 & 29 \\
\hline $18 p 11.31$ & 3.74 & 2.95 & 27 \\
\hline $18 q 23$ & 74.35 & 1.65 & 30 \\
\hline $22 q 11.1-q 13.33$ & 15.84 & 32.98 & 44 \\
\hline Xp11.21-p22.31 & 7.57 & 47.81 & 32 \\
\hline Xq13.1-q13.3 & 71.32 & 3.47 & 26 \\
\hline Xq26-q28 & 134.79 & 18.50 & 27 \\
\hline
\end{tabular}


B

\begin{tabular}{lcccc}
\hline $\begin{array}{l}\text { Tumor } \\
\text { classification }^{\text {9q22.2-q33.2 }} \\
\text { gain }^{\mathbf{c}}\end{array}$ & $\begin{array}{c}\text { 11q23.3-q24.3 } \\
\text { loss }^{\mathbf{c}}\end{array}$ & $\begin{array}{c}\text { 22q13.1-13.31 } \\
\text { loss }^{\mathbf{c}}\end{array}$ & $\begin{array}{c}\text { 22q13.31-q13.32 } \\
\text { loss }^{\mathbf{c}}\end{array}$ \\
\hline Benign $(\mathrm{n}=15)$ & $9(2)$ & 7 & $10(2)$ & 5 \\
UB $(\mathrm{n}=6)$ & 3 & 5 & $5(1)$ & 5 \\
Malignant $(\mathrm{n}=6)$ & 5 & 4 & $6(1)$ & 5 \\
\hline
\end{tabular}

Cruz genome browser (May 2004 freeze).

${ }^{\mathrm{b}}$ Percentage of total group of tumors. This percentage is the mean of the percentages per clone. Regions contain at least 5 clones with a maximum of two intermediate clones without the aberration.

'Number of tumors with the aberration. In parentheses are those tumors without any of the other listed aberrations. UB, uncertain behavior.

\subsubsection{Validation of chromosomal regions by FISH analysis}

The array $\mathrm{CGH}$ results were validated in nine insulinomas by FISH using five different BAC clones located on chromosomes 4p15, 9q22, 11q23.3 and 22q13.31 (Table 3.2). In general, the FISH results confirmed our array CGH findings. Analysis of the mean chromosome copy number per tumor $\left(a t \log _{2}=0\right)$ showed a diploid or triploid DNA content. Loss was seen as an under-representation with respect to this mean copy number from the whole chromosome or a locus-specific region. Figures 3.3A-D (p.120) show representative examples of the FISH validation results with the respective array CGH profiles of an amplification at 9q22 (A), a highlevel gain at 4p15 (B), and losses at 11q23 (C) and 22q13 (D).

Gain of 9q22.2-q33.2 and loss of 22q13.1-q13.31, described above as aberrations occurring early in tumorigenesis, were also validated by FISH to evaluate if these aberrations were present in the same cell nuclei or in independent cell clones in different areas of the tumor. Table 3.3 and Fig. 3.4 (p.120) show the results of this validation together with the evaluation of the mean copy number of centromeres 1 and 7 . The array CGH results were not only confirmed by $\mathrm{FISH}$, but these data also show that $9 q 32$ gain and 22q13.1 loss can occur independently and that in cases where both $9 \mathrm{q} 32$ gain and $22 \mathrm{q} 13.1$ loss are detected by array $\mathrm{CGH}$, these aberrations occur in the same tumor cells. 
Table 3.2. Comparison of array CGH and FISH results in selected insulinoma cases

\begin{tabular}{|c|c|c|c|c|c|c|c|c|c|}
\hline $\mathrm{T}^{\mathrm{a}}$ & $\begin{array}{l}\text { Ploidy at } \\
\log _{2}=0^{b}\end{array}$ & $\begin{array}{c}\text { Array } \\
11 q 23^{c}\end{array}$ & $\begin{array}{l}\text { FISH 11C: } \\
\text { 11q23 }^{d}\end{array}$ & $\begin{array}{c}\text { Array } \\
22 q 13^{c}\end{array}$ & $\begin{array}{l}\text { FISH 22C: } \\
22 q 13^{d}\end{array}$ & $\begin{array}{l}\text { Array } \\
4 p 15^{c}\end{array}$ & $\begin{array}{l}\text { FISH } \\
4 p 15^{d}\end{array}$ & $\begin{array}{l}\text { Array } \\
9 q 22^{c}\end{array}$ & $\begin{array}{l}\text { FISH } \\
9 \mathrm{C}: \\
9 q 22^{d}\end{array}$ \\
\hline 1 & 2 & & & - & $\begin{array}{l}1: 1(70 \%) \\
2: 1(30 \%)\end{array}$ & & & + & $\begin{array}{l}3-4: \geq 8 \\
(\mathrm{Amp})\end{array}$ \\
\hline 2 & 3 & & & & & + & $2-6$ & & \\
\hline 3 & 3 & - & $2: 1$ & - & $2: 2$ & & & & \\
\hline 4 & 3 & - & $2: 1(30 \%)$ & - & $1: 1(25 \%)$ & & & & \\
\hline 5 & 2 & - & $2: 1$ & - & $1: 1$ & & & & \\
\hline 6 & 2 & - & $\begin{array}{l}1: 1(35 \%) \\
2: 1(15 \%)\end{array}$ & - & $1: 1$ & & & & \\
\hline 7 & 2 & 0 & $2: 2$ & NA & $1: 1$ & & & & \\
\hline 8 & 2 & - & $\begin{array}{l}2: 1(20 \%) \\
1: 1(20 \%)\end{array}$ & - & $2: 1(35 \%)$ & & & & \\
\hline 9 & 2 & 0 & $2: 2$ & - & $2: 1$ & & & & \\
\hline
\end{tabular}

T, tumor; NA, not analyzable; Amp, amplification

aParaffin-embedded tissue: cases 1,2,5,6; touch preparations: cases $3,4,7,8,9$.

'Indication of chromosome copy number at $\log _{2}=0$, based on FISH with centromeric probes (see the Materials and Methods section).

cArray results: 0 =no aberrations; + =gain; - =loss.

dFISH results: 2:1 $(n \%)$, two copies of the centromere probe and one copy of the locus-specific probe in $n \%$ of nuclei (in the case of a subpopulation of cells).

Table 3.3. Comparison of array CGH and FISH results for copy number validation of $9 q 32$ and 22q13.1 and centromere 1 and 7 loci in five benign tumors

\begin{tabular}{lcccccccc}
\hline & \multicolumn{3}{c}{ Array CGH $^{\mathrm{b}}$} & \multicolumn{4}{c}{ FISH $^{\mathrm{c}}$} \\
Tumor $^{\mathrm{a}}$ & $\mathbf{1}$ & $\mathbf{7}$ & $\mathbf{9}$ & $\mathbf{2 2}$ & $\mathbf{1 C}$ & $\mathbf{7 C}$ & $\mathbf{9 q 3 2}$ & $\mathbf{2 2 q 1 3 . 1}$ \\
\hline 10 & - & 0 & + & - & 2 & 3 & $3-5$ & $1-2$ \\
11 & - & + & + & - & 2 & 4 & $\geq 3$ & 2 \\
12 & 0 & 0 & + & - & 3 & 3 & 5 & 2 \\
13 & 0 & 0 & + & 0 & 2 & 2 & $\geq 5$ & NA \\
14 & - & 0 & 0 & - & $1-2$ & $2-3$ & $2-3$ & $1-2$ \\
\hline
\end{tabular}

NA, not analyzable

aTumor cases 10-14: paraffin-embedded tissue

${ }^{\text {b} A r r a y ~ r e s u l t s: ~} 0=$ no aberrations; + = gain; - = loss

cFISH results: copy number of centromere-specific probes for chromosomes 1 and 7 (1C and 7C) and locus-specific probes for $9 \mathrm{q} 32$ and $22 \mathrm{q} 13.1$ 


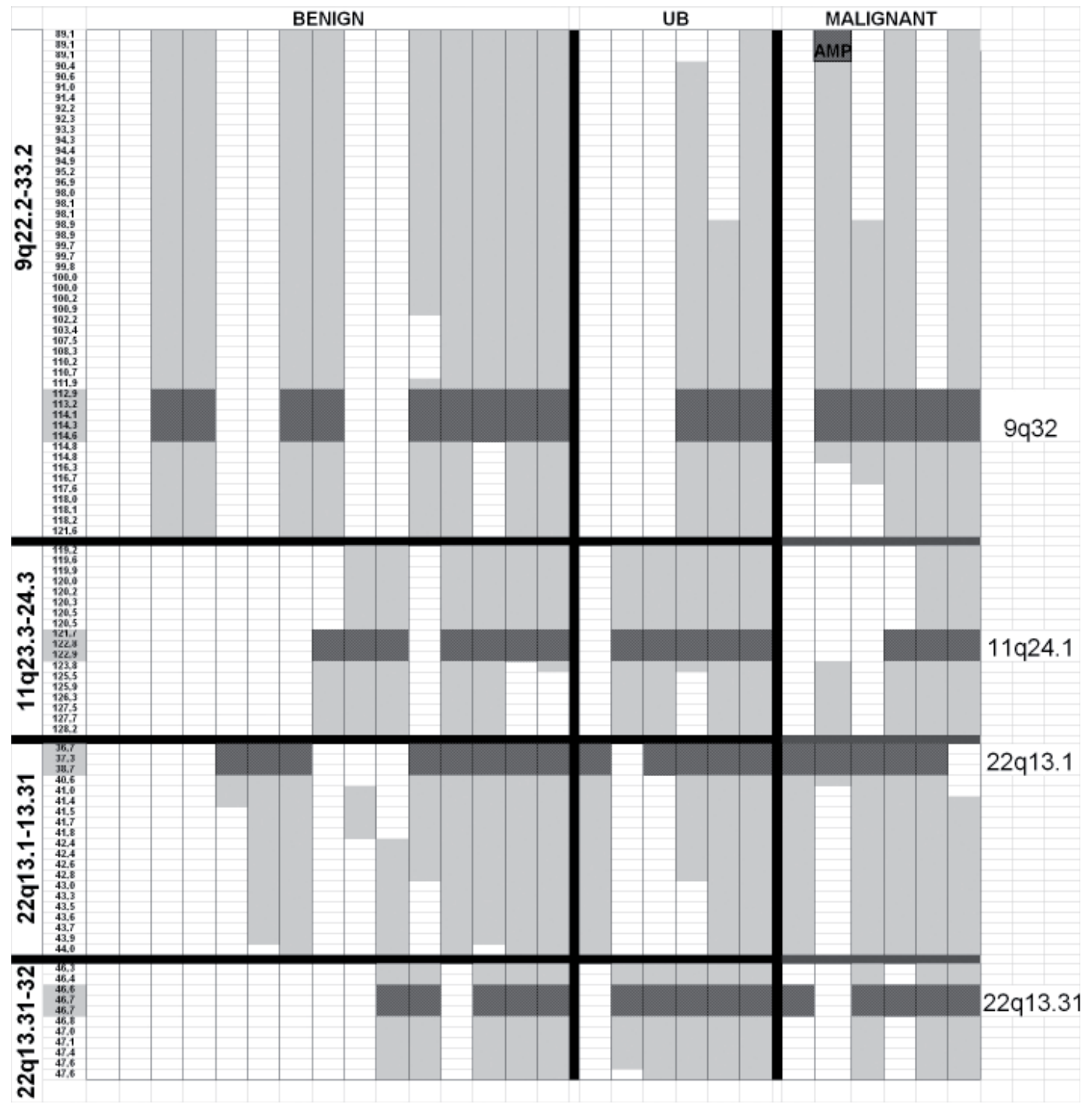

Figure 3.2. Chromosomal alterations identified in at least $50 \%$ of insulinomas, visualized per individual tumor. Each vertical column represents one tumor. The tumors have been arranged according to their classification (benign, uncertain behavior (UB), and malignant) and the number of alterations detected. Each horizontal row represents one BAC clone. The chromosomal regions of interest are shown as dark grey horizontal bars. The amplification on chromosome $9 q 22$ is indicated by AMP. 


\subsection{Discussion}

We performed a genome-wide array-based CGH analysis to map genomic alterations in a series of 27 insulinomas. Along with 9q22.2-33.2 gain, chromosome 11q23.3-q24.3, 22q13.1-q13.31 and 22q13.31-q13.32 deletions were the most common chromosomal aberrations detected by array $\mathrm{CGH}$ in more than $50 \%$ of cases, which have not been identified before by conventional CGH (Chapter 2). In addition, further proof was found for the accumulation of chromosomal alterations with increasing malignant potential.

Previous studies have reported frequent loss of heterozygosity ( $\mathrm{LOH}$ ) of chromosome 11q13 in sporadic EPTs and in tumors of patients with the MEN1 syndrome [16-19]. The tumor suppressor gene MEN1 has been localized to this $11 \mathrm{q} 13$ region [20]. However, in the sporadic tumors, the frequency of allelic deletions at 11 q13 was more than three times higher than the frequency of identified MEN1 gene mutations, i.e. $43 \%$ vs $13 \%$, respectively [18], suggesting the existence of another tumor suppressor gene at this chromosome arm [17]. In human insulinomas, fewer than $5 \%$ of cases appeared to harbor a MEN1 mutation and 11q loss was detected in $18 \%$ of insulinomas by conventional CGH (Chapter 2) [3]. Here we detected loss of chromosome $11 \mathrm{q}$ in 17 out of $27(63 \%)$ tumors, most probably as a result of the higher resolution of the array CGH technique. Loss of the 11q23.3-q24.3 locus was detected in 16 of these cases, nine of which had only loss of this region. This finding indicates that this region might contain the additional tumor suppressor gene playing a role in tumorigenesis. Because this deletion was never seen as a single alteration in the 15 benign insulinomas, our data indicate that this region is not likely involved in initiating tumor development, but rather in tumor progression. An interesting candidate gene located in the minimal region of loss at 11q24.1 is the BRCC2 (breast cancer cell 2) gene. BRCC2 has been proven to be a pro-apoptotic protein, the function of which can be suppressed by co-expression of the anti-apoptotic protein $\mathrm{Bcl}-\mathrm{XL}$ [21]. Because co-expression of $\mathrm{Bcl}-\mathrm{XL}$ and the oncogene $\mathrm{c}-\mathrm{Myc}$ has been demonstrated to induce highly malignant $\beta$-cell tumors in a transgenic mouse model, it is tempting to speculate that inactivation of BRCC2 might be an important event in insulinoma progression [22]. An additional candidate gene at $11 \mathrm{q} 23.3-\mathrm{q} 24.3$ is $Z W 10$, encoding a protein that is involved in mechanisms to ensure proper chromosome segregation during cell division [23]. Deletion of this gene may play a role in the induction of chromosomal instability often observed in malignant tumors. It is unlikely that the tumor suppressor gene $S D H D$ at $11 \mathrm{q} 23$ is a candidate gene, as no mutations have been detected in, amongst others, EPTs [24].

Chromosome 22q13 deletions are common alterations in a number of different cancers, including sporadic and neurofibromatosis type 2 (NF2)-related meningiomas, schwannomas and ependymomas [25]. In this study, 22q13 losses were detected by array $\mathrm{CGH}$ in at least $50 \%$ of insulinomas. This percentage is much higher than previously found for loss of the entire $22 q$ arm by us using conven- 
tional $\mathrm{CGH}$, i.e. $5 \%$ in the benign and $17 \%$ in the malignant insulinomas (Chapter 2). This discrepancy can be explained by the higher resolution of array $\mathrm{CGH}$ and the more reliable analysis of changes at chromosomes 1p36-pter, 16p, 19 and 22. Two critical regions of loss were identified: at 22q13.1-q13.31 and 22q13.31q13.32. The former deletion could be detected in $67 \%$ of benign tumors including two tumors with neither gain at chromosome 9q22.2-q33.2, nor loss at 11q23.3$\mathrm{q} 24.3$ or $22 \mathrm{q} 13.31-\mathrm{q} 13.32$, indicating early involvement in tumorigenesis. The latter region was more frequently lost in the more advanced tumors and always in combination with the 22q13.1-q13.31 region, suggesting loss of larger portions of $22 q$ or the entire chromosome 22 during tumor progression. This is in agreement with published $\mathrm{LOH}$ data on insulinomas [26]. Putative tumor suppressor genes include PRR5, $\beta$-parvin (PARVB) and y-parvin (PARVG) $[27,28]$. The parvins comprise a family of actin-binding proteins that function as focal adhesion proteins. Reduced expression of particularly PARVG in cancer cell lines suggests a role in metastatic progression. In a recent study, the tumor suppressor gene $h S N F 5 / I N / 1$ has been excluded as a candidate gene in insulinomas [26]. This LOH study suggested the NF2 gene as a candidate gene. However, NF2 is located $8 \mathrm{Mb}$ from the $22 q 13.1-q 13.31$ region and is therefore unlikely to be involved in insulinoma tumorigenesis.

In agreement with our previous findings, gain of chromosome 9q was the most frequent aberration in both benign and malignant insulinomas (Chapter 2). The most frequently involved genomic region was 9q22.2-q33.2. One insulinoma showed amplification in this region. A candidate gene in this region is $\mathrm{ShcC}$, the product of which is a substrate of the RET receptor tyrosine kinase. High expression of this gene seems to be associated with an aggressive tumor phenotype of neuroblastomas [29]. The used microarrays did not contain a BAC clone harboring the $c A b l$ gene at 9q34. Copy number increases of this locus also appear to be involved in insulinoma tumorigenesis [15]. The detection of gain of chromosome $9 q$ in nine out of 15 benign tumors, occurring twice without the presence of losses on chromosomes $11 q$ and $22 q$, underscores the importance of this genetic event in early insulinoma development. Despite the occurrence of insulinomas with either $9 q$ gain or $22 q$ loss as the initial chromosomal aberration, six benign tumors showed simultaneous detection of both loci in the same tumor cells. The former tumors proved to harbor fewer than five alterations, whereas the simultaneous occurrence of $9 q$ gain and 22q loss was always observed in tumors with a higher number of chromosomal alterations. This finding suggests that accumulation of genetic changes, which is also associated with loss of $11 \mathrm{q} 23.3-\mathrm{q} 24.3$ and $22 \mathrm{q} 13.31-\mathrm{q} 13.32$, is favorable for further tumor development. On the basis of these data, we propose a genetic progression model for sporadic insulinomas with 9q22.2-q33.2 gain and 22q13.1-q13.31 loss depicted as the earliest genetic events, followed by 11q23.3q24.3 and 22q13.31-q13.32 loss during further tumor development, as shown in Fig. 3.5. The progression to a more malignant phenotype requires further genetic damage and can therefore be recognized by an accumulation of chromosomal 
aberrations. Chromosomal instability has been shown to be associated with malignant progression and chapter 4 will show that it is preceded by telomeric loss. In conclusion, the high-resolution array CGH approach has allowed us to detect and further fine-tune critical genetic events, which will likely lead to the identification of putative cancer genes underlying the pathogenesis of insulinomas.

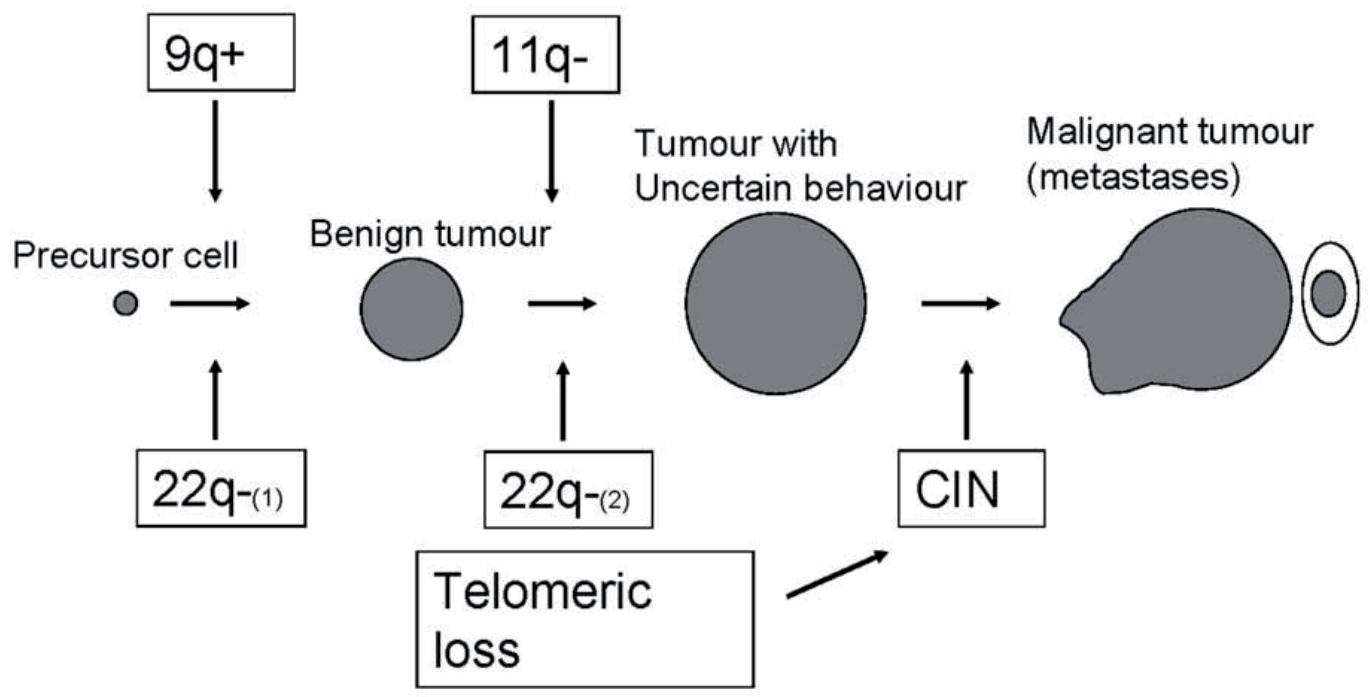

Figure 3.5. Proposed genetic progression model of insulinomas with $9 q 22.2-q 33.2$ gain and $22 q 13.1$ q13.31 $\left(22 q_{(1)}\right)$ loss as the earliest events in tumor development, followed by 11q23.3-q24.3 and $22 q 13.31-q 13.32\left(22 q_{-(2)}\right)$ loss. Chromosomal instability $(\mathrm{CIN})$ is a late event in tumor progression preceded by telomeric loss (Chapter 4).

\subsection{Acknowledgements}

We thank Dr. Aurel Perren (Department of Pathology, University Hospital Zurich, Switzerland), Prof. Dr. Paul Komminoth (Department of Pathology, Hospital Baden, Switzerland), Dr. Albert A. Verhofstad and Prof. Dr. Piet J. Slootweg (Department of Pathology, RUNMC Nijmegen, the Netherlands), Dr. Leo J. Hofland (Department of Internal Medicine, UMC Rotterdam, the Netherlands), and Dr. Ronald R. de Krijger (Department of Pathology, UMC Rotterdam, the Netherlands), for the collection of samples and helpful discussions, and Lisenka E.L.M. Vissers, Irene M. Janssen, and Walter van der Vliet (Department of Human Genetics, RUNMC Nijmegen, the Netherlands) for expert technical assistance. This study was supported by the Netherlands Foundations Vanderes and Sacha Swarttouw-Hijmans, and the Association for International Cancer Research AICR), St. Andrews, UK. 


\subsection{References}

1. Komminoth P, Perren A, Öberg K, Rindi G, Heitz PU, Klöppel G. Insulinoma. In: Pathology \& Genetics. Tumours of endocrine organs, DeLellis RA, Lloyd RV, Heitz PU, Eng C (eds). Lyon: IARC Press, 2004; 183-186.

2. Bartsch DK, Kersting M, Wild A, Ramaswamy A, Gerdes B, Schuermann M, et al. Low frequency of p16 (INK4a) alterations in insulinomas. Digestion 2000; 62: 171-177.

3. Moore PS, Missiaglia E, Antonello D, Zamo A, Zamboni G, Corleto V, et al. Role of disease-causing genes in sporadic pancreatic endocrine tumours: MEN1 and VHL. Genes Chromosomes Cancer 2001; 32: 177-181.

4. Solinas-Toldo S, Lampel S, Stilgenbauer S, Nickolenko J, Benner A, Döhner H, et al. Matrix-based comparative genomic hybridization: biochips to screen for genomic imbalances. Genes Chromosomes Cancer 1997; 20: 399-407.

5. Pinkel D, Segraves R, Sudar D, Clark S, Poole I, Kowbel D, et al. High resolution analysis of DNA copy number variation using comparative genomic hybridization to microarrays. Nat. Genet. 1998; 20 : 207-211.

6. Richter J, Jiang F, Görög JP, Sartorius G, Egenter C, Gasser TC, et al. Marked genetic differences between stage pTa and stage pT1 papillary bladder cancer detected by comparative genomic hybridization. Cancer Res. 1997; 57: 2860-2864.

7. Wessendorf S, Fritz B, Wrobel G, Nessling M, Lampel S, Göettel D, et al. Automated screening for genomic imbalances using matrix-based comparative genomic hybridization. Lab. Invest. 2002; 82: 47-60.

8. Veltman JA, Jonkers YMH, Nuijten I, Janssen I, van der Vliet W, Huys E, et al. Definition of a critical region on chromosome 18 for congenital aural atresia by array CGH. Am. J. Hum. Genet. 2003; 72: 1578-1584.

9. Davies JJ, Wilson IM, Lam WL. Array CGH technologies and their applications to cancer genomes. Chromosome Res. 2005; 13: 237-248.

10. Pinkel D, Albertson DG. Array comparative genomic hybridization and its applications in cancer. Nat Genet 2005; 37: 11-17.

11. Veltman JA, Schoenmakers EF, Eussen BH, Janssen I, Merkx G, van Cleef B, et al. High-throughput analysis of subtelomeric chromosome rearrangements by use of array-based comparative genomic hybridization. Am. J. Hum. Genet. 2002; 70: 1269-1276.

12. Zafarana G, Grygalewicz B, Gillis AJ, Vissers LE, van de Vliet W, van Gurp RJ, et al. 12p-amplicon structure analysis in testicular germ cell tumours of adolescents and adults by array CGH. Oncogene 2003; 22: 7695-7701.

13. Vissers LELM, de Vries BBA, Osoegawa K, Janssen IM, Feuth T, Choy CO. Array-based comparative genomic hybridization for the genomewide detection of submicroscopic chromosomal abnormalities. Am. J. Hum. Genet. 2003; 73: 1261-1270.

14. Fridlyand J, Snijders AM, Pinkel D, Albertson DG, Jain AN. Hidden markov models approach to the analysis of array CGH data. J. Multivariate analysis 2004; 90: 132-53.

15. Speel EJM, Scheidweiler AF, Zhao J, Matter C, Saremaslani P, Roth J, et al. Genetic evidence for early divergence of small functioning and nonfunctioning endocrine pancreatic tumours: gain of 9q34 is an early event in insulinomas. Cancer Res. 2001; 61: 5186-5192.

16. Debelenko LV, Zhuang Z, Emmert-Buck MR, Chandrasekharappa SC, Manickam P, Guru SC, et al. Allelic deletions on chromosome 11q13 in multiple endocrine neoplasia type 1-associated and sporadic gastrinomas and pancreatic endocrine tumours. Cancer Res. 1997; 57: 2238-2243.

17. Chakrabarti R, Srivatsan ES, Wood TF, Eubanks PJ, Ebrahimi SA, Gatti RA, et al. Deletion mapping of endocrine tumours localizes a second tumour suppressor gene on chromosome band 11q13. Genes Chromosomes Cancer 1998; 22: 130-137. 
18. Görtz B, Roth J, Krähenmann A, de Krijger RR, Muletta-Feurer S, Rutimann K, et al. Mutations and allelic deletions of the MEN1 gene are associated with a subset of sporadic endocrine pancreatic and neuroendocrine tumours and not restricted to foregut neoplasms. Am. J. Pathol. 1999; 154: 429-436.

19. Hessman O, Lindberg D, Einarsson A, Lillhager P, Carling T, Grimelius L, et al. Genetic alterations on $3 p, 11 q 13$, and 18q in nonfamilial and MEN1-associated pancreatic endocrine tumours. Genes Chromosomes Cancer 1999; 26: 258-264.

20. Chandrasekharappa SC, Guru SC, Manickam P, Olufemi SE, Collins FS, Emmert-Buck MR, et al. Positional cloning of the gene for multiple endocrine neoplasia-type 1. Science 1997; $276: 404-407$.

21. Broustas CG, Gokhale PC, Rahman A, Dritschilo A, Ahmad I, Kasid U. BRCC2, a novel BH3-like domain-containing protein, induces apoptosis in a caspase-dependent manner. J. Biol. Chem. 2004; 279: 26780-26788.

22. Pelengaris S, Khan M, Evan GI. Suppression of Myc-induced apoptosis in $\beta$ cells exposes multiple oncogenic properties of Myc and triggers carcinogenic progression. Cell 2002; 109: 321-334.

23. Kops GJPL, Kim Y, Weaver BAA, Mao Y, Mc Leod I, Yates JR, et al. ZW10 links mitotic checkpoint signaling to the structural kinetochore. J. Cell. Biol. 2005; 169: 49-60.

24. Perren A, Barghorn A, Schmid S, Saremaslani P, Roth J, Heitz PU, et al. Absence of somatic SDHD mutations in sporadic neuroendocrine tumours and detection of two germline variants in paraganglioma patients. Oncogene 2002; 21: 7605-7608.

25. Gutmann DH. The neurofibromatosis: when less is more. Hum. Mol. Genet. 2001; 10: 747-755.

26. Wild A, Langer P, Ramaswamy A, Chaloupka B, Bartsch DK. A novel insulinoma tumour suppressor gene locus on chromosome 22q with potential prognostic implications. J. Clin. Endocrinol. Metab. 2001; 86: 5782-5787.

27. Johnstone CN, Castellvi-Bel S, Chang LM, Sung RK, Bowser MJ, Pique JM, et al. PRR5 encodes a conserved praline-rich protein predominant in kidney: analysis of genomic organization, expression, and mutation status in breast and colorectal carcinomas. Genomics 2005; 85: 338-351.

28. Castellvi-Bel S, Castells A, Johnstone CN, Pinol V, Pelisse M, Elizalde Jl, et al. Evaluation of PARVG located on 22q13 as a candidate tumour suppressor gene for colorectal and breast cancer. Cancer Genet. Cytogenet. 2003; 144: 80-82.

29. Terui E, Matsunaga T, Yoshida H, Kouchi K, Kuroda H, Hishiki T, et al. Shc family expression in neuroblastoma: high expression of shcC is associated with a poor prognosis in advanced neuroblastoma. Clin. Cancer Res. 2005; 11: 3280-3287. 


\section{CHAPTER 4}

Molecular parameters associated with insulinoma progression: Chromosomal instability versus p53 and CK19 status

Yvonne M.H. Jonkers, Sandra M.H. Claessen, Joris A. Veltman, Ad Geurts van Kessel, Winand N.M. Dinjens, Britt Skogseid, Frans C.S. Ramaekers, Ernst-Jan M. Speel

Cytogenetic and Genome Research 115: 289-297 (2006) 


\section{Abstract}

Insulinomas represent the predominant syndromic subtype of endocrine pancreatic tumors (EPTs). Their metastatic potential cannot be predicted reliably using histopathological criteria. In the past few years, several attempts have been made to identify prognostic markers, among them TP53 mutations and immunostaining of p53 and recently cytokeratin 19 (CK19). In a previous study using conventional comparative genomic hybridization (CGH) we have shown that chromosomal instability $(C I N)$ is associated with metastatic disease in insulinomas. It was our aim to evaluate these potential parameters in a single study. For the determination of CIN, we applied CGH to microarrays because it allows a high- resolution detection of DNA copy number changes in comparison with conventional CGH as well as the analysis of chromosomal regions close to the centromeres and telomeres, and at 1p32-pter, 16p, 19 and 22. These regions are usually excluded from conventional CGH analysis, because they may show DNA gains in negative control hybridizations.

Array CGH analysis of 30 insulinomas (15 tumors of benign, eight tumors of uncertain and seven tumors of malignant behavior) revealed that $\geq 20$ chromosomal alterations and $\geq 6$ telomeric losses were the best predictors of malignant progression. A subset of 22 insulinomas was further investigated for TP53 exon 5-8 gene mutations, and $p 53$ and CK19 expression. Only one malignant tumor was shown to harbor an arginine 273 serine mutation and immunopositivity for p53. CK19 immunopositivity was detected in three malignant tumors and one tumor with uncertain behavior.

In conclusion, our results indicate that $\mathrm{CIN}$ as well as telomeric loss are very powerful indicators for malignant progression in sporadic insulinomas. Our data do not support a critical role for p53 and CK19 as molecular parameters for this purpose.

\subsection{Introduction}

Chromosomal instability (CIN) is a feature of most human cancers. CIN refers to an increased rate of losing or gaining whole or large parts of chromosomes during cell division [1-2]. It is known that critically short telomeres, in the setting of abrogated DNA damage checkpoints, cause CIN due to end-to-end chromosomal fusions, subsequent breakage, and rearrangement, resulting in an increased cancer incidence in animal models [3]. The role of telomeres in preventing chromosome fusion has led to the proposal that loss of telomere function is a mechanism for $\mathrm{CIN}$ in cancer [4]. In addition, defects in mitotic segregation seem to cause CIN [5]. A crucial question of cancer biology is whether $\mathrm{CIN}$ is an early event resulting in gene mutations that drive tumorigenesis, or a late event in tumor progression as a consequence of alterations in oncogenes and tumor suppressor genes (TSGs) [2, 6]. In many neuroendocrine tumor types, including pheochromocytomas, adreno- 
cortical tumors, and different endocrine pancreatic tumor (EPT) subtypes, CIN has been detected as a late event in tumor progression [7-10].

Insulinomas are the most frequently detected functioning EPTs. They show evidence of $ß$-cell differentiation and clinical symptoms of hypoglycemia due to uncontrolled insulin production. Insulinomas clearly differ from other EPT subtypes with respect to their clinical behavior and low MEN1 mutation frequency. According to the most recent WHO classification, the only feature that separates benign from malignant disease is organ and / or lymph node infiltration or distant metastases [11]. When only a primary lesion is identified, however, no reliable markers for malignancy are available. Tumors with parameters such as a tumor diameter $\geq$ $2 \mathrm{~cm}$, an increased mitotic index and / or necrosis, are classified as tumors with uncertain behavior, having an increased risk for malignant outgrowth compared to benign tumors [12]. Interestingly, by using conventional $\mathrm{CGH}$ we observed significant differences in the number of genomic alterations per tumor between benign and malignant insulinomas. CIN was a more powerful predictor of malignancy than a tumor diameter $\geq 2 \mathrm{~cm}$ or a proliferative index $\geq 2 \%$ (Chapter 2 ).

Besides chromosomal alterations, a number of immunomarkers have been indicated that predict the prognosis of insulinomas, including the alpha chain of human chorionic gonadotropin (HCG- $\alpha$ ), p53 and cytokeratin 19 (CK19). HCG- $\alpha$ is expressed by approximately $65 \%$ of malignant functioning EPTs. Because it is also expressed in benign tumors, this marker is considered to be of limited value [1314]. The TP53 tumor suppressor gene is mutated in more than $50 \%$ of all human neoplasms [15]. If the remaining wildtype TP53 gene is inactivated (predominantly by deletion), these mutations abrogate the negative growth regulatory functions of p53 and are often associated with CIN. Immunohistochemical detection of p53 is associated with the presence of a TP53 mutation in most cases. Controversy exists with respect to the p53 status in EPTs. Lee suggested no role for p53, whereas Pavelic et al. identified p53 overexpression in three out of three cases of malignant insulinomas [16-17]. Mutations of TP53 have only been found in a few isolated EPT cases [18-19]. CK19 is widely expressed in (pre)malignant cells of epithelial origin [20]. Its presence in normal cells has been related to functional growth, keeping post-stem cells in a flexible state of differentiation. In the normal pancreas, it is only expressed in the exocrine ducts [21]. CK19 has recently been proposed as a predictor of survival in EPTs, including insulinomas [22]. Recently, La Rosa et al. confirmed these findings with the restriction that CK19 expression should be detected with the RCK108 antibody [23]. Albarello et al. however demonstrated a low specificity for CK19 immunostaining, already showing expression in $57 \%$ of EPTs with benign and uncertain behavior [24].

The aim of this study was to evaluate CIN and the p53 and CK19 status as prognostic parameters in insulinomas. For this purpose we analyzed a group of 30 insulinomas with $\mathrm{CGH}$ to genomic microarrays containing 3,700 FISH-verified bacterial artificial chromosome (BAC) clones. Array CGH was used because of its higher resolution compared to conventional $\mathrm{CGH}$ and to allow a more reliable 
analysis of DNA copy number changes at regions close to the centromeres and telomeres, and at chromosomes 1p32-pter, 16p, 19, and 22. These regions are usually excluded in conventional $\mathrm{CGH}$, because they often show gains in negative control hybridizations. A subgroup of 22 tumors was subsequently examined for mutations of TP53 and immunoreactivity for p53 and CK19.

\subsection{Materials and methods}

\subsubsection{Tumor material and patient data}

36 cases of insulinoma (19 females, mean age $51.4 \pm 17.5$ years and 17 males, mean age $50.9 \pm 12.8$ years) were selected from the archives of the Departments of Pathology of the University Hospital Zurich, Switzerland and the University Medical Centers Rotterdam, Utrecht and Nijmegen, The Netherlands. From all cases paraffin embedded material was available. Frozen material was present from 30 of these cases. They were all sporadic tumors and not associated with the inherited MEN1 (multiple endocrine neoplasia) syndrome. The tumors were classified according to the most recent WHO classification [11]. The samples included 17 benign tumors, nine tumors of uncertain behavior, and ten malignant tumors. All insulinomas exhibited hyperinsulinism followed by a hypoglycemia syndrome. The study protocol was approved by the institutional ethical committee, and all of the patients gave informed consent.

The 30 insulinomas of which frozen material was available were analyzed by array CGH. A subgroup of 22 insulinomas was analyzed for TP53 mutations and p53 and CK19 expression by immunohistochemistry on paraffin tissue sections.

\subsubsection{DNA extraction}

Genomic DNA, isolated from blood lymphocytes of four cytogenetically normal, healthy individuals (two males and two females), was used for array validation and as normal reference DNA. Genomic DNA from frozen insulinoma samples was extracted by homogenizing approximately $5 \mathrm{~mm}^{3}$ of each sample prior to proteinase $\mathrm{K}$ treatment and purification using the QIAamp DNA mini kit (Qiagen, Hilden, Germany) (Chapter 2).

\subsubsection{Array CGH analysis}

Array CGH was performed on microarrays containing 3,700 FISH-verified BAC clones in triplicate, including $\sim 3,200$ clones selected through an international collaboration to cover the genome with a $1 \mathrm{Mb}$ resolution, and clones specifically selected for previous studies. Array preparation, labeling, hybridization, and scanning procedures were performed as described already in chapter 3. 


\subsubsection{Image analysis and evaluation}

Fluorescence images of microarray slides were acquired by using an Affymetrix 428 scanner and analyzed using GenePix Pro 6.0 software (Axon Instruments Inc., Foster City, CA), as described elsewhere [25]. To obtain a genomic copy number ratio for each spot, the median local background was subtracted from the median pixel intensity of both dyes. Data normalization was performed by using the software package SAS version 8.0 (SAS institute, Cary, NC) for each array sub-grid, by applying loess curve fitting with a smoothing factor of 0.3 to predict the $\log _{2}$-transformed test-over-reference values. This smoothing factor was shown to result in the lowest percentage of false-positive results while not increasing the amount of false-negative results in the validation experiments. To utilize the spatial coherence between nearby clones, we used an unsupervised Hidden Markov Models (HMM) approach [26]. The clones are partitioned into the states which represent the underlying copy number of the group of clones. Chromosomal aberrations $\geq 10 \mathrm{Mb}$ were counted as a measure for CIN. Furthermore, telomeric loss was counted when at least 2 clones at the chromosomal end were deleted. All mapping information regarding clone locations, cytogenetic bands, and genomic content were retrieved from the UCSC genome browser (May 2004 freeze).

\subsubsection{Single Strand Conformation Polymorphism (SSCP) and sequence analysis of TP53 exons 5-8}

Exons 5-8 of the TP53 gene were investigated by SSCP analysis in 22 insulinoma samples. Each exon was amplified in two overlapping fragments. All primers used are listed in Table 4.1.

DNA was amplified by a radioactive $15 \mu$ Polymerase Chain Reaction (PCR). The PCR mix per sample consisted of $10 \mu \mathrm{l}$ distilled $\mathrm{H}_{2} \mathrm{O}, 1.5 \mu \mathrm{l}$ goldbuffer, $1.5 \mu \mathrm{l} 25$ $\mathrm{mM} \mathrm{MgCl}_{2}$-solution, $0.3 \mu \mathrm{l} 10 \mathrm{mM}$ dGTP, dTTP, dCTP, $0.3 \mu \mathrm{l} 1 \mathrm{mM}$ dATP, 0.9 Units $(5 \mathrm{U} / \mu \mathrm{l} \times 0.18 \mu \mathrm{l})$ Amplitaq polymerase (Perkin-Elmer, Wellesley, Mass., USA), 30 ng $(0.1 \mu \mathrm{g} / \mu \mathrm{l} \times 0.3 \mu \mathrm{l})$ of forward and reverse primer, $0.075 \mu \mathrm{l} \mathrm{aP}^{32}$-dATP (Amersham, Buckinghamshire, UK) and $1 \mu$ DNA sample. Before amplification the PCR-mix was heated at $95^{\circ} \mathrm{C}$ for 5 min to activate the Amplitaq polymerase. The temperatures for amplification were $95^{\circ} \mathrm{C}$ for $30 \mathrm{~s}, 55^{\circ} \mathrm{C}$ for $45 \mathrm{~s}$ and $72^{\circ} \mathrm{C}$ for 45 s. These steps were repeated for 35 cycles followed by a final extension at $72^{\circ} \mathrm{C}$ for $10 \mathrm{~min}$.

PCR products were diluted with $14 \mu$ l loading buffer (95\% formamide, $10 \mathrm{mM}$ EDTA $\mathrm{pH} 8,0.05 \%$ bromophenol blue and $0.05 \%$ xylene cyanol) and denatured at $95^{\circ} \mathrm{C}$ for $5 \mathrm{~min}$. Solutions were chilled on ice and, per sample, $4 \mu \mathrm{l}$ was loaded on a $15 \%$ polyacrylamide gel (acrylamide to bisacrylamide $49: 1$ ) containing 10\% of glycerol. Electrophoresis was performed at $8 \mathrm{~W}(15.8 \mathrm{~V} / \mathrm{cm})$ overnight at room temperature. The gels were vacuum dried at $80{ }^{\circ} \mathrm{C}$ and exposed to X-ray films. Films were evaluated by visual inspection.

TP53 mutations indicated by SSCP analysis were identified by direct sequencing. PCR products were used for cycle sequencing using a Dye Terminator Cycle Se- 
quencing Ready Reaction and analyzed on an ABI Prism 3100 genetic analyser according to the instructions of the manufacturer (PE Biosystems, Foster City, CAm USA).

Table 4.1. p53 exon 5-8 PCR primer information

\begin{tabular}{lclc}
\hline Primer & Forward $/$ reverse & \multicolumn{1}{c}{ Sequence } & Product size (bp) \\
\hline p53 exon 5/1 & $\mathrm{F}$ & CCT GAC TTT CAA CTC TTG CTC & 158 \\
p53 exon 5/2 & $\mathrm{R}$ & ACT GCT TGT AGA TGG CCA TG & \\
& $\mathrm{F}$ & CAG CTG TGG GTT GAT TCC AC & 176 \\
$\mathrm{p} 53$ exon 6/1 & $\mathrm{R}$ & CTG GGG ACC CTG GGC AAC & \\
& $\mathrm{F}$ & AGG CCT CTG ATT CCT CAC TG & 127 \\
p53 exon 6/2 & $\mathrm{R}$ & GCA CCA CCA CAC TAT GTC GA & \\
& $\mathrm{F}$ & CTC CTC AGC ATC TTA TCC GA & 159 \\
p53 exon 7/1 & $\mathrm{R}$ & CCA CTG ACA ACC ACC CTT & \\
& $\mathrm{F}$ & AGG CGC ACT GGC CTC ATC TT & 141 \\
p53 exon 7/2 & $\mathrm{R}$ & TCC AGT GTG ATG ATG GTG AGG & \\
& $\mathrm{F}$ & CAT GTG TAA CAG TTC CTG CAT G & 135 \\
p53 exon 8/1 & $\mathrm{R}$ & GCG GCAAGC AGA GGC TGG & \\
& $\mathrm{F}$ & CCT TAC TGC CTC TTG CTT CTC & 130 \\
p53 exon 8/2 & $\mathrm{R}$ & CTT GCG GAG ATT CTC TTC CTC & \\
& $\mathrm{F}$ & TTG TGC CTG TCC TGG GAG AG & 127 \\
\hline
\end{tabular}

\subsubsection{Immunostaining of $p 53$ and CK19}

p53 and CK19 antigen staining was performed on 4- $\mu$ m-thick paraffin-embedded tissue sections of 22 insulinomas (seven benign, five of unknown behavior and ten malignant) as described previously [27]. Briefly, sections were deparaffinized and treated with $10 \mathrm{mM}$ citrate buffer $(\mathrm{pH} \mathrm{6.0)}$ in a microwave oven at $600 \mathrm{~W}$ for 15 min (antigen retrieval). Endogenous peroxidase was inactivated by treatment with $2 \% \mathrm{H}_{2} \mathrm{O}_{2}$ in methanol, followed by incubation in 3\% BSA / PBS to block non-specific binding of antibody conjugates. The sections were incubated for 1 $\mathrm{h}$ at room temperature either with mouse monoclonal antibody directed against human CK19 (RCK108, Mubio, Maastricht, the Netherlands) at a 1:200 dilution in $1 \%$ bovine serum albumin (BSA) / PBS, or with mouse monoclonal antibody DO7 against p53 protein (Dako, Glostrup, Denmark) at a 1:50 dilution in 1\% BSA / PBS. Primary antibodies were detected using biotin-labeled horse anti-mouse antibody at a 1:200 dilution in 1\% BSA / PBS, and avidin-biotinylated peroxidase complex (Vector laboratories, Burlingame, CA, USA) at a 1:50 dilution in 4x SSC. Peroxidase activity was visualized using diaminobenzidine (DAB) / $\mathrm{H}_{2} \mathrm{O}_{2}$ (Sigma Chemical Co., St Louis, MO) and sections were counterstained with hematoxylin and mounted in Entellan (Merck, Darmstadt, Germany). 
Although the DO-7 antibody binds to both normal and mutant p53 protein, in general normal levels of wild-type p53 protein are too low to detect by immunohistochemistry. A premalignant laryngeal specimen was used as a positive control, showing nuclear p53 staining above the threshold level of $\geq 30 \%$ of cells [27]. All tumor cases with cytoplasmic staining for CK19 in $\geq 10 \%$ of tumor cells were considered positive in this study. Ductal cells of the normal exocrine pancreas expressing CK19 in the cytoplasm served as a positive control in the tissue sections. Three observers independently evaluated all immunostained slides.
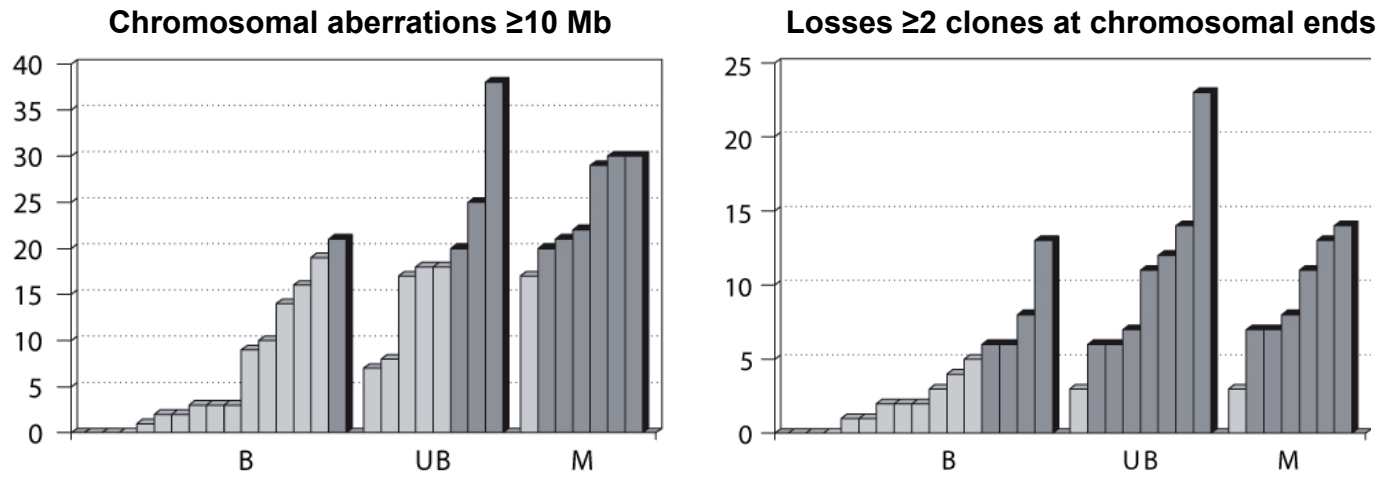

Figure 4.1. Graphs representing the number of chromosomal aberrations of $\geq 10 \mathrm{Mb}$ (left side), and the number of telomeric losses (loss of at least two BAC clones at the chromosomal ends) (right side) in tumors with benign (B), uncertain (UB) and malignant (M) behavior. Each bar represents one tumor. The dark grey bars are used in the left graph for $\geq 20$ chromosomal aberrations (CIN) and in the right graph for $\geq 6$ telomeric losses per tumor.

\subsection{Results}

\subsubsection{DNA copy number alterations detected by array CGH}

Genomic DNA extracted from 30 frozen insulinoma specimens was analyzed by array CGH for the presence of chromosomal alterations. In the benign group, the average number of large chromosomal changes per tumor $(\geq 10 \mathrm{Mb})$ was $6.6 \pm$ 7.2 , whereas the tumors with uncertain behavior and malignant behavior showed an average number of $19.1 \pm 9.7$ and $24.1 \pm 5.4$, respectively. The most optimal discrimination between benign and malignant tumors (when excluding the tumors with uncertain behavior) could be made by classification of the tumors according to the presence of more or less than 20 chromosomal aberrations $\geq 10 \mathrm{Mb}$ (Fig. 4.1; left graph). More than 20 alterations (CIN) were detected in one out of 15 benign tumors, three out of eight tumors with uncertain behavior, and six out of seven malignant tumors. Based on this classification, the insulinomas with uncertain behavior comprise both tumors that most likely belong to the benign group and tumors that rather belong to the malignant group. Comparison of the benign with the malignant tumors showed that $\mathrm{CIN}$ is a very sensitive marker for malignancy 
$(\mathrm{OR}=84)$, which is in agreement with our previous conventional $\mathrm{CGH}$ data. Both the specificity and sensitivity of this parameter were further improved by the use of array CGH (93 and $86 \%$ vs 82 and $83 \%$ with conventional CGH) (Table 4.2 ).

In order to identify the chromosomal regions most frequently involved in $\mathrm{CIN}$, we determined those regions that encompass at least three adjacent BAC clones, and occur in insulinomas with CIN at a frequency $\geq 25 \%$ higher than in tumors without CIN. Only those regions that are significantly different in frequency between those two groups are listed in Table 4.2. Furthermore, the percentage of malignant tumors with the aberration, defined as sensitivity, and the percentage of benign tumors without the aberration, defined as specificity, and their odds ratios were calculated. The regions 22q11.21-q13.31 and 7p21.1-p11.2 were the best classifying markers for malignant behavior according to their sensitivity in univariate analysis ( $71 \%$ each). Discrimination on basis of more or less than 20 aberrations per tumor however showed to be more sensitive (86\%).

\subsubsection{Loss of telomeric regions}

The loss of telomeric regions, defined as a deletion of at least two clones at the chromosomal end, was subsequently determined. The average number of telomeric losses per tumor were significantly higher in the tumors with CIN than without CIN (10.0 \pm 5.6 vs $4.9 \pm 4.5 ; p=0.01)$. The best classification between benign and malignant tumors could be achieved by using a threshold of six telomeric losses (OR=39; see Table 4.2), which approaches the discriminating value of CIN. Figure 4.1 (right graph) shows the number of telomeric losses per tumor in insulinomas with benign, uncertain and malignant behavior. At least six telomeric losses were detected in four out of 15 benign tumors, seven out of eight tumors with uncertain behavior and six out of seven malignant tumors. In addition, in insulinomas with uncertain behavior telomeric losses were more frequently observed than CIN.

\subsection{3. p53 mutation analysis and immunohistochemistry}

A subgroup of 22 insulinomas, including five cases of which only paraffin embedded material was available, was analyzed for TP53 mutations. The results are shown in Table 4.3. Only one hotspot mutation in exon 8 (arginine 273 serine) was detected in a malignant insulinoma (Fig. 4.2 B and C, p.121). This mutation coincided with loss of chromosome 17 as detected by array $\mathrm{CGH}$, indicating deletion of the wild-type locus. This insulinoma was the only tumor with less than 20 chromosomal aberrations in the malignant group. P53 immunostaining was positive in this tumor only. The results are shown in Table 4.3. Fig. 4.2 D and E (p.121) show the presence and absence of nuclear p53 expression in tumor case 20 and tumor case 16. 
Table 4.2. Chromosomal aberrations associated with chromosomal instability

\begin{tabular}{|c|c|c|c|c|c|c|c|c|c|}
\hline $\begin{array}{l}\text { Chromosomal } \\
\text { region of loss }\end{array}$ & bp position ${ }^{a}$ & $\begin{array}{l}\text { Candidate } \\
\text { genes }\end{array}$ & $\begin{array}{l}\text { Size } \\
(\mathrm{Mb})\end{array}$ & $\begin{array}{l}\text { no } \\
\text { CIN }^{b}\end{array}$ & $\mathrm{CIN}^{\mathrm{b}}$ & $\begin{array}{l}P \\
\text { value }^{\text {b }}\end{array}$ & Sens. ${ }^{c}$ & Spec. ${ }^{c}$ & $\begin{array}{l}\text { OR } \\
>1^{c}\end{array}$ \\
\hline $1 \mathrm{p} 36.33-34.1$ & 294,060 & APITD1 & 45 & 13 & 58 & 0.030 & 57 & 87 & 9 \\
\hline 1p31.1-22.1 & $82,255,496$ & & 9 & 0 & 30 & 0.030 & 0 & 93 & \\
\hline 1p12 & $117,527,043$ & & 2 & 5 & 40 & 0.031 & 29 & 93 & \\
\hline $1 q 43-44$ & $239,198,790$ & AKT3 & 3 & 17 & 60 & 0.030 & 57 & 87 & 9 \\
\hline $2 q 11.2-12.2$ & $99,888,629$ & & 7 & 5 & 40 & 0.031 & 43 & 100 & $>11$ \\
\hline $3 p 25.3-21.31$ & $9,204,214$ & PPARG & 37 & 2 & 42 & 0.008 & 43 & 93 & 11 \\
\hline $6 p 21.32-21.1$ & $33,032,994$ & VEGF & 10 & 4 & 44 & 0.031 & 43 & 93 & 11 \\
\hline $6 q 24.3-27$ & $148,731,560$ & & 19 & 0 & 41 & 0.008 & 43 & 100 & $>11$ \\
\hline 8p23.3-23.2 & 384,739 & & 3 & 0 & 30 & 0.030 & 14 & 100 & \\
\hline 10p15.3-14 & 290,388 & & 9 & 2 & 40 & 0.008 & 43 & 93 & 11 \\
\hline $10 q 21.3$ & $64,873,350$ & & 4 & 1 & 32 & 0.030 & 29 & 100 & \\
\hline $10 q 22.2-23.33$ & $77,323,046$ & FAS & 17 & 0 & 50 & 0.002 & 43 & 100 & $>11$ \\
\hline $10 q 25.2-26.11$ & $113,549,135$ & & 6 & 0 & 30 & 0.030 & 29 & 100 & \\
\hline $10 q 26.13-26.3$ & $124,043,135$ & $B C C I P$ & 11 & 4 & 50 & 0.009 & 43 & 93 & 11 \\
\hline $15 q 12-14$ & $23,790,070$ & TRPM1 & 12 & 4 & 42 & 0.031 & 29 & 87 & 3 \\
\hline $22 q 11.21-13.31$ & $19,910,708$ & NF2 & 25 & 32 & 73 & 0.056 & 71 & 73 & 7 \\
\hline $\begin{array}{l}\text { Chromosomal } \\
\text { region of gain }\end{array}$ & bp position ${ }^{a}$ & $\begin{array}{l}\text { Candidate } \\
\text { genes }\end{array}$ & $\begin{array}{l}\text { Size } \\
(\mathbf{M b})\end{array}$ & $\begin{array}{l}\text { no } \\
\text { CIN }^{b}\end{array}$ & $\mathrm{CIN}^{\mathrm{b}}$ & $\begin{array}{l}P \\
\text { value }^{\mathrm{b}}\end{array}$ & Sens. ${ }^{c}$ & Spec. ${ }^{c}$ & $\begin{array}{l}\text { OR } \\
>1^{c}\end{array}$ \\
\hline 4p16.2-q35.2 & $5,000,272$ & $M A D 2 L 1, C D C 4$ & 178 & 4 & 43 & 0.031 & 43 & 100 & $>11$ \\
\hline 7p21.1-11.2 & $17,428,379$ & GCK & 37 & 14 & 60 & 0.030 & 71 & 87 & 16 \\
\hline $7 q 11.22-31.32$ & $69,645,684$ & & 52 & 8 & 47 & 0.026 & 43 & 93 & 11 \\
\hline $7 q 33-35$ & $134,622,057$ & $B R A F$ & 10 & 6 & 46 & 0.009 & 43 & 93 & 11 \\
\hline $12 \mathrm{p} 13.31-13.2$ & $9,155,207$ & & 1 & 6 & 48 & 0.009 & 57 & 100 & $>19$ \\
\hline $12 \mathrm{p} 12.1-11.23$ & $23,984,770$ & KRAS & 3 & 6 & 40 & 0.031 & 43 & 100 & $>11$ \\
\hline $12 q 12-24.33$ & $39,747,507$ & KNTC1 & 90 & 0 & 51 & 0.002 & 43 & 93 & 11 \\
\hline $13 q 21.1-33.1$ & $57,539,975$ & & 45 & 2 & 36 & 0.008 & 29 & 93 & 6 \\
\hline $14 q 11.2-32.2$ & $20,145,562$ & & 80 & 6 & 51 & 0.009 & 43 & 100 & $>11$ \\
\hline $17 p 13.1-q 25.3$ & $8,282,767$ & CK19, BRCA1 & 67 & 1 & 36 & 0.008 & 43 & 100 & $>11$ \\
\hline 18p11.32-11.31 & $2,222,012$ & & 4 & 0 & 30 & 0.030 & 43 & 100 & $>11$ \\
\hline $18 q 11.2-12.1$ & $19,366,416$ & & 5 & 0 & 30 & 0.030 & 43 & 100 & $>11$ \\
\hline $18 q 12.3$ & $36,066,444$ & & 3 & 0 & 30 & 0.030 & 43 & 100 & $>11$ \\
\hline $18 q 21.32-22.2$ & $56,872,706$ & $B C L 2$ & 8 & 0 & 30 & 0.030 & 43 & 100 & $>11$ \\
\hline 20p13-11.23 & 467,506 & & 19 & 18 & 65 & 0.015 & 57 & 80 & 5 \\
\hline $\mathrm{CIN}$ & & & & & & & 86 & 93 & 84 \\
\hline Telomeric loss ${ }^{d}$ & & & & & & & 86 & 87 & 39 \\
\hline p53 & & & & & & & 14 & 100 & \\
\hline CK19 & & & & & & & 14 & 100 & \\
\hline
\end{tabular}

aMap positions are based on data of the UCSC genome browser (May 2004); 'Percentage of tumors with the aberration in the CIN group ( $\geq 20$ aberrations $\geq 10 \mathrm{Mb} ; \mathrm{n}=10$ ) and the no CIN group ( $<20$ aberrations $\geq 10 \mathrm{Mb}$; $n=20$ ). This percentage is the mean of the percentages per clone in that region. Regions contain $\geq 5$ clones with a maximum of 2 intermediate clones without the aberration; 'Sens., sensitivity, $\%$ of malignant tumors with the aberration. Spec., specificity, \% of benign tumors without the aberration; OR, Odds Ratio. Only OR $>1$ are indicated; ${ }^{\mathrm{d}}$ Telomeric loss as defined by $\geq 6$ telomeric losses (2 BAC clones lost at the chromosomal ends). 


\subsubsection{CK19 immunohistochemistry}

Consecutive tissue sections of the 22 insulinomas were also analyzed for CK19 immunoreactivity. Table 4.3 shows that only four tumors expressed cytoplasmic CK19, i.e. three out of ten malignant insulinomas and one out of five tumors with uncertain behavior (Fig. 4.2 F, p.121). Ductal cells of the normal pancreas expressing CK19 in the cytoplasm served as positive control in the tissue sections (Fig. 4.2 G, p.121). Although no benign tumors showed immunopositivity, the sensitivity of this parameter is insufficient to serve as a reliable predictor of malignancy.

Table 4.3. Results of mutation analysis (TP53) and immunohistochemistry (p53 and CK19)

\begin{tabular}{|c|c|c|c|c|c|}
\hline Tumor & Classification $^{a}$ & Regions $\geq 10 \mathrm{Mb}$ & TP53 m.a. ${ }^{b}$ & p53 IHC & CK19 IHC \\
\hline 1 & Benign & & - & - & - \\
\hline 2 & Benign & 3 & - & - & - \\
\hline 3 & Benign & & - & - & - \\
\hline 4 & Benign & 3 & - & - & - \\
\hline 5 & Benign & & - & - & - \\
\hline 6 & Benign & 16 & - & - & - \\
\hline 7 & Benign & 10 & - & - & - \\
\hline 8 & UB & 18 & - & - & - \\
\hline 9 & UB & 18 & - & - & - \\
\hline 10 & UB & 38 & - & - & - \\
\hline 11 & UB & 20 & - & - & - \\
\hline 12 & UB & 8 & - & - & + \\
\hline 13 & Malignant & 30 & - & - & - \\
\hline 14 & Malignant & 30 & - & - & - \\
\hline 15 & Malignant & & - & - & - \\
\hline 16 & Malignant & & - & - & - \\
\hline 17 & Malignant & 22 & - & - & - \\
\hline 18 & Malignant & 21 & - & - & - \\
\hline 19 & Malignant & 20 & - & - & + \\
\hline 20 & Malignant & 17 & + & + & + \\
\hline 21 & Malignant & 29 & - & - & - \\
\hline 22 & Malignant & & - & - & + \\
\hline
\end{tabular}

aUB, uncertain behavior; ${ }^{\text {} T P 53 ~ m . a ., ~ T P 53 ~ m u t a t i o n ~ a n a l y s i s ; ~}{ }^{\mathrm{c}} \mathrm{HC}$, immunohistochemistry 


\subsection{Discussion}

We performed a genome-wide array-based CGH analysis on a series of 30 human sporadic insulinomas with the goal of identifying powerful genomic parameters that can predict malignant progression. In addition, a subset of tumors was analyzed for TP53 mutations and expression of p53 and CK19 by immunohistochemistry, which have been indicated as prognostic markers in EPTs. Particularly a high number of chromosomal alterations and loss of telomeric ends were strongly associated with metastatic disease. P53 and CK19 status proved to be of little value for this purpose, because only rare, isolated cases showed a TP53 mutation or detectable amounts of protein.

In many cancers, alterations in the number of chromosomes are detected, which are believed to be caused by CIN. Mutations in genes playing a role in mitotic segregation as well as loss of telomeric ends have been recognized as molecular mechanisms underlying this phenomenon $[1,4-5,28]$. On the basis of the number of alterations per tumor as identified by array CGH in this study, a marked distinction between benign and malignant insulinomas could be made. The most potential indicators for malignant progression are $\geq 20$ chromosomal alterations of $\geq 10$ $\mathrm{Mb}$ and $\geq 6$ telomeric losses per tumor. It is tempting to speculate that the tumors with uncertain behavior and undetectable metastases can be classified as benign or malignant according to these genomic parameters. Since this group shows evident heterogeneity in the number of genomic alterations per tumor. The clinical follow-up data of patients required to evaluate such a classification are currently being collected (see Chapter 5). Interestingly, seven out of eight insulinomas with uncertain behavior harbored $\geq 6$ telomeric losses per tumor, whereas only three of these cases contained $\geq 20$ chromosomal aberrations. This suggests that telomeric loss occurs prior to and is causative for $\mathrm{CIN}$ during insulinoma tumorigenesis.

Besides genomic parameters, we examined the value of TP53 exon 5-8 mutations and the expression of nuclear p53 for predicting metastatic disease in insulinomas. Only one malignant insulinoma proved to exhibit a hot-spot mutation in exon 8 of the TP53 gene, i.e. A273S. Interestingly, this tumor also showed a different genomic profile compared to the other malignant tumors. First, it revealed loss of chromosome 17, indicating deletion of the remaining wild-type allele, whereas chromosome 17 was gained in four out of seven malignant insulinomas. Second, it was the only malignant tumor with $<20$ aberrations. The fact that only one malignant tumor showed a TP53 mutation indicates that this gene does not play an important role in insulinoma progression. This finding is in agreement with earlier studies describing only rare EPT cases with a TP53 mutation [18-19]. Immunopositivity for p53 was only found in the tumor with the mutation, further underscoring the little value of p53 in predicting malignant progression. Nevertheless, if a TP53 mutation is identified, the insulinoma is most likely malignant.

CK19 is expressed in many types of simple and non-keratinizing normal and neoplastic epithelia, including pancreatic ductal cells. Normal endocrine pancreatic 
cells are negative for this marker. Deshpande et al. have recently reported that CK19 immunostaining is a powerful predictor of survival in EPTs and that four out of 20 insulinomas expressed CK19, two of which occurred in patients with advanced disease [22]. It was unclear which CK19 monoclonal antibody (clone BA17 and RCK108, both from Dako) was used in this study. It was recently found that CK19 expression only when tested with the RCK108 antibody correlates with prognosis in EPTs and especially in insulinomas [23]. Therefore, we have used the RCK108 antibody in this study for critical evaluation of its predictive value in malignant insulinoma progression. CK19 immunoreactivity was detected in three tumors with malignant and one with uncertain behavior, whereas the exocrine duct cells stained strongly positive in many CK19 negative tumor cases. Our study thus does not support the use of CK19 immunopositivity as a strong predictor for insulinoma progression. Because we are in the process of collecting the clinical patient data, we were unable to determine the role of CK19 as a parameter associated with patient survival.

Our previous molecular studies have shown that gain of chromosome $9 \mathrm{q}$, rather than mutations in the MEN1 gene at 11q13, is an early event in insulinoma development (Chapter 2) [29]. Besides CIN and telomeric losses, as described above, we searched for chromosomal regions which are most often involved in the tumors with malignant behavior and therefore may contain candidate genes involved in tumor progression. The regions 7p21.1-p11.2 and 22q11.21-q13.31 were the best classifying markers for malignant behavior according to their sensitivity in univariate analysis. A putative candidate gene in the $7 p$ region is the glucokinase (GCK) gene. Glucokinase is a key regulatory enzyme in the pancreatic $\beta$-cell. It plays a crucial role in the regulation of insulin secretion and has been termed the pancreatic $\beta$-cell sensor. Mutations in this gene have been reported to cause both hyperglycemia and hypoglycemia [30], and thus can be considered an interesting candidate gene in insulinoma tumorigenesis. However, because hypoglycemia can already be detected in patients with small benign insulinomas, a relation with malignant progression is disputable. Losses of $22 q$ loci have also been found by Wild et al., who excluded a putative role of the $h S N F 5 / I N / 1$ gene in insulinomas [31]. A candidate gene in the 22q11.21-q13.31 region identified by array CGH is the NF2 gene, which is often deleted in sporadic and neurofibromatosis type 2 (NF2)related meningiomas, schwannomas and ependymomas [32]. A gene involved in various tumors with $\mathrm{CIN}$ is BRCA1 [33], which is localized on the 17p13.1-q25.3 region, often detected in insulinomas with $\mathrm{CIN}$. Mutations of this gene are usually seen in combination with loss of this locus. In our series we detect predominantly gain of this region. Therefore, the intriguing finding that duplication / amplification of mutated alleles may also lead to tumorigenesis [34] should be examined in this respect. A role for these genes in insulinoma progression remains to be elucidated.

In conclusion, the presented findings indicate that $\mathrm{CIN}$ as well as telomeric loss are very powerful indicators for malignant progression in sporadic insulinomas. Our 
data do not support a critical role for p53 and CK19 as molecular parameters for this purpose. Furthermore, the chromosomal regions identified in tumors with CIN may harbor candidate cancer genes important in insulinoma progression.

\subsection{Acknowledgements}

We thank J.L.M. Uytdewilligen and H.F.B.M. Sleddens (Department of Pathology, UMC Rotterdam, the Netherlands) and M. Halin (Department of Medical Sciences, University Hospital Uppsala, Sweden) for expert technical assistance, and Dr. A. Perren (Department of Pathology, University Hospital Zurich, Switzerland), Prof. Dr. P. Komminoth (Department of Pathology, Hospital Baden, Switzerland), Prof. Dr. A. de Bruïne (Department of Pathology, UMC Maastricht, the Netherlands), Dr. A.A. Verhofstad (Department of Pathology, RUNMC Nijmegen, the Netherlands), Dr. L.J. Hofland (Department of Internal Medicine, UMC Rotterdam, the Netherlands), Dr. R.R. de Krijger (Department of Pathology, UMC Rotterdam, the Netherlands), and Prof. Dr. P.J. Slootweg (Department of Pathology, RUNMC Nijmegen, the Netherlands) for the collection of samples and helpful discussions.

\subsection{References}

1. Draviam VM, Xie S, Sorger PK. Chromosome segregation and genomic stability. Curr. Opin. Genet. Dev. 2004; 14: 120-125.

2. Michor F, Iwasa Y, Vogelstein B, Lengauer C, Nowak MA. Can chromosomal instability initiate tumorigenesis? Sem. Cancer Biol. 2005; 15: 43-49.

3. Meeker AK, Hicks JL, Platz EA, March GE, Bennett CJ, Delannoy MJ, et al. Telomere shortening is an early somatic DNA alteration in human prostate tumorigenesis. Cancer Res. 2002; 62: 6405-6409.

4. Murnane JP, Sabatier L. Chromosome rearrangements resulting from telomere dysfunction and their role in cancer. BioEssays 2004; 26: 1164-1174.

5. Rajagopalan H, Lengauer C. Aneuploidy and cancer. Nature 2004; 432: 338-341.

6. Duesberg P, Rasnick D. Aneuploidy, the somatic mutation that makes cancer a species of its own. Cell. Motil. Cytoskeleton 2000; 47: 81-107.

7. Dannenberg H, Speel EJ, Zhao J, Saremaslani P, van Der Harst E, Roth J, et al. Losses of chromosomes $1 p$ and $3 q$ are early genetic events in the development of sporadic pheochromocytomas. Am. J. Pathol. 2000; 157: 353-359.

8. Kjellman M, Kallioniemi OP, Karhu R, Hoog A, Farnebo LO, Auer G, et al. Genetic aberrations in adrenocortical tumors detected using comparative genomic hybridization correlate with tumor size and malignancy. Cancer Res. 1996; 56: 4219-23.

9. Zhao J, Speel EJM, Muletta-Feurer S, Rütimann K, Saremaslani P, Roth J, et al. Analysis of genomic alterations in sporadic adrenocortical lesions. Am. J. Pathol. 1999; 155: 1039-1045.

10. Speel EJM, Richter J, Moch H, Egenter C, Saremaslani P, Rütimann K, et al. Genetic differences in endocrine pancreatic tumor subtypes detected by comparative genomic hybridization. Am. J. Pathol. 1999; 155: 1787-1794.

11. Komminoth P, Perren A, Öberg K, Rindi G, Heitz PU, Klöppel G. Insulinoma. In: RA DeLellis, RV Lloyd, PU Heitz, C Eng, editors. Pathology \& Genetics. Tumours of endocrine organs. Lyon: IARC Press 2004: 183-186.

12. Hochwald SN, Zee S, Conlon KC, Colleoni R, Louie O, Brennan MF, et al. Prognostic factors in pancreatic endocrine neoplasms: an analysis of 136 cases with a proposal for low-grade and intermediate-grade groups. J. Clin. Oncol. 2002; 20: 2633-2642. 
13. Heitz PU, von Herbay G, Kloppel G, Komminoth P, Kasper M, Hofler H, et al. The expression of subunits of human chorionic gonadotropin (hCG) by nontrophoblastic, nonendocrine, and endocrine tumors. Am. J. Clin. Pathol. 1987; 88: 467-472.

14. Graeme-Cook F, Nardi G, Compton CC. Immunocytochemical staining for human chorionic gonadotropin subunits does not predict malignancy in insulinomas. Am. J. Clin. Pathol. 1990; 93: 273-276.

15. Hollstein M, Sidransky D, Vogelstein B, Harris CC. P53 mutations in human cancers. Science 1991; 253: 49-53.

16. Lee CS. Lack of p53 immunoreactivity in pancreatic endocrine tumors. Pathology 1996; 28: 139141.

17. Pavelic K, Hrascan R, Kapitanovic S, Karapandza N, Vranes Z, Belicza M, et al. Multiple genetic alterations in malignant metastatic insulinomas. J. Pathol. 1995; 177: 395-400.

18. Bartz C, Ziske C, Wiedenmann B, Moelling K. p53 tumor suppressor gene expression in pancreatic neuroendocrine tumor cells. Gut 1996; 38: 403-409.

19. Lin HJ, French SW, Reichenbach D, Wan YY, Passaro E, Sawicki MP. Novel p53 mutation in a malignant tumor secreting vasoactive intestinal peptide. Arch. Pathol. Lab. Med. 1997; 121: 125-128.

20. Kwaspen FHL, Smedts FMM, Broos A, Bulten H, Debie WMH, Ramaekers FCS. Reproducible and highly sensitive detection of the broad spectrum epithelial marker keratin 19 in routine cancer diagnosis. Histopathol. 1997; 31: 503-516.

21. Bouwens L. Cytokeratins and cell differentiation in the pancreas. J. Pathol. 1998; 184: $234-239$.

22. Deshpande V, Fernandez-del Castillo C, Muzikansky A, Deshpande A, Zukerberg L, Warshaw AL, et al. Cytokeratin 19 is a powerfull predictor of survival in pancreatic endocrine tumors. Am. J. Surg. Pathol. 2004; 28: 1145-1153.

23. La Rosa S, Bianchi V, Rigoli E, Uccella S, Capella C. The prognostic significance of cytokeratin 19 expression in pancreatic endocrine tumors (PETs). Virchows Arch. 2005; 447: 188.

24. Albarello L, Capitanio V, Zerbi A, Di Carlo V, Doglioni C. Cytokeratin 19 expression in pancreatic endocrine tumors. J. Pancreas 2004; 6: 514.

25. Vissers LELM, de Vries BBA, Osoegawa K, Janssen IM, Feuth T, Choy CO, et al. Array-based comparative genomic hybridization for the genomewide detection of submicroscopic chromosomal abnormalities. Am. J. Hum. Genet. 2003; 73: 1261-1270.

26. Fridlyand J, Snijders AM, Pinkel D, Albertson DG, Jain AN. Hidden markov models approach to the analysis of array CGH data. J. Multivariate analysis 2004; 90: 132-153.

27. Hafkamp HC, Speel EJM, Haesevoets A, Bot FJ, Dinjens WNM, Ramaekers FCS, et al. A subset of head and neck squamous cell carcinomas exhibits integration of HPV 16/18 DNA and overexpression of p16INK4A and p53 in the absence of mutations in p53 exons 5-8. Int. J. Cancer 2003; 107: 394-400.

28. Gisselsson D, Jonson T, Petersen A, Strombeck B, Dal Cin P, Hoglund M, et al. Telomere dysfunction triggers extensive DNA fragmentation and evolution of complex chromosome abnormalities in human malignant tumors. Proc. Natl. Acad. Sci. USA 2001; 98: 12683-12688.

29. Speel EJ, Scheidweiler AF, Zhao J, Matter C, Saremaslani P, Roth J, et al. Genetic evidence for early divergence of small functioning and nonfunctioning endocrine pancreatic tumors: gain of $9 q 34$ is an early event in insulinomas. Cancer Res. 2001; 61: 5186-5192.

30. Gloyn AL. Glucokinase (GCK) mutations in hyper- and hypoglycemia: maturity-onset diabetes of the young, permanent neonatal diabetes, and hyperinsulinemia of infancy. Human mutat. 2003; 22: 353362.

31. Wild A, Langer P, Ramaswamy A, Chaloupka B, Bartsch DK. A novel insulinoma tumor suppressor gene locus on chromosome $22 q$ with potential prognostic implications. J. Clin. Endocrinol. Metab. 2001; 86: 5782-5787.

32. Gutmann DH. The neurofibromatosis: when less is more. Hum. Mol. Genet. 2001; 10: 747-755. 
33. Hartman AR, Ford JM. BRCA1 and p53: compensatory roles in DNA repair. J. Mol. Med. 2003; 81: 700-707.

34. Zhuang Z, Park WS, Pack S, Schmidt L, Vortmeyer AO, Pak E, et al. Trisomy 7-harbouring nonrandom duplication of the mutant MET allele in hereditary papillary renal carcinomas. Nature Genet. 1998; 20:66-69. 


\section{CHAPTER 5}

\section{DNA copy number status is a powerful predictor of}

poor survival in insulinoma patients

Yvonne M.H. Jonkers, Sandra M.H. Claessen, Aurel Perren, Anja M. Schmitt, Leo J. Hofland, Wouter W. de Herder, Ronald R. de Krijger, Albert A.J. Verhofstad, Ad R. Hermus, Alain J. Kummer, Britt Skogseid, Marco Volante, Adri C. Voogd, Frans C.S. Ramaekers, Ernst-Jan M. Speel

Submitted for publication

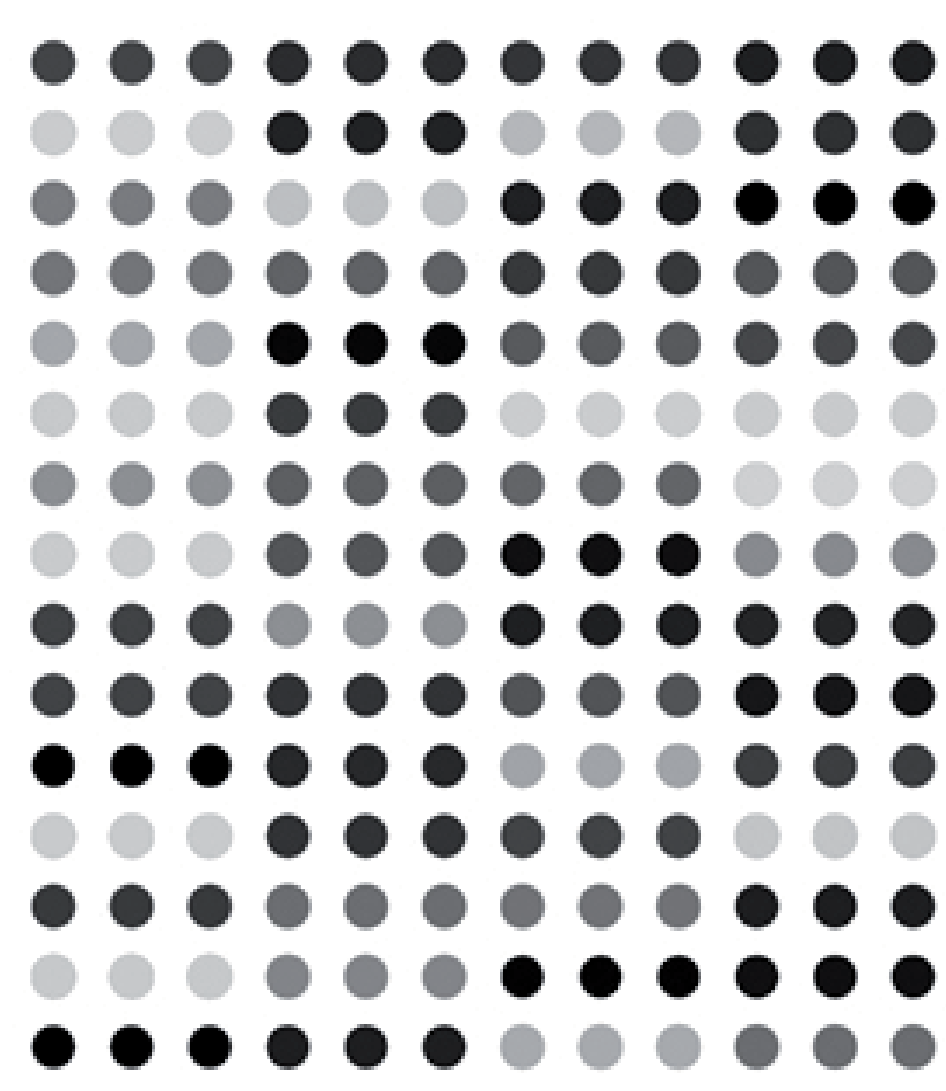




\section{Abstract}

The clinical behavior of EPTs is difficult to predict in the absence of metastases or invasion to adjacent organs. Several markers have been indicated as potential predictors of metastatic disease, such as tumor size $\geq 2 \mathrm{~cm}$, Ki67 proliferative index $\geq 2 \%$, CK19 status, and recently in insulinomas, CIN. The goal of this study was to evaluate the value of these markers, and in particular of CIN, to predict tumor relapse and / or tumor-specific death, using a series of insulinomas and non-insulinoma EPTs. From 71 EPT cases, including 47 insulinomas, a genomic profile could be generated and follow-up data could be obtained. The proliferative index could be determined in 68 tumors and a CK19 expression pattern in 50 tumors. Results were statistically analyzed using Kaplan-Meier plots and the log-rank statistic.

General CIN, as well as specific chromosomal alterations such as $3 p$ and $6 q$ loss and $12 q$ gain, turned out to be the most powerful indicators for poor tumor-free survival ( $p \leq 0.0004)$ and tumor-specific death ( $p \leq 0.0113)$ in insulinomas. CIN, chromosome $7 q$ gain, and a proliferative index $\geq 2 \%$ were reliable in predicting a poor tumor-free survival in non-insulinoma EPTs ( $p \leq 0.0181)$, whereas CK19 expression was the most optimal predictor of tumor-specific death in these tumors. In conclusion, DNA copy number status is the most sensitive and efficient marker of adverse clinical outcome in insulinomas and of potential interest in non-insulinoma EPTs. As a consequence, this marker should be implemented as a prognosticator to improve clinical diagnosis.

\subsection{Introduction}

The clinical behavior of EPTs is difficult to predict on basis of their histological features. The presence of metastases is generally accepted to be the only definitive feature of malignancy. A reliable classification system is therefore crucial to predict the biological behavior of these tumors. The current WHO classification system is based on expert opinion, but so far its power in a large series of EPTs with a long term follow-up remains to be evaluated [1]. The classification criteria comprise the presence of metastases, gross invasion, tumor size, percentage of mitoses, proliferative index, and vascular invasion. Tumor resection, the absence of liver and lymph node metastases, and the presence of MEN1 syndrome appear to be related with a better survival rate [2].

Several studies have reported potential biomarkers that are indicators for malignancy of EPTs, such as alpha chain of human chorionic gonadotropin (HCG- $\alpha$ ), cyclooxigenase-2 (COX2), p27KIP1, CD99, CK19, and p53. HCG- $\alpha$ is expressed by approximately $65 \%$ of malignant functioning EPTs. However, since it is also expressed in benign tumors, this marker is considered to be of limited value [34]. Upregulation of COX2 and CK19, and down-regulation of p27 and CD99 were found to be associated with Ki67 positive, proliferating tumor cells [5-10]. Contro- 
versy exists with respect to p53 expression as a marker for malignancy in EPTs. Lee [11] suggested no role for p53, whereas Pavelic et al. [12] identified p53 overexpression in 3 out of 3 cases of malignant insulinomas. We have recently shown that in insulin producing EPTs, CIN, as identified by analysis of DNA copy number changes using $\mathrm{CGH}$, is an optimal predictor for malignant progression (Chapter 2 and 4). Ki67, p53, and/or CK19 expression were found to be associated with malignancy only in a few individual insulinoma cases (Chapter 4).

The only potential immunomarker described to predict poor survival in EPTs is CK19 [13]. By comparing classification criteria and CK19 immunostaining in a series of $101 \mathrm{EPTs}$, others found that CK19 was the only significant predictor of poor survival [13]. In the study presented here, our aim was to investigate the reliability of DNA copy number alterations, including CIN in comparison with CK19 and other clinical parameters to predict poor survival in EPT patients. For this purpose, we have collected follow-up data of 71 EPT patients, including 47 cases of insulinoma.

\subsection{Materials and methods}

\subsubsection{Tumor material and patient data}

Seventy-one EPTs for which a CGH profile has been generated (Chapter 2,3) [1416] and follow-up data could be obtained, were studied here. They included 47 insulinomas, 6 gastrinomas, 2 glucagonomas, 5 vipomas, and 11 non-functioning tumors. These cases and their corresponding follow-up data were available from the archives of the Departments of Pathology of the University Hospital Zurich (Switzerland), the University of Torino (Italy), and the University Medical Centers of Rotterdam, Utrecht and Nijmegen (the Netherlands), and the Department of Medical Sciences, University Hospital Uppsala (Sweden). Ki67 proliferative index could be determined in 68 tumors and CK19 expression in 50 tumors. The study is done in line with the code "proper secondary use of human tissue" as implemented by the Federation of Biomedical Scientific Societies. The tumors were classified according to the most recent WHO classification [1]. All tumors were not associated with the inherited MEN1 syndrome. The mean age of the 71 EPT patients, including 40 females and 31 males, was 50.6 years (range 5-82 years). Follow-up ranged from $0.6-21.5$ years (mean 7.3 years). The diameter of all tumors ranged from 0.5 to $10 \mathrm{~cm}$ (mean $3.0 \mathrm{~cm}$ ).

Twenty-eight of the patients had localized disease at diagnosis as defined by 1) the absence of extra-pancreatic spread of the tumor as evidenced by Computed Tomography (CT), Magnetic Resonance Imaging (MRI) or ultrasound scanning, and 2) a tumor size smaller than $2 \mathrm{~cm}$ in diameter. Eighteen patients had a tumor with uncertain behavior, defined by the absence of extra-pancreatic spread of the tumor, but with a tumor size of at least $2 \mathrm{~cm}$ in diameter. Twenty-five patients showed metastatic disease at diagnosis. 


\subsubsection{Detection of $\mathrm{CIN}$ by $\mathrm{CGH}$ analysis}

CGH was used to analyze genome-wide DNA copy number imbalances in EPTs (Chapter 2-4) [14-16]. This approach uses differentially labeled tumor and 'reference' DNA, which are competitively hybridized to normal metaphase chromosomes (conventional $\mathrm{CGH}$ ) or to mapped genomic clones (array $\mathrm{CGH}$ ). The ratio of the fluorescence intensities detected is indicative of the relative DNA copy number in tumor versus reference DNA [17-19].

$\mathrm{CIN}$ was defined as the presence of at least 8 chromosomal aberrations by conventional CGH or 20 aberrations of at least $10 \mathrm{Mb}$ by array CGH (Chapter 2,4). Sixtythree patient samples were analyzed by conventional $\mathrm{CGH}, 26$ by array $\mathrm{CGH}$, and 18 by both methods. In 16 out of these 18 cases, the results matched based on the criteria described above. In the two other cases $\mathrm{CIN}$ was detected by conventional $\mathrm{CGH}$, and 18 aberrations of at least $10 \mathrm{Mb}$ were detected by array $\mathrm{CGH}$. These cases were thus considered to have CIN. Also individual chromosomal alterations were evaluated for their predictive value with respect to metastatic disease or poor survival.

\subsubsection{CK19 and Ki67 immunohistochemistry}

CK19 and Ki67 antigen staining was performed on $4 \mu \mathrm{m}$ thick paraffin-embedded tissue sections as described previously (Chapter 2,4). Sections were pretreated with $10 \mathrm{mM}$ citrate buffer $(\mathrm{pH} \mathrm{6.0)}$ in a microwave oven at $600 \mathrm{~W}$ for $15 \mathrm{~min}$, and incubated with a mouse monoclonal antibody directed against Ki67 (MIB1, 1:100 dilution; DAKO, Glostrup, Denmark) or human CK19 (RCK108, 1:200 dilution, MUbio products BV, Maastricht, the Netherlands), respectively. The primary antibodies were detected by the avidin-biotinylated peroxidase complex protocol (ABC Elite kit, Vector laboratories, Burlingame, CA) and peroxidase activity was visualized using diaminobenzidine (DAB) / H2O2 (Sigma Chemical Co., St. Louis, $\mathrm{MO})$. The Ki-67 proliferative index was expressed as the percentage of tumor cells that were immunopositive. All tumor cases with cytoplasmic staining for RCK108 in $\geq 5 \%$ of tumor cells were considered CK19 positive.

\subsubsection{Statistical analysis}

For the statistical analyses of the clinical data SPSS software was used (SPSS 12.0.1 software, Chicago, IL, USA). The sensitivity and specificity of each factor for predicting the presence of metastatic disease were calculated. The relationship between different parameters was analyzed by using the chi-square or Fisher exact test, as appropriate. The level of significance was defined as $p \leq 0.05$. All factors with statistical significance in a univariate analysis were also included in subsequent multivariate analyses. Survival curves were calculated using the Kaplan-Meier method. The comparison between survival functions for the different factors was assessed with the log-rank statistic. 


\subsection{Results}

\subsubsection{Parameters to predict metastatic disease}

\section{Insulinomas}

We examined the reliability of different parameters to predict metastatic disease, including tumor size, Ki67 proliferative index, CK19 expression, CIN, and specific chromosomal aberrations. Table 5.1 shows that $\mathrm{CIN}$ turned out to be the most reliable indicator of metastatic disease with a sensitivity of $85 \%$, followed by $7 q$ gain and tumor size. Multivariate analysis showed that a combination of $\mathrm{CIN}$ and size or size and $6 q$ loss could increase the sensitivity to $92 \%$. A combination of $\mathrm{CIN}$ and Ki67 could even increase this sensitivity to $100 \%$.

\section{Other EPTs}

$\mathrm{CIN}$ also proved to be the only significant parameter to predict metastatic disease in the non-insulinoma EPTs (Table 5.1). Multivariate analysis showed an increase in sensitivity when combining CIN with Ki67 or CK19 expression, or when combining $3 p$ loss and $7 q$ or $14 q$ gain as markers. Because this tumor group predominantly comprises tumors with a diameter $\geq 2 \mathrm{~cm}$ at presentation, size cannot be used as a discriminative predictor for this purpose. 
Table 5.1. Strong parameters for prediction of metastatic disease in EPTs

\begin{tabular}{|c|c|c|c|c|c|}
\hline Insulinomas & Sensitivity ${ }^{1}$ & Specificity $^{2}$ & OR & $95 \% \mathrm{Cl}$ & $P$ value \\
\hline \multicolumn{6}{|l|}{ Univariate } \\
\hline Size $\geq 2 \mathrm{~cm}$ & $77 \%$ & $82 \%$ & 15.6 & 3.3-74.2 & 0.000 \\
\hline $\mathrm{Ki} 67 \geq 2 \%$ & $39 \%$ & $94 \%$ & 10.0 & $1.6-61.3$ & 0.012 \\
\hline CK19 & $17 \%$ & $100 \%$ & & & NS \\
\hline $\mathrm{CIN}$ & $85 \%$ & $77 \%$ & 17.9 & 3.3-98.1 & 0.000 \\
\hline $3 p$ loss & $46 \%$ & $91 \%$ & 8.9 & $1.8-44.3$ & 0.008 \\
\hline $6 q$ loss & $54 \%$ & $97 \%$ & 38.5 & $4.0-372.2$ & 0.000 \\
\hline $7 q$ gain & $85 \%$ & $68 \%$ & 11.5 & $2.2-61.0$ & 0.002 \\
\hline $12 q$ gain & $54 \%$ & $85 \%$ & 6.8 & $1.6-28.7$ & 0.010 \\
\hline $14 q$ gain & $62 \%$ & $88 \%$ & 12.0 & $2.6-55.3$ & 0.001 \\
\hline \multicolumn{6}{|l|}{ Multivariate } \\
\hline $\mathrm{CIN}$ and/or Ki67 $\geq 2 \%$ & $100 \%$ & $74 \%$ & n.a. & n.a. & 0.000 \\
\hline $\mathrm{CIN}$ and/or size $\geq 2 \mathrm{~cm}$ & $92 \%$ & $74 \%$ & 33.3 & $3.8-294.3$ & 0.000 \\
\hline Size $\geq 2 \mathrm{~cm}$ and/or $6 \mathrm{q}$ loss & $92 \%$ & $82 \%$ & 56.0 & $6.1-516.8$ & 0.000 \\
\hline \multicolumn{6}{|l|}{ EPTs excluding insulinomas } \\
\hline \multicolumn{6}{|l|}{ Univariate } \\
\hline Size $\geq 2 \mathrm{~cm}$ & $100 \%$ & $13 \%$ & & & NS \\
\hline $\mathrm{Ki} 67 \geq 2 \%$ & $53 \%$ & $83 \%$ & & & NS \\
\hline CK19 & $67 \%$ & $71 \%$ & & & NS \\
\hline $\mathrm{CIN}$ & $81 \%$ & $75 \%$ & 13.0 & $1.7-99.4$ & 0.021 \\
\hline $3 p$ loss & $81 \%$ & $63 \%$ & & & NS \\
\hline $6 q$ loss & $56 \%$ & $63 \%$ & & & NS \\
\hline $7 q$ gain & $56 \%$ & $75 \%$ & & & NS \\
\hline $12 q$ gain & $31 \%$ & $88 \%$ & & & NS \\
\hline $14 q$ gain & $50 \%$ & $88 \%$ & & & NS \\
\hline \multicolumn{6}{|l|}{ Multivariate } \\
\hline CIN and/or CK19 & $94 \%$ & $50 \%$ & 15.0 & $1.3-174.4$ & 0.028 \\
\hline $\mathrm{CIN}$ and/or Ki67 $\geq 2 \%$ & $88 \%$ & $63 \%$ & 11.7 & $1.5-91.5$ & 0.021 \\
\hline $3 p$ loss and/or $7 q / 14 q$ gain & $94 \%$ & $50 \%$ & 15.0 & $1.3-174.4$ & 0.028 \\
\hline
\end{tabular}

OR, Odds Ratio; $95 \%$ Cl, 95\% Confidence Interval

${ }^{1}$ Percent of the patients with metastases with the parameter

${ }^{2}$ Percent of the patients without metastases without the parameter 


\subsubsection{Parameters to predict poor survival}

\section{Insulinomas}

The association between the evaluated parameters and the clinical outcome of insulinomas is presented in Table 5.2. Tumor relapse or tumor-specific death occurs in a minority of patients with insulinomas, because of their early presentation usually followed by resection of the tumor. Four insulinoma patients died of disease and 3 were alive with disease. Nineteen patients showed CIN, including these 7 patients. Six out of 7 patients with an event had a size larger than $2 \mathrm{~cm}$ in diameter. Only 2 of these patients showed a Ki67 proliferative index of more than $2 \%$ or CK19 expression. Kaplan-Meier survival analysis underscored the power of $\mathrm{CIN}$ and size as significant markers for poor tumor-free survival in insulinomas, as shown in Table 5.3 and Fig. 5.1A and B. CK19 expression was also shown to be a significant indicator of poor tumor-free survival in insulinomas, although only 2 out of 6 insulinomas with an event (1 with tumor specific death and 1 with tumor relapse) showed a positive CK19 staining. None of the other insulinomas showed expression of CK19.

Also specific chromosomal alterations, including $3 p$ and $6 q$ loss, and $7 q, 12 q$, and $14 q$ gain were strong parameters for tumor relapse and / or tumor-specific death in these tumors. Fig. 5.1C shows the Kaplan-Meier curve for chromosome $6 \mathrm{q}$ loss as the most significant chromosomal marker for poor tumor-free survival. Furthermore, female patients had a significantly better tumor-specific and tumor-free survival compared to male patients ( $p=0.017$ and 0.014 , respectively), which is in line with the higher incidence of metastases in male versus female patients [20]. Multivariate analysis did not improve significance.

\section{Other EPTs}

Table 5.3 shows also the parameters for poor survival in the non-insulinoma EPT patients. CIN proved to be a reliable marker for poor tumor-free survival in these patients, followed by Ki67 proliferative index and chromosome 7q gain (Fig. 5.1D and E). CK19 was detected as the most significant marker for tumor-associated mortality, because of its positive staining in 6 out of 7 patients with tumor-specific death (Fig. 5.1F). 
Table 5.2. Correlation of prognostic parameters with clinical behavior in EPTs

\begin{tabular}{|c|c|c|c|c|}
\hline Type of tumor (n) & AW & DOD & AWD & DOC \\
\hline Insulinomas (47) & 40 & 4 & 3 & 0 \\
\hline Gastrinomas (6) & 3 & 1 & 2 & 0 \\
\hline Glucagonomas (2) & 0 & 2 & 0 & 0 \\
\hline Vipomas (5) & 1 & 2 & 1 & 1 \\
\hline Non-functioning (11) & 3 & 3 & 5 & 0 \\
\hline \multicolumn{5}{|l|}{ Parameter (n) } \\
\hline \multicolumn{5}{|l|}{ Insulinomas } \\
\hline \multicolumn{5}{|l|}{ CIN } \\
\hline present (19) & 12 & 4 & 3 & 0 \\
\hline absent (28) & 28 & 0 & 0 & 0 \\
\hline \multicolumn{5}{|l|}{ Size } \\
\hline$\geq 2 \mathrm{~cm} \mathrm{(16)}$ & 10 & 3 & 3 & 0 \\
\hline$<2 \mathrm{~cm}(31)$ & 30 & 1 & 0 & 0 \\
\hline \multicolumn{5}{|l|}{ Ki67 } \\
\hline$\geq 2 \%(7)$ & 5 & 1 & 1 & 0 \\
\hline$<2 \%(40)$ & 35 & 3 & 2 & 0 \\
\hline \multicolumn{5}{|l|}{ CK19 } \\
\hline positive (2) & 0 & 1 & 1 & 0 \\
\hline negative (26) & 22 & 2 & 2 & 0 \\
\hline
\end{tabular}

\begin{tabular}{|c|c|c|c|c|}
\hline \multicolumn{5}{|c|}{ EPTs excluding insulinomas } \\
\hline \multicolumn{5}{|l|}{ CIN } \\
\hline present (15) & 0 & 6 & 8 & 1 \\
\hline absent (9) & 7 & 2 & 0 & 0 \\
\hline \multicolumn{5}{|l|}{ Size } \\
\hline$\geq 2 \mathrm{~cm}(20)$ & 5 & 6 & 8 & 1 \\
\hline$<2 \mathrm{~cm}(1)$ & 1 & 0 & 0 & 0 \\
\hline \multicolumn{5}{|l|}{ Ki67 } \\
\hline$\geq 2 \%(9)$ & 1 & 4 & 3 & 1 \\
\hline$<2 \%(12)$ & 5 & 3 & 4 & 0 \\
\hline \multicolumn{5}{|l|}{ CK19 } \\
\hline positive (12) & 2 & 6 & 4 & 0 \\
\hline negative (10) & 5 & 1 & 3 & 1 \\
\hline
\end{tabular}

$\overline{A W}$, alive without disease; $D O D$, dead of disease; $A W D$, alive with disease; DOC, dead other cause 
Table 5.3. Significant parameters for tumor relapse (AWD) and tumor-specific death (DOD) in EPTs

\begin{tabular}{|c|c|c|c|}
\hline \multicolumn{4}{|c|}{ Insulinomas $(n=47)$} \\
\hline \multicolumn{2}{|c|}{ DOD $(n=4)$} & \multicolumn{2}{|c|}{ DOD + AWD (n=7) } \\
\hline Marker & $P$ value & Marker & $P$ value \\
\hline CIN & 0.0113 & $\mathrm{CIN}$ & 0.0004 \\
\hline $3 p$ loss & 0.0000 & CK19 & 0.0011 \\
\hline $6 q$ loss & 0.0009 & Size & 0.0017 \\
\hline $7 q$ gain & 0.0269 & $3 p$ loss & 0.0000 \\
\hline $12 q$ gain & 0.0003 & $6 q$ loss & 0.0000 \\
\hline \multirow[t]{3}{*}{$14 q$ gain } & 0.0003 & $7 q$ gain & 0.0013 \\
\hline & & $12 q$ gain & 0.0000 \\
\hline & & $14 q$ gain & 0.0013 \\
\hline \multicolumn{4}{|c|}{ EPTs excluding insulinomas $(n=24)$} \\
\hline \multicolumn{2}{|c|}{ DOD $(n=8)$} & \multicolumn{2}{|c|}{ DOD + AWD (n=16) } \\
\hline Marker & $P$ value & Marker & $P$ value \\
\hline CK19 & 0.0314 & CIN & 0.0012 \\
\hline \multirow[t]{2}{*}{$7 q$ gain } & 0.0497 & Ki67 & 0.0074 \\
\hline & & $7 q$ gain & 0.0181 \\
\hline
\end{tabular}

DOD, dead of disease; AWD, alive with disease

\subsection{Discussion}

In this study we have examined the value of several proposed indicators of malignancy and clinical outcome in a large group of insulinomas and non-insulinoma EPTs. These parameters include tumor size $\geq 2 \mathrm{~cm}$, Ki67 proliferative index of $\geq 2 \%$, CK19 expression, and chromosomal alterations, including CIN. CIN and specific chromosomal alterations turned out to be the most reliable indicators for metastatic disease and poor tumor-free survival in all EPTs, and for tumor-specific death in insulinomas. CK19 expression was not a strong prognostic indicator in insulinomas, but CK19 expression was the most optimal indicator of tumor-specific death in the other EPTs.

From previous studies, it has become clear that malignant progression of EPTs is associated with an accumulation of genetic alterations (Chapter 2,4) [14-15]. Although the underlying mechanism leading to $\mathrm{CIN}$ is yet unknown, we have shown here that this parameter can reliably predict clinical outcome in insulinomas, and also metastatic disease as described before (Chapter 2). CIN was defined as the presence of at least 8 chromosomal aberrations detected by conventional CGH or 20 aberrations of at least $10 \mathrm{Mb}$ detected by array CGH. Also several frequently occurring specific chromosomal aberrations, associated with CIN in insulinomas, were highly effective as prognostic indicators. In particular, loss of chromosome 
$3 p$ and $6 q$, and gain of $12 q$ proved to be very strong parameters for poor survival. This finding underscores previous results by molecular allelotyping providing evidence for association of metastatic progression with chromosome $3 p$ and $6 q$ loss in EPTs [21-26]. Amongst the putative candidate genes is FANCD2 which plays a role in the repair of DNA damage [27]. This gene is located on chromosome 3p25, a critical region of loss in EPTs [21]. One of the putative tumor suppressor genes on chromosome 6q24 is LOT1 (lost on transformation), a widely expressed zinc finger protein that inhibits cell growth through induction of apoptotic cell death and G1 arrest. It appears to be epigenetically silenced in different types of cancer, including parathyroid adenomas [28-29].

Large series of individual EPT subtypes other than insulinomas have so far not been studied for the occurrence of CIN. Rigaud et al. [25] examined a group of 16 non-functioning EPTs by flow cytometry and indicated aneuploidy and Ki67 proliferative index to be prognostic markers for this tumor subtype. In contrast, Chung et al. [30] could not identify a correlation between frequency of allelic loss and disease stage using genome-wide allelotyping, but this study was hampered by the small groups of individual EPT subtypes. In this study we were able to collect follow-up data of 24 non-insulinoma EPTs from which CGH data were available. CIN turned out to be the only significant indicator of metastatic disease and the highest independent predictor of poor tumor-free survival in this group. For the prediction of tumor-specific death, gain of chromosome $7 q$ and CK19 status were the most reliable markers. It will be essential to further substantiate these findings in larger numbers of individual EPT subtypes in subsequent studies. This is of particular importance, because genetic studies indicate differences in genetic make-up in the different EPT subtypes, despite the occurrence of CIN in the malignant tumors $[1,14]$.

As stated above, CK19 expression proved to be the most optimal marker for tumor-specific death in non-insulinoma EPTs. These data are in accordance with the data of Deshpande et al. [13] and a recent study by Schmitt et al. [31], investigating large series of EPTs, including different subtypes. Our data in this study, however, strongly indicate that CK19 expression is a sub-optimal marker for poor survival in insulinomas. This is probably the consequence of the low percentage of malignant tumors with CK19 immunostaining, as also reported by Ali et al. [10] and in one of our previous studies (Chapter 4). So far, only one study was unable to correlate CK19 expression with malignancy in EPTs [32]. A reason for the discrepancy between these studies could be the use of different CK19 directed monoclonal antibodies and / or criteria for evaluation of immunostaining results. We have used the RCK108 clone, which is used by most other studies and shown to be more reliable for CK19 analysis than the BA17 clone [33].

Of the clinico-pathological criteria used in the WHO classification, tumor size proved to be a very simple and reliable clinical marker for metastatic disease and poor tumor-free survival in insulinomas, in contrast to Ki67 proliferative index which is often $<2 \%$ in this tumor subtype. In combination with $\mathrm{CIN}$, however, Ki67 is very 
useful for predicting metastatic disease in insulinomas and both metastatic disease and poor tumor-free survival in non-insulinoma EPTs. In the latter group size can not be efficiently used to discriminate between benign and malignant tumors, because the tumor diameter is usually larger than $2 \mathrm{~cm}$, as also found in this study. Size $\geq 2 \mathrm{~cm}$, however, has been described as a predictable marker, because most studies consider EPTs as one group, with the smaller tumors being predominantly benign insulinomas and the larger ones generally comprising the non-insulinoma EPTs with a more malignant behavior [14, 34-35].

In summary, we have identified CIN, as well as specific chromosomal alterations as the most reliable indicators of metastatic disease and poor tumor-free survival in all EPTs, and for tumor-specific death in insulinomas. CK19 expression was the most optimal indicator of tumor-specific death in the non-insulinoma EPTs. Tumor size is particularly powerful as a predictor of malignancy in insulinomas. The implementation of these parameters in diagnostic protocols will make the prediction of the clinical behavior of EPTs more accurate. 
INSULINOMAS
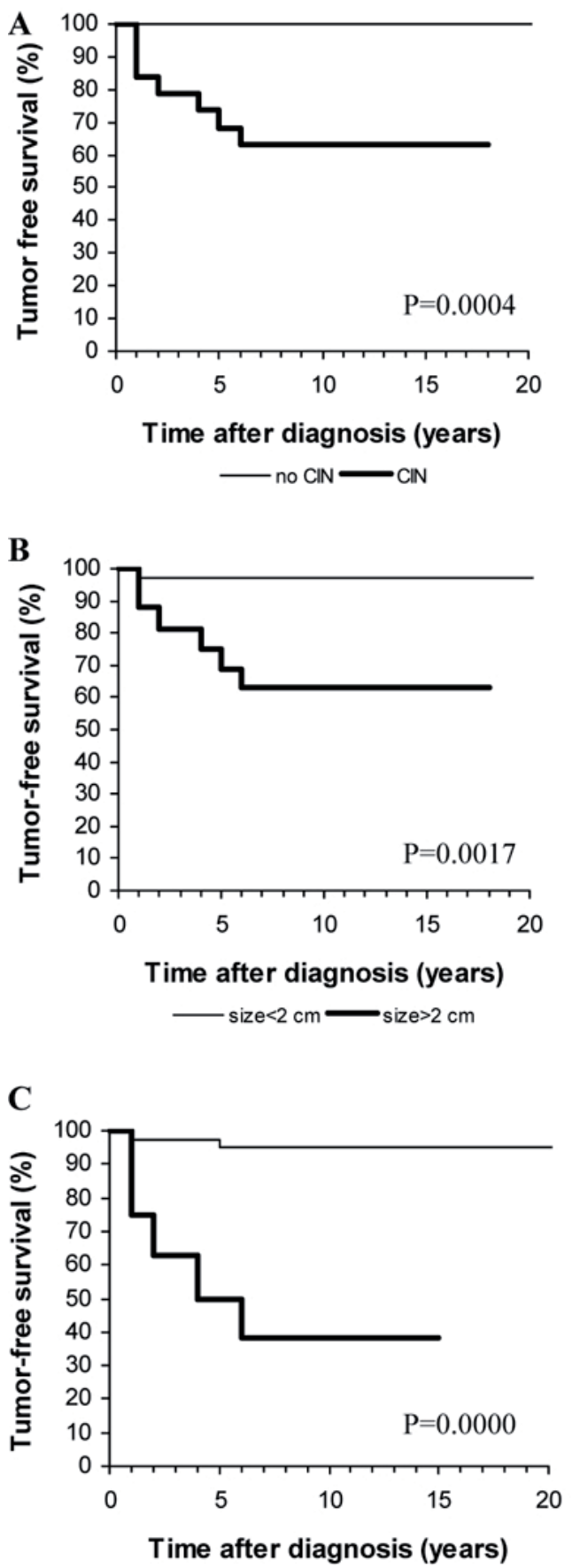
mor size (B), and chromosome $6 q$ loss (C). (D-F) Kaplan-Meier curves correlating tumor-free survival in the non-insulinoma EPTs with CIN (D) or chromosome 7q gain (E), and tumor-specific survival with CK19 (F). Significance scores are indicated. 


\subsection{References}

1. Heitz PU, Komminoth P, Perren A, Klimstra DS, Dayal Y. Tumours of the endocrine pancreas, in: DeLellis RA, Lloyd RV, Heitz PU, Eng C, editors. Pathology \& Genetics. Tumours of endocrine organs. Lyon: IARC Press; 2004, pp. 177-208.

2. Tomassetti P, Campana D, Piscitelli L, Casadei R, Santini D, Nori F, et al. Endocrine pancreatic tumors: factors correlated with survival. Ann. Oncol. 2005; 16: 1806-1810.

3. Heitz PU, von Herbay G, Klöppel G, Komminoth P, Kasper M, Höfler H, et al. The expression of subunits of human chorionic gonadotropin (hCG) by nontrophoblastic, nonendocrine, and endocrine tumors. Am. J. Clin. Pathol. 1987; 88: 467-472.

4. Graeme-Cook F, Bell DA, Flotte TJ, Preffer F, Pastel-Levy C, Nardi G, et al. Aneuploidy in pancreatic insulinomas does not predict malignancy. Cancer 1990; 66: 2365-2368.

5. Ohike N, Morohoshi T. Immunohistochemical analysis of cyclooxygenase (COX)-2 expression in pancreatic endocrine tumors: association with tumor progression and proliferation. Pathol. Int. 2001; 51: 770-777.

6. Guo SS, Wu X, Shimoide AT, Wong J, Sawicki MP. Anomalous overexpression of p27(Kip1) in sporadic pancreatic endocrine tumors. J. Surg. Res. 2001; 96: 284-288.

7. Canavese G, Azzoni C, Pizzi S, Corleto VD, Pasquali C, Davoli C, et al. P27: A potential main inhibitor of cell proliferation in digestive endocrine tumors but not a marker of benign behavior. Hum. Pathol. 2001; 32: 1094-1101.

8. Rahman A, Maitra A, Ashfaq R, Yeo CJ, Cameron JL, Hansel DE. Loss of p27 nuclear expression in a prognostically favorable subset of well-differentiated pancreatic endocrine neoplasms. Am. J. Clin. Pathol. 2003; 120:685-690.

9. Goto A, Niki T, Terado Y, Fukushima J, Fukayama M. Prevalence of CD99 protein expression in pancreatic endocrine tumors (PETs). Histopathology 2004; 45: 384-392.

10. Ali A, Serra S, Asa SL, Chetty R. The predictive value of CK19 and CD99 in pancreatic endocrine tumors. Am. J. Surg. Pathol. 2006; 30: 1588-1594.

11. Lee CS. Lack of p53 immunoreactivity in pancreatic endocrine tumors. Pathology 1996; 28: 139-141.

12. Pavelic K, Hrascan R, Kapitanovic S, Karapandza N, Vranes Z, Belicza M, et al. Multiple genetic alterations in malignant metastatic insulinomas. J. Pathol. 1995; 177: 395-400.

13. Deshpande V, Fernandez-del Castillo C, Muzikansky A, Deshpande A, Zukerberg L, Warshaw AL, et al. Cytokeratin 19 is a powerful predictor of survival in pancreatic endocrine tumors. Am. J. Surg. Pathol. 2004; 28: 1145-1153.

14. Speel EJM, Richter J, Moch H, Egenter C, Saremaslani P, Rutimann K, et al. Genetic differences in endocrine pancreatic tumor subtypes detected by comparative genomic hybridization. Am. J. Pathol. 1999; 155: 1787-1794.

15. Speel EJM, Scheidweiler AF, Zhao J, Matter C, Saremaslani P, Roth J, et al. Genetic evidence for early divergence of small functioning and nonfunctioning endocrine pancreatic tumors: gain of 9q34 is an early event in insulinomas. Cancer Res. 2001; 61: 5186-5192.

16. Zhao J, Moch H, Scheidweiler AF, Baer A, Schäffer AA, Speel EJM, et al. Genomic imbalances in the progression of endocrine pancreatic tumors. Genes Chromosomes Cancer 2001; 32: 364-372.

17. Kallioniemi A, Kallioniemi OP, Sudar D, Rutovitz D, Gray JW, Waldman F, et al. Comparative genomic hybridization for molecular cytogenetic analysis of solid tumors. Science 1992; 258: 818-821.

18. Davies JJ, Wilson IM, Lam WL. Array CGH technologies and their applications to cancer genomes. Chromosome Res. 2005; 13: 237-248.

19. Pinkel D, Albertson DG. Array comparative genomic hybridization and its applications in cancer. Nat. Genet. 2005; 37: 11-17.

20. Danforth DN, Gorden P, Brennan MF. Metastatic insulin-secreting carcinoma of the pancreas: clinical course and the role of surgery. Surgery 1984; 96: 1027-1037. 
21. Chung DC, Smith AP, Louis DN, Graeme-Cook F, Warshaw AL, Arnold AA. Novel pancreatic endocrine tumor suppressor gene locus on chromosome $3 p$ with clinical prognostic implications. J. Clin. Invest. 1997; 100: 404-410.

22. Hessman O, Lindberg D, Einarsson A, Lillhager P, Carling T, Grimelius L, et al. Genetic alterations on $3 p, 11 q 13$, and 18q in nonfamilial and MEN1-associated pancreatic endocrine tumors. Genes Chromosomes Cancer 1999; 26: 258-264.

23. Barghorn A, Komminoth P, Bachmann D, Rütimann K, Saremaslani P, Mulatta-Feurer S, et al. Deletion at 3p25.3-p23 is frequently encountered in endocrine pancreatic tumors and is associated with metastatic progression. J. Pathol. 2001; 94: 451-458.

24. Barghorn A, Speel EJM, Farspour B, Saremaslani P, Schmid S, Perren A, et al. Putative tumor suppressor loci at $6 \mathrm{q} 22$ and $6 \mathrm{q} 23-\mathrm{q} 24$ are involved in the malignant progression of sporadic endocrine pancreatic tumors. Am. J. Pathol. 2001; 158: 1903-1911.

25. Rigaud G, Missiaglia E, Moore PS, Zamboni G, Falconi M, Talamini G, et al. High resolution allelotype of nonfunctional pancreatic endocrine tumors: identification of two molecular subgroups with clinical implications. Cancer Res. 2001; 61: 285-292.

26. Guo SS, Arora C, Shimoide AT, Sawicki MP. Frequent deletion of chromosome 3 in malignant sporadic pancreatic endocrine tumors. Mol. Cell. Endocrinol. 2002; 190: 109-114.

27. Jin S, Mao H, Schnepp RW, Sykes SM, Silva AC, D'Andrea AD, et al. Menin associates with FANCD2, a protein involved in repair of DNA damage. Cancer Res. 2003; 63: 4204-4210.

28. Pagotto U, Arzberger T, Theodoropoulou M, Grubler Y, Pantaloni C, Saeger W, et al. The expression of the antiproliferative gene ZAC is lost or highly reduced in non-functioning pituitary adenomas. Cancer Res. 2000; 60: 6794-6799.

29. Abdollahi A, Pisarcik D, Roberts D, Weinstein J, Cairns P, Hamilton TC. LOT1 (PLAGL1/ZAC1), the candidate tumor suppressor gene at chromosome 6q24-25, is epigenetically regulated in cancer. J. Biol. Chem. 2003; 278: 6041-6049.

30. Chung DC, Brown SB, Graeme-Cook F, Tillotson LG, Warshaw AL, Jensen RT, et al. Localization of putative tumor suppressor loci by genome-wide allelotyping in human pancreatic endocrine tumors. Cancer Res. 1998; 58: 3706-3711.

31. Schmitt AM, Anlauf M, Rousson V, Schmid S, Kofler A, Riniker F, et al. WHO 2004 criteria and CK19 are reliable prognostic markers in pancreatic endocrine tumors. Am. J. Surg. Pathol. 2007 In press.

32. Albarello L, Capitanio V, Zerbi A, Di Carlo V, Doglioni C. Cytokeratin 19 expression in pancreatic endocrine tumors. J. Pancreas 2004; 6: 514.

33. La Rosa S, Bianchi V, Rigoli E, Uccella S, Capella C. The prognostic significance of cytokeratin 19 expression in pancreatic endocrine tumors (PETs). Virchows Arch. 2005; 447: 188.

34. Schindl M, Kaczirek K, Kaserer K, Niederle B. Is the new classification of neuroendocrine pancreatic tumors of clinical help? World J. Surg. 2000; 24: 1312-1318.

35. Ohike N, Morohoshi T. Pathological assessment of pancreatic endocrine tumors for metastatic potential and clinical prognosis. Endocr. Pathol. 2005; 16: 33-40. 


\section{CHAPTER 6}

\section{GENERAL DISCUSSION}

Adapted in part from:

Molecular alterations during insulinoma tumorigenesis

Yvonne M.H. Jonkers, Frans C.S. Ramaekers, Ernst-Jan M. Speel

Accepted for publication in BBA Reviews on Cancer 
The aim of the studies described in this thesis was to obtain a better understanding of the molecular processes underlying the development of insulinomas and to study molecular markers that can accurately predict progression and prognosis. In this chapter, the results from the previous chapters will be discussed further in the light of the current knowledge on this subtype of endocrine pancreatic tumors (EPTs). In addition, the candidate genes in endocrine pancreatic tumorigenesis, especially in insulinomas, as well as the prognostic markers that have been analyzed so far, will be considered.

\subsection{Deregulated cell signaling pathways in insulinomas}

In order to improve diagnosis, prognosis and therapy of insulinoma patients, it is important to increase our understanding of the molecular processes underlying tumor development and progression. During tumorigenesis in general the cell physiology is altered as a result of the accumulation of (epi)genetic alterations, leading to uncontrolled cell growth, tissue invasion and metastatic spread. The altered cellular phenotype may show the following characteristics: self-sufficiency in growth signals, insensitivity to growth-inhibitory signals, evasion of programmed cell death (apoptosis), unlimited replicative potential, sustained angiogenesis, and tissue invasion and metastases [1]. We will now consider the current knowledge on these features in insulinomas, and combine these data with our (array) CGH data to indicate specific genes of interest involved in the pathogenesis of these tumors (Fig. 6.1 and Table 6.1).

\subsubsection{The role of the MEN1 gene in insulinoma tumorigenesis}

The MEN1 gene was the first gene that has been described as a candidate gene in insulinoma tumorigenesis. We have studied a group of 43 sporadic insulinomas for MEN1 mutations, and identified only one patient carrying a tumor with a mutation (Chapter 2) in which the wild type allele was also lost. This finding is in agreement with other studies suggesting a minor role for MEN1 inactivation by mutation in human sporadic insulinomas [2-6]. However, other mechanisms of gene inactivation may be involved in insulinoma development. Promoter hypermethylation of the MEN1 gene has not been detected so far in EPTs, although only one insulinoma was investigated [7]. Menin, the 610-amino acid protein encoded by MEN1, has been found to partner in vitro with a variety of proteins that comprise transcription factors, DNA processing factors, DNA repair proteins, and cytoskeletal proteins (Fig. 6.1). The diverse functions of menin interactors suggest roles for these proteins in multiple biological pathways [8-9]. FANCD2 is such an interactor of menin, playing a role in the repair of DNA damage [10]. Previously, an increase in the frequency of spontaneous chromosomal alterations has been observed in MEN1 pancreatic tumors, indicating that MEN1 EPTs fail to maintain DNA integrity and demonstrate signs of chromosomal instability [11-12]. We have also observed by array $\mathrm{CGH}$ that tumors of MEN1 patients often show high numbers of chromo- 
somal alterations, already at a benign stage. It is tempting to speculate that this is the result of inactive FANCD2, located on chromosome 3p25, a region which has been found frequently deleted in malignant EPTs, including insulinomas (Table 6.1) [13].

Another role of menin is the maintaining of the (in vivo) expression of cyclin-dependent kinase (CDK) inhibitors by histone methylation to prevent pancreatic islet tumor development [14]. In vivo expression of CDK inhibitors, including p27 and p18, and other cell cycle regulators is disrupted in mouse islet tumors lacking menin, leading to accelerated S-phase entry and enhanced cell proliferation in pancreatic islets [15]. Double knock-out mice for both p18 and p27 develop pancreatic islet hyperplasia and other endocrine tumors resembling those observed in the MEN1 syndrome, including anterior pituitary adenoma, adrenal tumors, and parathyroid lesions [16]. Chromatin immunoprecipitation studies reveal that menin directly associates with regions of the p27 and p18 promoters, and increases methylation of lysine 4 (Lys-4) in histone $\mathrm{H} 3$ associated with these promoters. Moreover, $\mathrm{H} 3$ Lys-4 methylation associated with p27 and p18 is reduced in islet tumors from MEN1 mutant mice [14]. Thus, H3 Lys-4 methylation seems to be an important mechanism in islet tumor suppression and needs to be further investigated. Pellegata et al. [17] have recently reported a mutation in the p27 gene in a MEN1 mutant-negative patient presenting with pituitary and parathyroid tumors. Expanded pedigree analysis showed that the mutation was associated with the development of a MEN1-like phenotype in multiple generations. This finding demonstrates that mutations in p27 can also predispose to the development of endocrine tumors [17]. Mutations of p27, however, have yet to be analyzed in sporadic EPTs.

Additional mechanisms suggested for tumorigenesis induced by menin inactivation include: (1) functional stimulation of the activator of S-phase kinase, an essential component of protein kinase complex cdc7/activator of S-phase kinase that is required for S-phase entry [18], (2) switching its JunD partner from a downstream action of growth suppression to growth promotion [9], (3) p65- or PMA (phorbol 12-myristate 13-acetate)- mediated transcriptional activation of NFKB, which leads to inhibition of apoptosis, and stimulation of cell growth [19], (4) activation of telomerase [20], and (5) neutralizing cell growth inhibition through SMAD3 [21], although SMAD3 gene mutations have not been detected in EPTs [22].

The human endocrine pancreatic cell line BON1 does not show menin expression despite the absence of a MEN1 mutation. Genes regulated by menin overexpression have been identified by cDNA macroarray analysis of this cell line transfected with the MEN1 gene [23]. JunD was upregulated by menin overexpression, whereas dlk1/Pref-1 (involved in the differentiation and growth of endocrine pancreatic cells and expressed in neuroendocrine tumors), PCNA (proliferating cell nuclear antigen), and QM/Jif-1 (a negative regulator of C-Jun) were down-regulated in the menin-overexpressing BON1 cells. These genes may be important in mediating to menin its tumor suppressor effect, and increasing our understanding of the tissuespecific predominance of neoplasia seen in MEN1. 
Although we and others have shown that inactivation by mutation only occurs rarely in sporadic insulinomas, a role for hypermethylation of MEN1 has to be investigated in more detail. Studies should focus on the presence of molecular alterations of menin interacting proteins that may mimic the effect of menin inactivation (Fig. 6.1).

\subsubsection{Self-sufficiency in growth signals}

Cell cycle deregulation is one of the defining features of cancer. CDK4, together with its regulatory subunit cyclin $D$, governs cell cycle progression through the G1 phase. In particular, deregulation of the cyclin D / CDK4 complex has been observed in a variety of human cancers. This complex has also been described as an essential regulator of Langerhans islet $\beta$-cell proliferation. Knock-in mice with a homozygous CDK4 mutation develop multiple neoplasia, most commonly endocrine tumors, including benign insulinomas [24]. However, CDK4 mutations have not been detected in human sporadic insulinomas, while CDK4 protein expression was detected in all 14 (11 benign, 3 malignant) insulinomas studied by immunohistochemistry and Western blotting. A significantly altered expression compared to normal pancreatic tissue could not be detected [25], which suggests no evident deregulation of CDK4 expression in human insulinomas. In contrast, overexpression of cyclin D1 has been observed already in benign EPTs, including 36\% of insulinomas, when compared to normal pancreatic islets, suggesting that this oncogene is involved in the tumorigenesis of at least a subgroup of insulinomas [26].

The Akt1 gene has also been described to induce $\beta$-cell proliferation in a CDK4 dependent manner by increasing cyclin D1 and cyclin D2 levels [27]. Akt1 is a convergent kinase of several growth signals induced by amongst others growth factors, insulin, and gut incretins. Transgenic mice overexpressing a constitutively active form of Akt 1 in islet $\beta$-cells have provided evidence for the role of this kinase in islet physiology, because they exhibit striking increases in $\beta$-cell mass, proliferation, cell size, and malignant tumor formation [27-28]. The Akt1 gene is located on chromosome $14 q 32$, a region that we have often found to be gained in insulinomas of malignant behavior, which underscores the possibility of its involvement in insulinoma progression (Chapters 2 and 3) [29].

One of the growth factor receptors that seem to trigger the PI3K/Akt pathway is the insulin-like growth factor receptor (IGF-R). Insulin-like growth factor (IGF) 1 and 2 bind to IGF-R type 1 or 2, respectively, and have been indicated to play a role in EPTs. A RT-PCR study on several components of the IGF system showed differences in mRNA expression within the various tumor subtypes, and accumulation of IGF binding protein 2 (IGFBP2) transcripts in all tumors. In insulinomas IGF1 was expressed in seven out of ten and IGF-1R in nine out of ten tumors, thus suggesting a prominent role in growth promotion [30]. Further indications for a role of IGF signaling in neuroendocrine tumorigenesis come from studies using the BON1 cell line [31] as well as mouse studies using menin-null cells showing upregulation of IGFBP2 [32]. 
The past several years, studies have focused on the gastrointestinal hormone ghrelin, that promotes cell growth of amongst others pancreatic $\beta$-cells through mediation of a number of pathways, including the PI3K/Akt, cAMP/PKA, and ERK1/2 signalling pathways [33-36]. Moreover, it counteracts apoptosis induced by serum starvation and / or cytokine synergism in either $\beta$-cells or human islets of Langerhans. Ghrelin expression has been found in three out of six and six out of 14 insulinomas, but also to be expressed in normal pancreatic islets, restricted to the $\beta$-cells [37-38]. Thus, ghrelin might be promoting growth in a subset of tumors.

An indication for involvement of the Ras signaling pathway came from studies showing $\mathrm{K}$-ras mutations in insulinomas, BRAF overexpression in EPTs, and ERK activation in the endocrine pancreatic cell lines MIN6 and BON1 [39-42]. However, a prominent role for Ras mutations could not be proved by others [43-44]. In addition, so far no mutations in the BRAF gene have been found [45-46]. We recently were able to detect BRAF expression in insulinomas, but also in the normal pancreatic islets (results not shown). Expression of pERK could be detected in only $11 \%$ of human sporadic insulinomas (our unpublished observation), excluding a prominent role for this signaling pathway in insulinoma tumorigenesis.

A gene expression profiling study described the guanine nucleotide binding protein alpha subunit (GNAS) gene as the most highly expressed gene in insulinomas compared to normal pancreatic tissue, with a three-fold increase in expression over that of normal human islet cells [47]. It is well established that activating mutations of the gene encoding GNAS can stimulate proliferation of endocrine cells and are involved in the pathogenesis of several tumors, such as growth-hormonesecreting pituitary adenomas, thyroid adenomas, and differentiated thyroid adenocarcinomas [48-50]. The underlying mechanism of this upregulation is unknown and until now no mutations in the GNAS gene have been identified in human insulinomas [51-52].

Transforming growth factor $\alpha$ (TGF $\alpha$ ) has previously been described to be associated with the development of insulinomas. Immunohistochemistry showed expression of TGFa already in benign tumors, and enhanced expression in malignant insulinomas [53]. TGFa secreted by tumor cells can bind to the epidermal growth factor receptor (EGFR), leading to an autocrine activation of the Ras signaling pathway and putatively to its oncogenic activity [54-55]. In addition, overexpression of EGFR and phosphorylated EGFR as determined by immunohistochemistry has been identified in approximately $25 \%$ of primary and metastatic EPTs $(n=40)$, although a subtype classification has not been indicated [56]. EGFR is located on chromosome $7 \mathrm{p} 12$, gained in $8 \%$ of benign versus $89 \%$ of malignant insulinomas, as revealed by array CGH (Table 6.1). It is tempting to speculate that EGFR is involved in malignant progression of insulinomas, although the involvement of the downstream signaling pathway in this respect is unclear.

Our CGH studies described in Chapter 2 and 3 revealed that gain of chromosome $9 q$ is one of the earliest aberrations in insulinoma development, because it is already detected in small benign insulinomas (see also [57]). FISH analysis showed 
multiple copies of the cAbl gene at chromosome $9 q 34$ in $60 \%$ of tumors, including amplification in 2 cases. In chronic myeloid leukemia, the cAbl tyrosine kinase gene is a proto-oncogene with growth-promoting activity as a result of its translocation to the BCR gene on chromosome 22q11 [58]. Overexpression of cAbl has also been detected in two rat insulinoma cell lines [59]. By means of RT-PCR and immunohistochemistry on a series of 30 insulinomas, we found overexpression of cAbl in insulinoma cells compared to normal islet cells in $24 \%$ of benign and $30 \%$ of malignant tumors, suggesting an early role for cAbl in a subgroup of insulinomas (Fig. 6.2A, p.122, Table 6.1). Because overexpression was not only detected in tumors with $9 q$ gain, a translocation of cAbl may be indicated, which remains to be determined.

In conclusion, several proteins, including cyclin D1, Akt1, ghrelin, GNAS, TGF $\alpha$, and cAbl have been suggested to stimulate cell proliferation in insulinomas, although their individual roles in insulinoma tumorigenesis still remain elusive.

\subsubsection{Insensitivity to anti-growth signals}

Within a normal tissue, multiple anti-proliferative signals operate to maintain cellular quiescence and tissue homeostasis. Cancer cells must evade these antiproliferative signals if they are to prosper. Cells monitor their external environment during the G1 phase of the growth cycle, and on basis of sensed signals decide whether to proliferate or to remain quiescent. At the molecular level, many anti-proliferative routes are controlled by the retinoblastoma protein $(p R b)$. In tumors with $\mathrm{pRb}$ inactivation as the basis of pathology somatic loss of one $R b$ allele commonly accompanies a point mutation or micro-deletion of the other allele. Deletion of the $R b$ gene has so far been detected in only one single human insulinoma tested by blot hybridization [60], while in a large series of EPTs, including insulinomas, no allelic loss of $R b$ was detected, suggesting that $R b$ gene deletion or mutation is only seldomly involved in the pathogenesis of EPTs [61]. Another mechanism of inactivation of $\mathrm{pRb}$ is phosphorylation. When in a hypophosphorylated state, $\mathrm{pRb}$ tightly binds to the transcription factor E2F, inhibiting its activity. Phosphorylated $\mathrm{pRb}$ dissociates from $\mathrm{E} 2 \mathrm{~F}$, which is then free to initiate DNA transcription. This phosphorylation can be carried out by the Cyclin D1 / CDK4 complex or by cAbl [62-63] which are indicated as insulinoma promoting factors. Therefore, $R b$ mutations may not be strictly required in the initiation of this EPT subtype.

The CDKN2 locus on chromosome 9p21 harbors tumor suppressor genes which restrain cell growth by affecting the function of $\mathrm{pRb}$ and $\mathrm{p} 53$. The CDKN2A gene coding for p16 was found to be homozygously deleted in five out of 12 EPTs (gastrinomas and non-functioning) and methylated in seven out of 12 , but no mutations were identified [64]. In contrast, Bartsch et al. [65] detected a homozygous deletion of p16 in only one malignant insulinoma, aberrant methylation in two benign insulinomas, and no mutations in 17 insulinomas studied. In our array CGH studies we did not detect deletions of this locus in 27 insulinomas (Chapter 3). At the protein level we observed no immunostaining of p16 in eight out of nine benign, 
and five out of six malignant tumors, whereas normal pancreatic islets showed a strong expression of p16 (Fig. 6.2B, p.122). This finding is in agreement with the study of Tomita et al. [66] who also detected a decrease in p16 immunostaining in insulinomas. Downregulation of expression of CDKN2A/p16, CDKN2B/p15, and CDKN2D/p14 was analyzed by RT-PCR in EPTs, including ten insulinomas (nine benign and one malignant). Absence of expression of p15 was detected in $33 \%$ of the benign insulinomas [67]. Thus, despite a low frequency of alterations in the p16 gene, downregulation of the p16 protein is likely to be involved in insulinoma tumorigenesis which should be the focus of future studies. The high level of p16 in normal pancreatic islets may participate in the growth arrest that limits cell proliferation, since recent evidence indicates that differentiated $\beta$-cells can divide [68]. Two other inhibitors of CDKs, i.e. p21 and p27, have also been investigated in EPTs. One study, including 17 insulinomas, reported a high expression of p21 in insulinomas compared to the other EPTs studied [69]. P27 was expressed in $88 \%$ of insulinomas, including the malignant tumors, but was also expressed in normal pancreatic islet cells. In contrast, Schmitt et al. [70] recently detected a high expression of p27 in only $30 \%$ of insulinomas. The strong expression of p21 and p27 may explain the slow growth in a subset of tumors and suggests differences in tumorigenesis between MEN1-associated and sporadic insulinomas [71].

The Raf-1 kinase inhibitory protein (RKIP) binds to Raf-1 and MEK in vivo and in vitro, thus interfering with the activation of the ERK signaling pathway, and plays an important role in the inhibition of $\beta$-cell proliferation. Expression of RKIP was determined in nine insulinomas, showing absence of expression in eight and decreased expression in one tumor, in comparison with normal islet cells [72]. This suggests a role for RKIP in tumorigenesis. However, as a consequence, pERK expression should be present, which was not analyzed for in this study. As mentioned above, we showed pERK expression only in incidental cases.

PTEN (phosphatase with tensin homology) is a potent negative regulator of the $\mathrm{PI} 3 \mathrm{~K} /$ Akt signaling pathway [73]. The PTEN gene is located on chromosome 10q23, a region which is often lost in malignant insulinomas, as determined by array $\mathrm{CGH}$ (chapter 4). Efficient PTEN deletion in mouse $\beta$-cells by the Cre/loxP knock-out system led to increased islet cell mass. PTEN was therefore suggested to play an integrative role in regulating growth and metabolism in vivo [74]. Perren et al. [75] analyzed a group of sporadic EPTs for this gene and found loss of heterozygosity in three out of four malignant insulinomas, but not in the 12 benign insulinomas studied. None of these tumors had a mutated PTEN gene. The 11 insulinomas studied by immunohistochemistry all showed strong expression of PTEN. Although normal islet cells always exhibit predominantly nuclear PTEN immunostaining, the insulinomas showed a predominantly cytoplasmic PTEN staining pattern. Thus, intragenic mutation of PTEN is not involved in insulinomas, but loss of PTEN seems to be associated with malignancy of insulinomas. Furthermore, an impaired transport system of PTEN to the nucleus or some other means of differential compartmentalization could also account for impaired PTEN function. 
In conclusion, evading anti-proliferative signals, for example through inactivation of pRb, p15, p16, and/or PTEN, may be an important feature in insulinoma development.

\subsubsection{Evading apoptosis}

The ability of tumor cell populations to expand is not only determined by the rate of cell proliferation but also by the rate of cell death. Acquired resistance toward programmed cell death (apoptosis) is a hallmark of most types of cancer [1].

The effect of deregulated c-Myc expression on adult $\beta$-cells in vivo has recently been investigated by developing transgenic mouse models in which the activity of c-Myc can be regulated ectopically. Co-expression of Bcl-XL and c-Myc has been demonstrated to induce highly malignant $\beta$-cell tumors in this mouse model, suggesting that early suppression of apoptosis is essential for the survival of Myc-activated $\beta$-cells and islet neoplasia [76]. Although c-Myc activation initially promotes both proliferation and apoptosis, cell death is the predominant outcome, giving rise to islet involution. Wang et al. [77] studied the role of c-Myc by immunoreactivity and detected its expression in all 11 benign insulinomas studied, but also in normal pancreatic tissue, including a weak immunoreactivity in the cytoplasm of cells of the islets of Langerhans. One study showed a stronger immunoreaction for c-Myc in three malignant insulinomas compared to the benign tumors [40]. It is obvious that more insulinomas need to be examined to further substantiate a possible role for C-Myc and Bcl-XL in tumor progression.

The protein product of the $\mathrm{Bcl}-2$ oncogene, a family member of $\mathrm{Bcl}-\mathrm{XL}$, blocks apoptosis without affecting cell proliferation [78]. Bcl-2 is frequently expressed in gastroenteropancreatic neuroendocrine tumors, which are usually slow-growing and less aggressive tumors, suggesting that in these tumors Bcl-2 expression leads to indolent tumor growth. Increased expression of the Bcl-2 protein in comparison with normal pancreatic tissue has been reported in four out of 11 human insulinomas [77], suggesting that suppression of apoptosis may contribute to the initiation of these tumors.

Survivin, a member of another family of apoptosis inhibitors, is a bifunctional protein that can suppress apoptosis and regulate cell division. This protein has been suggested to be of prognostic value in gastroenteropancreatic neuroendocrine tumors [79]. The gene encoding this protein, BIRC5, is located on chromosome $17 q 25$, a region gained in one third of malignant insulinomas versus none of the benign insulinomas (Chapter 4). Modulation of apoptosis is also one of the biological activities of the $\mathrm{p} 53$ protein, which transcriptionally activates the cell death promoting factor Bax or death factor Fas [80-81]. Wild-type p53 is also involved in the mediation of c-Myc induced apoptosis [82]. We have found only one malignant insulinoma with a TP53 mutation out of 22 tumors studied (Chapter 4), which suggests that TP53 gene mutations are only involved in individual progressive insulinoma cases.

The TP73 gene, however, which encodes a protein with significant amino-acid 
sequence and functional similarity to p53 [83], might be an interesting candidate for insulinoma progression. It is located on chromosome $1 \mathrm{p} 36$, a region which is deleted in $44 \%$ of malignant insulinomas (Chapter 3 ) and associated with metastatic disease [84].

In conclusion, because of the overall low proliferation rate in insulinomas, it is tempting to speculate that instead of increased proliferation, evasion of apoptosis is an important mechanism in insulinoma progression. This can occur by activation of anti-apoptotic proteins, such as $\mathrm{Bcl} 2$, BclXL, or BIRC5, or by inactivation of proapoptotic proteins, such as p53 or p73. Other putative candidate proteins are the pro-apoptotic BRCC2 protein, whose gene-locus at 11q24 is often deleted in malignant insulinomas (Chapter 3), and the anti-apoptotic protein NOTCH1 on 9q34.

\subsubsection{Unrestricted replicative potential}

Many mammalian cells carry a cell-autonomous program that limits their multiplication. This program operates independently of the cell-to-cell signaling pathways. It must be disrupted in order for a clone of cells to expand to a size that becomes lifethreatening. Replicative generations are counted by the $50-100$ basepair loss of telomeric DNA from the end of every chromosome during each cell cycle. The progressive erosion of telomeres through successive cycles of replication eventually causes them to lose their ability to protect the ends of chromosomal DNA. These unprotected ends may participate in end-to-end chromosomal fusions, which are lethal to cells. Telomere maintenance is evident in virtually all types of malignant cells. For this purpose the malignant cells up-regulate the expression of the telomerase enzyme, which adds hexanucleotide repeats onto the ends of telomeric DNA [85]. Also stem cells do have a high telomerase activity. Because pancreatic stem cells are suggested as the clonal origin of insulinomas, telomerase activity may be expected in these tumors. However, in 13 benign insulinomas studied by using the telomeric repeat amplification protocol, no telomerase activity was detectable [86]. This is in agreement with Lam et al [87], who detected no telomerase activity in seven sporadic benign insulinomas. They did detect telomerase activity in the only malignant insulinoma studied and in one MEN1-associated insulinoma [87]. Recently it has been shown that menin is a repressor of telomerase activity through the telomerase gene TERT in human fibroblasts [88]. This may suggest a role for telomerase activity in insulinomas of MEN1 patients, which has not been described so far. By array CGH we have previously shown that telomeric loss is associated with malignant behavior of insulinomas. Telomeric losses were detected in $27 \%$ of benign tumors, $88 \%$ of tumors with uncertain behavior and $86 \%$ of malignant tumors. In insulinomas with uncertain behavior telomeric losses were more frequently observed than CIN (chapter 4). This suggests that telomeric loss occurs prior to and is causative for $\mathrm{CIN}$ during insulinoma tumorigenesis. These data indicate that escape from replicative senescence, which is expected to occur as a result of telomeric loss, is the basis for tumor progression. It is tempting to speculate that the down-regulation of $\mathrm{p} 16$, as described above, may play an im- 
portant role in this process. Moreover, our array CGH results showed gain of chromosome 5p15.33, the region harboring the TERT gene, in malignant tumors of two patients that died from metastatic disease within two years. This suggests an important role for telomerase activity in insulinomas with poor prognosis, although an association between gain or amplification of TERT and induction of telomerase activity remains to be determined.

In summary, telomerase activity does not seem to play an important role in early insulinoma development. Telomeric loss and $\mathrm{CIN}$ accumulate during tumor progression. It is tempting to speculate that p16 downregulation and induction of telomerase activity in addition ensure unrestricted replicative potential. Inactivation of menin may trigger activation of telomerase earlier in tumor development.

\subsubsection{Sustained angiogenesis}

Tumorigenesis in general is critically dependent on the development of a vascular supply. The regulators of neo-angiogenesis have been shown to play a coordinated role in the progression of a variety of tumors. The fact that endocrine tumors are highly vascular in nature renders analysis of angiogenesis as a prognostic factor highly pertinent. However, in contrast to other cancers, a high micro-vessel density in EPTs was found to correlate with previously established markers of good prognosis as well as with hormone production [89].

Although EPT cells overproduce the angiogenic peptide vascular endothelial growth factor (VEGF), which is likely to play an important role in the angiogenic process associated with endocrine tumorigenesis, they seem to loose this expression during tumor progression. In addition, there is a low angiogenic activity, shown by a low endothelial proliferation index [90]. VEGF is a key target gene of the SMAD4 / DPC4 (deleted in pancreatic carcinoma) protein. SMAD4 influences angiogenesis by decreasing the expression of VEGF [91]. Mutations in the SMAD4 gene, however, have not been detected in insulinomas and other EPTs [92-93].

In conclusion, although activation of angiogenesis is not indicated in tumor progression, it will be necessary to study additional angiogenic factors that may substitute loss of blood supply in insulinomas. 
Table 6.1. Candidate genes for insulinoma tumorigenesis

\begin{tabular}{|c|c|c|c|c|c|}
\hline Gene symbol & Gene name & Chr. ${ }^{1}$ & Function & Ref. $^{2}$ & $\begin{array}{l}\text { Array } \\
\text { CGH } \\
\text { result }^{3}\end{array}$ \\
\hline \multicolumn{6}{|c|}{ Cell cycle progression } \\
\hline K-Ras & Kirsten Ras oncogene & $12 \mathrm{p} 12$ & $\begin{array}{l}\text { Control of cell cycle } \\
\text { progression }\end{array}$ & 40 & $\begin{array}{l}\text { Gain UB, } \\
\text { M }\end{array}$ \\
\hline ASK & S-phase kinase & $7 q 21$ & S-phase entry & 18 & Gain M \\
\hline CDKN1A/p21 & $\begin{array}{l}\text { Cyclin-dependent } \\
\text { kinase inhibitor } 1 \mathrm{~A}\end{array}$ & $6 p 21$ & $\begin{array}{l}\text { Inhibition of cell cycle } \\
\text { progression }\end{array}$ & 69 & Loss M \\
\hline CDKN1B/p27 & $\begin{array}{l}\text { Cyclin-dependent } \\
\text { kinase inhibitor1B }\end{array}$ & $12 \mathrm{p} 13$ & $\begin{array}{l}\text { Inhibition of cell cycle } \\
\text { progression }\end{array}$ & $\begin{array}{l}14-15 \\
69\end{array}$ & $\begin{array}{l}\text { Gain UB, } \\
\text { M }\end{array}$ \\
\hline CDKN2A/p16 & $\begin{array}{l}\text { Cyclin-dependent } \\
\text { kinase inhibitor } 2 \mathrm{~A}\end{array}$ & $9 p 21$ & $\begin{array}{l}\text { Inhibition of cell cycle } \\
\text { progression }\end{array}$ & $65-67$ & $\begin{array}{l}\text { No } \\
\text { changes }\end{array}$ \\
\hline CDKN2B/p15 & $\begin{array}{l}\text { Cyclin-dependent } \\
\text { kinase inhibitor 2B }\end{array}$ & $9 p 21$ & $\begin{array}{l}\text { Inhibition of cell cycle } \\
\text { progression }\end{array}$ & 67 & $\begin{array}{l}\text { No } \\
\text { changes }\end{array}$ \\
\hline CDKN2C/p18 & $\begin{array}{l}\text { Cyclin-dependent } \\
\text { kinase inhibitor } 2 \mathrm{C}\end{array}$ & $1 \mathrm{p} 32$ & $\begin{array}{l}\text { Inhibition of cell cycle } \\
\text { progression }\end{array}$ & $14-15$ & $\begin{array}{l}\text { No } \\
\text { changes }\end{array}$ \\
\hline CCND1 & Cyclin D1 & $11 q 13$ & $\begin{array}{l}\text { Control of the cell cycle } \\
\text { at the } \mathrm{G} 1 / \mathrm{S} \text { transition }\end{array}$ & 26,114 & $\begin{array}{l}\text { No } \\
\text { changes }\end{array}$ \\
\hline \multicolumn{6}{|c|}{ Proliferation / Transcription } \\
\hline Dlk1/Pref1 & Delta like 1 & $14 q 32$ & Regulator of proliferation & 23 & $\begin{array}{l}\text { Gain UB, } \\
\text { M }\end{array}$ \\
\hline Akt1 & $\begin{array}{l}\text { v-akt murine thymoma } \\
\text { viral oncogene homo- } \\
\text { log } 1\end{array}$ & $14 q 32$ & Regulator of proliferation & 27 & $\begin{array}{l}\text { Gain UB, } \\
M\end{array}$ \\
\hline GNAS & $\begin{array}{l}\text { Guanine nucleotide } \\
\text { binding protein } \alpha \\
\text { subunit }\end{array}$ & $20 q 13$ & Regulator of proliferation & 47 & $\begin{array}{l}\text { No } \\
\text { changes }\end{array}$ \\
\hline PCNA & $\begin{array}{l}\text { Proliferating cell } \\
\text { nuclear antigen }\end{array}$ & 20p12 & Replication & 23 & $\begin{array}{l}\text { Gain UB, } \\
M\end{array}$ \\
\hline TGF $\alpha$ & $\begin{array}{l}\text { Transforming growth } \\
\text { factor } \alpha\end{array}$ & $2 \mathrm{p} 13$ & Growth factor & $54-55$ & $\begin{array}{l}\text { No } \\
\text { changes }\end{array}$ \\
\hline EGFR & $\begin{array}{l}\text { Epidermal growth fac- } \\
\text { tor receptor }\end{array}$ & $7 p 11$ & Growth factor receptor & $54-55$ & Gain M \\
\hline Abl & $\begin{array}{l}\text { v-Abl Abelson murine } \\
\text { leukemia viral onco- } \\
\text { gene }\end{array}$ & $9 q 34$ & $\begin{array}{l}\text { Tyrosine kinase. proto- } \\
\text { oncogene }\end{array}$ & 59 & $\begin{array}{l}\text { Gain B, } \\
\text { UB, M }\end{array}$ \\
\hline TSC1 & Tuberous sclerosis 1 & $9 q 34$ & $\begin{array}{l}\text { Anti-proliferative, tumor } \\
\text { suppressor }\end{array}$ & 133 & $\begin{array}{l}\text { Gain B, } \\
\text { UB, M }\end{array}$ \\
\hline QM/Jif1 & Jun-interacting factor 1 & Xq28 & $\begin{array}{l}\text { Jun binding gene, tumor } \\
\text { suppressor gene }\end{array}$ & 23 & $\begin{array}{l}\text { Loss B, } \\
\text { UB, M }\end{array}$ \\
\hline $\mathrm{Rb}$ & Retinoblastoma & $13 q 14$ & $\begin{array}{l}\text { Tumor suppressor gene, } \\
\text { regulator of other genes }\end{array}$ & $\begin{array}{l}60-61 \\
134\end{array}$ & $\begin{array}{l}\text { No } \\
\text { changes }\end{array}$ \\
\hline
\end{tabular}




\begin{tabular}{|c|c|c|c|c|c|}
\hline PTEN & $\begin{array}{l}\text { Phosphatase and ten- } \\
\text { sin homolog }\end{array}$ & $10 q 23$ & $\begin{array}{l}\text { Tumor suppressor gene, } \\
\text { involved in regulation } \\
\text { of the Akt1 signaling } \\
\text { pathway }\end{array}$ & $74-75$ & $\begin{array}{l}\text { Loss UB, } \\
\mathrm{M}\end{array}$ \\
\hline RKIP & $\begin{array}{l}\text { Raf1 kinase inhibitory } \\
\text { protein }\end{array}$ & $12 q 24$ & Inhibitor of Raf1 & 72 & $\begin{array}{l}\text { Loss UB, } \\
\text { loss and } \\
\text { gain } \mathrm{M}\end{array}$ \\
\hline MEN1 & $\begin{array}{l}\text { Multiple endocrine } \\
\text { neoplasia type } 1\end{array}$ & $11 q 13$ & tumor suppressor gene & $\begin{array}{l}2-3,6 \\
125- \\
126\end{array}$ & $\begin{array}{l}\text { No } \\
\text { changes }\end{array}$ \\
\hline
\end{tabular}

\begin{tabular}{|c|c|c|c|c|c|}
\hline \multicolumn{6}{|c|}{ Repair DNA damage } \\
\hline FANCD2 & $\begin{array}{l}\text { Fanconi anemia } \\
\text { complementation group } \\
\text { D2 isoform }\end{array}$ & $3 p 25$ & $\begin{array}{l}\text { Repair DNA double } \\
\text { strand breaks }\end{array}$ & 10 & Loss M \\
\hline \multicolumn{6}{|c|}{ Apoptosis } \\
\hline c-myc & $\begin{array}{l}\text { Cellular myelocytoma- } \\
\text { tosis oncogene }\end{array}$ & $8 q 24$ & Pro-apoptosis & 40,77 & Loss M \\
\hline BRCC2 & Breast cancer cell 2 & $11 q 24$ & Pro-apoptosis & 135 & $\begin{array}{l}\text { Loss UB, } \\
\mathrm{M}\end{array}$ \\
\hline TP53 & Tumor protein p53 & $17 p 13$ & $\begin{array}{l}\text { Tumor suppressor, pro- } \\
\text { apoptosis }\end{array}$ & 40,118 & $\begin{array}{l}\text { Gain and } \\
\text { loss UB, } \\
\text { M }\end{array}$ \\
\hline TP73 & Tumor protein p73 & $1 p 36$ & Pro-apoptosis & 83 & $\begin{array}{l}\text { Loss UB, } \\
\mathrm{M}\end{array}$ \\
\hline JunD & JunD proto-oncogene & $19 p 13$ & $\begin{array}{l}\text { Protect cells from p53- } \\
\text { dependent senescence } \\
\text { and apoptosis }\end{array}$ & 9 & $\begin{array}{l}\text { No } \\
\text { changes }\end{array}$ \\
\hline $\mathrm{Bcl} 2$ & $\begin{array}{l}\text { B-cell lymphoma } 2 \text { beta } \\
\text { isoform }\end{array}$ & $18 q 21$ & Anti-apoptosis & $77-78$ & Gain M \\
\hline BIRC5 & $\begin{array}{l}\text { Baculoviral IAP repeat- } \\
\text { containing protein } 5\end{array}$ & $17 q 25$ & Anti-apoptosis & 79 & Gain M \\
\hline NOTCH1 & NOTCH1 preprotein & $9 q 34$ & $\begin{array}{l}\text { Cell growth, anti-apop- } \\
\text { tosis }\end{array}$ & 136 & $\begin{array}{l}\text { Gain B, } \\
\text { UB, M }\end{array}$ \\
\hline$N F K \beta$ & Nuclear factor kappa B & $4 q 24$ & $\begin{array}{l}\text { Cell growth, anti-apop- } \\
\text { tosis }\end{array}$ & 19 & Gain M \\
\hline
\end{tabular}

Chromosomal Instability

\begin{tabular}{llclll}
\hline TERT & $\begin{array}{l}\text { Telomerase reverse } \\
\text { transcriptase }\end{array}$ & $5 \mathrm{p} 15$ & $\begin{array}{l}\text { Maintenance of telomere } \\
\text { ends }\end{array}$ & 20 & $\begin{array}{l}\text { Gain UB, } \\
\mathrm{M}\end{array}$ \\
\hline
\end{tabular}

TChromosomal localization; 'References; ${ }^{3}$ Gain or loss of the chromosomal region by array CGH in insulinomas with benign (B), uncertain (UB), and malignant behavior (M). 


\subsubsection{Tissue invasion and metastases}

By means of invasion and metastasis cancer cells can escape the primary tumor mass and colonize new terrain in the body where nutrients and space are less limiting [1]. The genetic and biochemical determinants of these processes remain incompletely understood, although several classes of proteins have been implicated, such as cell adhesion molecules (CAMs), and extracellular matrix proteinases. Changes in the expression of CAMs of the immunoglobulin superfamily appear to play critical roles in the processes of invasion and metastases. The clearest case involves N-CAM, which undergoes a switch in expression from a highly adhesive isoform to poorly adhesive forms in Wilms' tumor, neuroblastoma, and small cell lung cancer [94-95] and reduction in overall expression level in invasive pancreatic and colorectal cancers [96]. Experiments in the RIP-Tag mouse model of $\beta$-cell carcinogenesis support a functional role for $\mathrm{N}-\mathrm{CAM}$ in suppressing metastases [97]. In a study on 53 EPTs (38 benign, 15 malignant) it was demonstrated that the expression of polysialylated NCAM and NCAM protein isoforms, with beta1,6-branched, asparagines-linked oligosaccharides, which have been associated with increased aggressiveness, metastatic potential, and survival in other tumor types [98], are not suitable to distinguish between malignant and benign EPTs. Polysialylated NCAM was not detectable in insulinomas, and the NCAM protein isoform pattern was similar in benign and malignant tumors. Furthermore, $74 \%$ of the malignant and $63 \%$ of the benign tumors exhibited staining for beta-1,6branches [99].

The most widely observed alteration in cell-to-environment interactions in cancer involves E-cadherin, a homotypic cell-to-cell interaction molecule ubiquitously expressed on epithelial cells [1]. Down-regulation of this protein, also reported in the RIP-Tag mouse model, has however, so far not been confirmed by studies on primary EPTs [100].

CD44 is a cell surface glycoprotein involved in cell-cell interactions, cell adhesion and migration. The expression of CD44 has also been shown to serve as an indicator of malignant progression in many neoplastic tissues [101]. However, analysis of CD44 expression in EPTs, including insulinomas, determined that CD44 was present in EPTs in different isoforms, and was not associated with a malignant phenotype or tumor progression, despite its presence in $50 \%$ of insulinomas [102103]. The NF2 gene on chromosome $22 q 12$ encodes merlin, a protein that functions as a tumor suppressor. It was found that merlin mediates contact inhibition of growth through signals from the extracellular matrix and that merlin's growth inhibitory activity depends on specific interaction with the cytoplasmic tail of CD44 [104]. Although a recent LOH study suggested the NF2 gene as a candidate gene in insulinoma tumorigenesis, we found that the critical region on chromosome $22 q$ is located $8 \mathrm{Mb}$ from the NF2 gene, and therefore this gene is unlikely to be involved in insulinoma tumorigenesis (Chapter 3 ).

Our data strongly indicate that insulinoma progression is driven by the accumulation of genetic changes as is also known to occur in other types of human carcino- 
mas [105-107]. Although the underlying mechanism leading to $\mathrm{CIN}$ in insulinomas is yet unknown, several candidate genes may be indicated to be involved in CIN, including MEN1, FANCD2, BIRC5 and TP73, which have to be examined in more detail. Telomeric loss has also been associated with $\mathrm{CIN}$ during insulinoma tumorigenesis, suggesting the generation of molecular alterations to allow for escape of replicative senescence. Furthermore, we have identified recurrent chromosomal aberrations associated with $\mathrm{CIN}$ in insulinomas, i.e. loss of several loci at chromosome $3 p, 6 q$, and 22q, and gains at chromosome $7 p q, 12 q, 14 q$, and $17 p q$. It is tempting to speculate that candidate genes in these chromosomal regions may be involved in the mechanism underlying the development of $\mathrm{CIN}$, and studies are underway to map genes in these loci that show deregulated expression in association with this process. The tumor suppressor genes $S D H D$ (11q23) and $h S N F 5 /$ INI1 (22q11.23) have recently been excluded as candidate genes [108-109].

\subsection{Markers to predict metastatic disease and clinical outcome in insulino- mas and other EPT subtypes}

Several studies have reported potential biomarkers that are indicators for malignancy of EPTs, such as the alpha-chain of human chorionic gonadotropin (HCGa), cyclooxigenase-2 (COX2), p27, CD99, p53, and cytokeratin 19 (CK19). HCG- $\alpha$ was one of the first markers proposed to indicate malignancy [110], but appeared also to be expressed in a subset of benign EPTs [111-112]. Therefore, this marker is of limited value. Upregulation of COX2, and down-regulation of p27 and CD99 were found to be associated with Ki67-positive, proliferating tumor cells, but so far they have not been verified in the different EPT subtypes, and inconsistent data was reported in the literature [69,113-117]. Controversy also exists with respect to p53 expression as a marker for malignancy in EPTs. Pavelic et al. [40] identified p53 overexpression in three out of three cases of malignant insulinomas, whereas Lee [118] could not detect a role for p53.

Cytokeratin 19 (CK19) is widely expressed in (pre)malignant cells of epithelial origin [119]. In the normal pancreas, it is only expressed in the exocrine ducts [120]. CK19 has recently been proposed as a predictor of survival in EPTs, including insulinomas [121]. La Rosa et al. [122] confirmed these findings with the restriction that CK19 expression should be detected with the RCK108 antibody. Albarello et al. [123] however demonstrated a low specificity for CK19 immunostaining, showing already expression in $57 \%$ of EPTs with benign and uncertain behavior. We have shown that in insulinomas, CK19 is associated with malignancy, but only in a few individual cases (chapter 4). CIN, identified by (array) $\mathrm{CGH}$, has been detected as an optimal predictor of metastatic disease (chapter 2 and 4). Ki67 $\geq 2 \%$ and p53 were found to be associated with malignancy in a few individual insulinoma cases (chapter 4).

Based on criteria such as the presence of metastases, gross invasion, tumor size, number of mitoses, proliferative index, and vascular invasion, a WHO classifica- 
tion system was proposed in 2004 for EPTs with four risk groups. Although its power in large series of EPTs with a long term follow-up remains to be evaluated, a recent study on 116 EPTs by Schmitt et al. [70] shows reliable results using this system for predicting both disease-free survival and the time span until tumorspecific death. This and other studies, moreover, show that CK19 immunostaining rather than differences in the expression of COX2, p27, and CD99, is a potential independent prognostic marker for EPTs.

We have investigated a series of 47 insulinomas and 24 non-insulinoma EPTs in order to compare the value of Ki67 proliferative index, tumor size (both criteria used in the WHO classification system) and CK19 immunostaining with CIN and specific chromosomal alterations to predict survival. We showed that $\mathrm{CIN}$ as well as the genomic alterations, including loss of chromosome $3 p$ and $6 q$, and gain of chromosome 12q, are the most reliable indicators for metastatic disease and tumor relapse in all EPTs, and for tumor-specific death in insulinomas. CK19 expression was the most optimal indicator of tumor-specific death in the non-insulinoma EPTs (Chapter 5). These data thus provide evidence that DNA copy number status is a very reliable parameter to predict metastatic disease and survival in insulinomas, and should be tested on larger series of other EPT subtypes to further explore its prognostic potential. In addition, our data underscore the power of CK19 immunostaining in predicting survival in particularly the non-insulinoma EPTs.

\subsection{Model-systems to study endocrine pancreatic tumorigenesis}

In the past 15 years several transgenic mouse models have been established for genes known to be involved in endocrine cancer syndromes, including MEN1, NF1, TSC1, and VHL [124]. Because EPTs can occur in association with these syndromes, these models may reveal a better understanding of the molecular mechanisms leading to tumor development and, if proven helpful, may be utilized for testing new therapeutic agents. For example, mice with homozygous loss of MEN1 in the pancreatic islet $\beta$-cells developed multiple insulinomas with elevated serum insulin and decreased blood glucose levels [125-126]. However, the mouse models for NF1, TSC1, and VHL did not develop EPTs. Various other transgenic mouse models have been generated in which EPTs can arise, including the RIPTag, CDK4 and cMyc/Bcl-xL mice. Transgenic mice expressing the SV40 large tumor antigen (Tag) in $\beta$-cells develop tumors of endocrine origin, from hyperplasia to solid, encapsulated tumors [127]. However, neither Tag, nor the inactivation of TP53 and $R b$ by Tag have been found to play a role in EPT pathogenesis. Therefore the relevance of the finding of a causal role for N-CAM and E-cadherin in the transition from adenoma to carcinoma in these mice may be debated. The CDK4 knock-in mouse with a homozygous CDK4 mutation develops multiple neoplasia, most commonly endocrine tumors, including insulinomas. However, as described above, CDK4 mutations have not been detected in human (sporadic) insulinomas. This accounts also for the $\mathrm{cMyc} / \mathrm{Bcl}-\mathrm{xL}$ mice, which develop islet cell tumors in- 
duced by overexpression of both genes, which however have not been confirmed to play a role in human islet cell tumors. One can thus question the relevance of these transgenic mice as reliable models for human endocrine pancreatic tumorigenesis, except for the MEN1 knock-out mouse. Because $15-20 \%$ of EPTs show MEN1 gene mutations and more and more menin interaction partners are identified, these and new transgenic mouse models will certainly increase our understanding of MEN1-induced EPT formation.

Apart from a few mouse and rat cell lines, a number of human EPT cell lines are available and are currently often used for in vitro studies, including BON1, derived from a metastatic human carcinoid tumor of the pancreas, QGP, established from a malignant pancreatic somatostatinoma, and $\mathrm{CM}$, a cell line obtained from peritoneal ascites of a patient affected by a primary pancreatic insulinoma [128130]. Despite their use in functional and therapy-based studies, these cell lines, however, need to be genetically and functionally characterized in more detail to determine their usefulness as a model for endocrine pancreatic tumorigenesis.

Recently, a method has been described that enables long-term in vitro culturing of insulin-secreting human insulinoma cells [131]. This would allow the generation of new in vitro cell systems, more closely related to the primary tumor, which are highly desirable for functional studies in the field of human EPT growth.

\subsection{Conclusions and future directions}

In the past ten years a considerable number of molecular and immunochemical studies have provided more insight into the pathogenesis of insulinomas. Investigations on sporadic EPTs have suggested a number of genes that promote tumor development. So far, a number of signaling pathways have been suggested to stimulate cell proliferation in insulinomas, including Ras/ERK signaling, and Akt/ $\mathrm{PI} 3 \mathrm{~K}$ signaling in combination with up-regulation of cyclin D1 and down-regulation of amongst others p16 (Fig. 6.2B, p.122). However, many other intermediates residing in these pathways have not yet been evaluated and gene expression studies have revealed conflicting results, urging for the future study of pathway-specific gene expression in insulinomas.

The only gene evidently involved in inherited MEN1 syndrome-associated EPTs and a substantial subset of sporadic EPTs is MEN1, which is usually mutated in combination with loss of the remaining wildtype allele. MEN1 inactivation by mutation plays a minor role in human sporadic insulinomas. However, other mechanisms of gene inactivation, such as promoter hypermethylation, may be involved in insulinoma development. MEN1 transfection in vitro and transgenic mouse studies have provided more insight into MEN1-associated tumor development and about the proteins to which menin associates (Fig. 6.1). Among the many interactors are the cell-cycle inhibitors p27 and p18, which are up-regulated as a result of the direct association of menin with their gene promoters. This process is inhibited in islet cell tumors found in MEN1 mutant mice. The fact that p27 mutations have 
also been demonstrated to predispose to the development of tumors in patients with a MEN1-like phenotype, warrants further analysis of p27 involvement particularly in sporadic tumors. The observation that MEN1-associated EPTs accumulate chromosomal aberrations indicate that they fail to maintain DNA integrity. A putative candidate gene playing a role in this process is FANCD2, product of which is involved in the repair of DNA damage and interacts with menin. Because it is located on chromosome 3p25, a region often deleted in malignant sporadic EPTs, an association between FANCD2 mutations and CIN seems rather obvious but needs to be proven.

Molecular genetic studies have provided evidence for recurrent chromosomal alterations in the development and progression of insulinomas. The most prominent aberrations have been shown in the genetic progression model (Chapter 3 ) with 9q22.2-q33.2 gain and 22q13.1-q13.31 loss as the earliest genetic events, followed by $11 \mathrm{q} 23.3-\mathrm{q} 24.3$ and $22 \mathrm{q} 13.31-\mathrm{q} 13.32$ loss during further tumor development. The progression to a more malignant phenotype requires further genetic damage, resulting from increased genomic instability. Several chromosomal regions have been found to be associated with CIN and further evaluation of candidate genes in these regions will undoubtedly provide more insight into the mechanisms leading to $\mathrm{CIN}$. Telomeric loss seems to play a role in CIN development and it is tempting to speculate that it is associated with an escape from replicative senescence due to downregulation of $\mathrm{p} 16$ and a reactivation of telomerase.

With respect to optimizing patient treatment, novel (bio)therapeutic strategies are required in combination with surgery, because the traditional DNA-damaging cytotoxic agents are of limited efficacy in the treatment of neuroendocrine tumors. The past decade has provided us with an increased knowledge on the molecular biology of these tumors which has stimulated the development of new drugs for anticancer treatment [132]. However, as indicated in this chapter, the knowledge on the molecular biology of insulinomas and other EPT subtypes needs further foundation and verification in order to select the most appropriate therapies. This requires detailed pathway-specific expression profiling as well as the development of more adequate model systems for functional validation of new therapeutic targets and diagnostic biomarkers. 


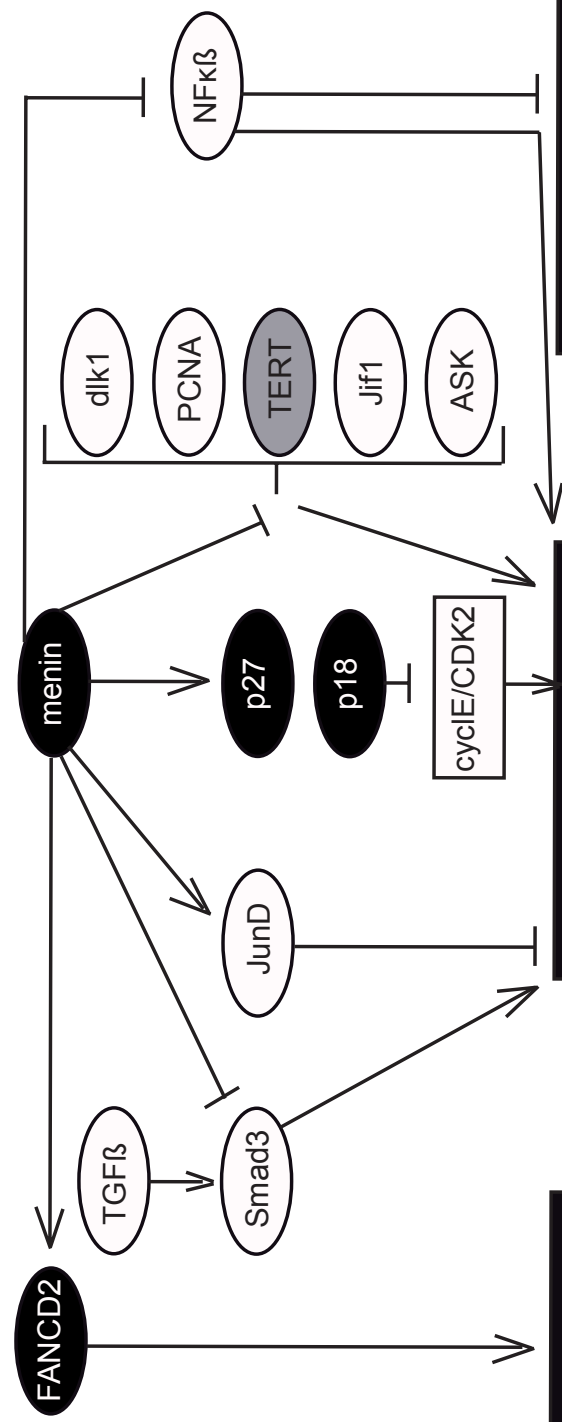

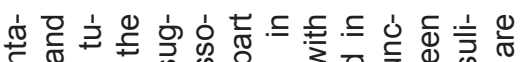
ब की

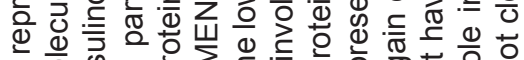

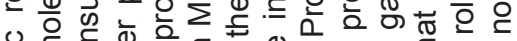
을 $\varepsilon$. 它 ब次 ऊ

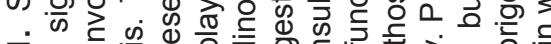
के (1) बे ब

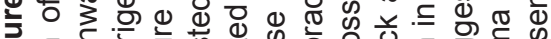

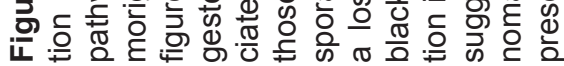
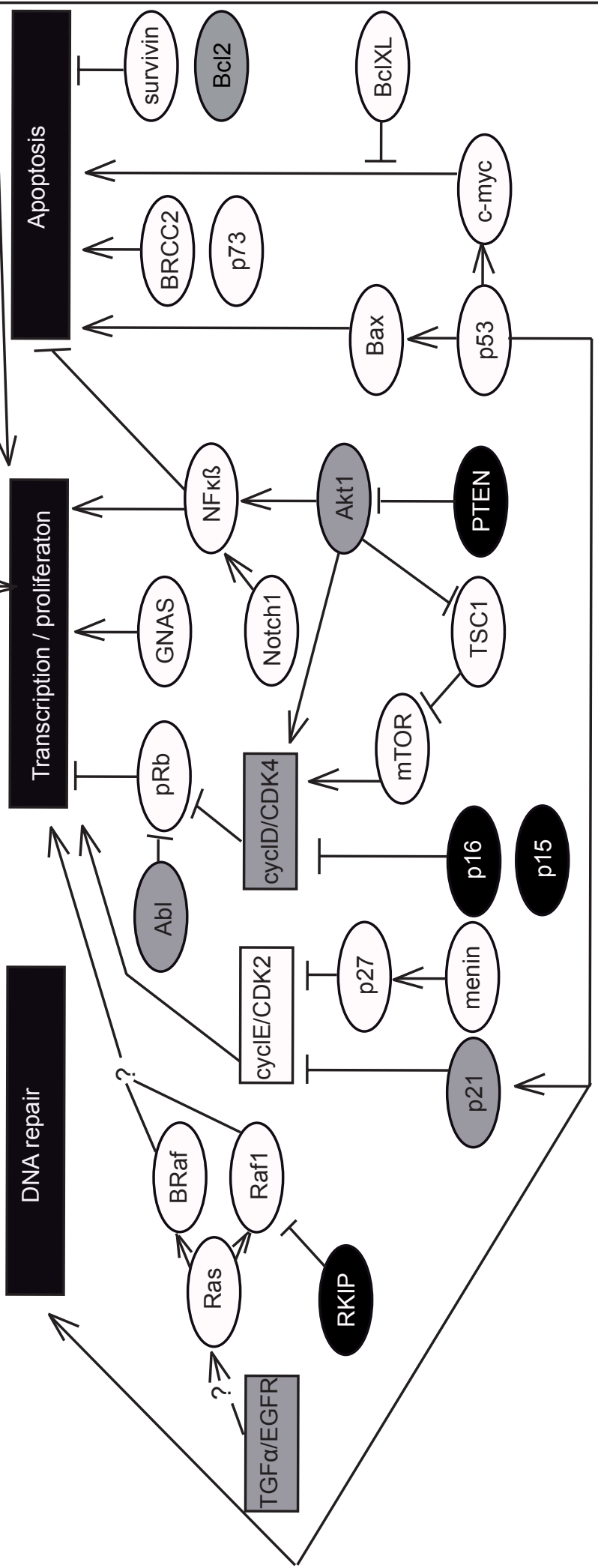


\subsection{References}

1. Hanahan D, Weinberg RA. The hallmarks of cancer. Cell 2000; 100: 57-70.

2. Zhuang Z, Vortmeyer AO, Pack S, Huang S, Pham TA, Wang C, et al. Somatic mutations of the MEN1 tumor suppressor gene in sporadic gastrinomas and insulinomas. Cancer Res. 1997; 57: 4682-4686.

3. Gortz B, Roth J, Krahenmann A, de Krijger RR, Muletta-Feurer S, Rutimann K, et al. Mutations and allelic deletions of the MEN1 gene are associated with a subset of sporadic endocrine pancreatic and neuroendocrine tumors and not restricted to foregut neoplasms. Am. J. Pathol. 1999; 154: 429-436.

4. Cupisti K, Hoppner W, Dotzenrath C, Simon D, Berndt I, Roher HD, et al. Lack of MEN1 gene mutations in 27 sporadic insulinomas. Eur. J. Clin. Invest. 2000; 30: 325-329.

5. Gumbs AA, Moore PS, Falconi M, Bassi C, Beghelli S, Modlin I, et al. Review of the clinical, histological, and molecular aspects of pancreatic endocrine neoplasms. J. Surg. Oncol. 2002; 81: 45-53.

6. Moore PS, Beghelli S, Zamboni G, Scarpa A. Genetic abnormalities in pancreatic cancer. Mol. Cancer 2003; 2: 7-12.

7. Chan AO, Kim SG, Bedeir A, Issa JP, Hamilton SR, Rashid A. CpG island methylation in carcinoid and pancreatic endocrine tumors. Oncogene 2003; 22: 924-934.

8. Chandrasekharappa SC, The BT. Functional studies of the MEN1 gene. J. Int. Med. 2003; 253: 606615.

9. Agarwal SK, Kennedy PA, Scacheri PC, Novotny EA, Hickman AB, Cerrato A, et al. Menin molecular interactions: insights into normal functions and tumorigenesis. Horm. Metab. Res. 2005; 37: 369-374.

10. Jin S, Mao H, Schnepp RW, Sykes SM, Silva AC, D'Andrea AD, et al. Menin associates with FANCD2, a protein involved in repair of DNA damage. Cancer Res. 2003; 63: 4204-4210.

11. Tomassetti P, Cometa G, Del Vecchio E, Baserga M, Faccioli P, Bosoni D, et al. Chromosomal instability in multiple endocrine neoplasia type 1. Cancer Genet. Cytogenet. 1995; 79: 123-126.

12. Hessman O, Skogseid B, Westin G, Akerstrom G. Mutiple allelic deletions and intratumoral genetic heterogeneity in MEN1 pancreatic tumors. J. Clin. Endocrinol. Metab. 2001; 86: 1355-1361.

13. Chung DC, Smith AP, Louis DN, Graeme-Cook F, Warshaw AL, Arnold AA. Novel pancreatic endocrine tumor suppressor gene locus on chromosome $3 p$ with clinical prognostic implications. J. Clin. Invest. 1997; 100: 404-410.

14. Karnik SK, Hughes CM, Gu X, Rozenblatt-Rosen O, McLean GW, Xiong Y, et al. Menin regulates pancreatic islet growth by promoting histone methylation and expression of genes encoding P27KIP1 and p18INK4C. PNAS 2005; 102: 14659-14664.

15. Schnepp RW, Chen YX, Wang H, Cash T, Silva A, Diehl JA, et al. Mutation of tumor suppressor gene MEN1 acutely enhances proliferation of pancreatic islet cells. Cancer Res. 2006; 66: 5707-5715.

16. Franklin DS, Godfrey VL, O'Brien DA, Deng C, Xiong Y. Functional collaboration between different cyclin-dependent kinase inhibitors suppresses tumor growth with distinct tissue specificity. Mol. Cell. Biol. 2000; 20: 6147-6158.

17. Pellegata NS, Quintanilla-Martinez L, Siggelkow H, Samson E, Bink K, Hofler H, et al. Germ-line mutations in p27Kip1 cause a multiple endocrine neoplasia syndrome in rats and humans. PNAS 2006; 103: 15558-15563.

18. Schnepp RW, Hou Z, Wang H, Petersen C, Silva A, Masai H, et al. Functional interaction between tumor suppressor menin and activator of S-phase kinase. Cancer Res. 2004; 64: 6791-6796.

19. Heppner C, Bilimoria KY, Agarwal SK, Kester M, Whitty LJ, Guru SC, et al. The tumor suppressor protein menin interacts with NF-kappaB proteins and inhibits NF-kappaB-mediated transactivation. Oncogene 2001; 20: 4917-4925.

20. Lin SY, Elledge SJ. Multiple tumor suppressor pathways negatively regulate telomerase. Cell 2003; 113: $881-889$.

21. Liu L, Broaddus RR, Yao JC, Xie SS, White JA, Wu TT, et al. Epigenetic alterations in neuroendocrine tumors: methylation of RAS-association domain family 1 , isoform $A$ and $p 16$ genes are associated with metastasis. Mod. Pathol. 2005; 18: 1632-1640. 
22. Shattuck TM, Costa J, Bernstein M, Jensen RT, Chung DC, Arnold A. Mutational analysis of Smad3, a candidate tumor suppressor implicated in TGF- $\beta$ and menin pathways, in parathyroid adenomas and enteropancreatic endocrine tumors. J. Clin. Endocrinol. Metab. 2002; 87: 3911-3914.

23. Stalberg P, Grimfjard P, Santesson M, Zhou Y, Lindberg D, Gobl A, et al. Transfection of the multiple endocrine neoplasia type 1 gene to a human endocrine pancreatic tumor cell line inhibits cell growth and affects expression of JunD, $\delta$-like protein 1/preadipocyte factor-1, proliferating cell nuclear antigen, and QM/Jif-1, J. Clin. Endocrinol. Metab. 2004; 89: 2326-2337.

24. Sotillo R, Dubus P, Martin J, de la Cueva E, Ortega S, Malumbres M, et al. Wide spectrum of tumors in knock-in mice carrying a Cdk4 protein insensitive to INK4 inhibitors. EMBO J. 2001; 20: 6637-6647.

25. Vax VV, Bibi R, Diaz-Cano S, Gueorguiev M, Kola B, Borboli N, et al. Activating point mutations in cyclin-dependent kinase 4 are not seen in sporadic pituitary adenomas, insulinomas or leydig cell tumors. J. Endocrinol. 2003; 178: 301-310.

26. Chung DC, Brown SB, Graeme-Cook F, Seto M, Warshaw AL, Jensen RT, et al. Overexpression of cyclin D1 occurs frequently in human pancreatic endocrine tumors. J. Clin. Endocrinol. Metab. 2000; 85: 4373-4378.

27. Fatrai S, Elghazi L, Balcazar N, Cras-Meneur C, Krits I, Kiyokawa H, et al. Akt induces $\beta$-cell proliferation by regulating cyclin D1, cyclin D2, and p21 levels and cyclin-dependent kinase-4 activity. Diabetes 2006; 55: 318-325.

28. Chang F, Lee JT, Navolanic PM, Steelman LS, Shelton JG, Blalock WL, et al. Involvement of PI3K/Akt pathway in cell cycle progression, apoptosis, and Neoplastic transformation: a target for cancer chemotherapy. Leukemia 2003; 17: 590-603.

29. Speel EJM, Richter J, Moch H, Egenter C, Saremaslani P, Rutimann K, et al. Genetic differences in endocrine pancreatic tumor subtypes detected by comparative genomic hybridization. Am. J. Pathol. 1999; 155: 1787-1794.

30. Wulbrand U, Remmert G, Zofel P, Wied M, Arnold R, Fehmann HC. mRNA expression patterns of insulin-like growth factor system components in human neuroendocrine tumors. Eur. J. Clin. Invest. 2000; 30: 729-739.

31. von Wichert G, Jehle PM, Hoeflich A, Koschnick S, Dralle H, Wolf E, et al. Insulin-like growth factor-1 is an autocrine regulator of chromogranin A secretion and growth in human neuroendocrine tumor cells. Cancer Res. 2000; 60: 4573-4581.

32. La P, Schnepp RW, Petersen CD, Silva AC, Hua X. Tumor suppressor menin regulates expression of insulin-like growth factor binding protein 2. Endocrinol. 2004; 145: 3443-3450.

33. Granata R, Settani F, Biancone L, Trovato L, Nano R, Bertuzzi F, et al. Acylated and unacylated ghrelin promote proliferation and inhibit apoptosis of pancreatic $\beta$ cells and human islets. Involvement of cAMP/PKA, ERK1/2 and PI3K/AKT signalling. Endocrinol. 2007; 148: 512-529.

34. Kojima M, Hosoda H, Date Y, Nakazato M, Matsuo H, Kangawa K. Ghrelin is a growth-hormone-releasing acylated peptide from stomach. Nature 1999; 402: 656-660.

35. Tomasetto C, Karam SM, Ribieras S, Masson R, Lefebvre O, Staub A, et al. Identification and characterization of a novel gastric peptide hormone: the motilin-related peptide. Gastroenterol. 2000; 119: 395-405.

36. Prado CL, Pugh-Bernard AE, Elghazi L, Sosa-Pineda B, Sussel L. Ghrelin cells replace insulin-producing beta cells in two mouse models of pancreas development. Proc. Natl. Acad. Sci. USA 2004; 101: 2924-2929.

37. Ekeblad S, Lejonklou MH, Grimfjard P, Johansson T, Eriksson B, Grimelius L, et al. Co-expression of ghrelin and its receptor in pancreatic endocrine tumors. Clin. Endocrinol. 2007; 66: 115-122.

38. Volante M, Allia E, Gugliotta P, Funaro A, Broglio F, Deghenghi R, et al. Expression of ghrelin and of the $\mathrm{GH}$ secretagogue receptor by pancreatic islet cells and related endocrine tumors. J. Clin. Endocrinol. Metab. 2002; 87: 1300-1308.

39. Schrader J, Arnold R, Horsch D. The Rap1/B-Raf signalling complex is a putative therapeutic target in neuroendocrine tumors of the digestive tract. Neuroendocrinol. 2006; 83: 57 (abstract B10). 
40. Pavelic K, Hrascan R, Kapitanovic S, Karapandza N, Vranes Z, Belicza M, et al. Multiple genetic alterations in malignant metastatic insulinomas. J. Pathol. 1995; 177: 395-400.

41. Burns $\mathrm{Cl}$, Squires PE, Persuad SI. Signaling through the p38 and p42/44 mitogen-activated families of protein kinases in pancreatic $\beta$ cell proliferation.Biochem. Biophys. Res. Comm. 2000; 268: 541-546.

42. Tanabe K, Okuya S, Tanizawa Y, Matsutani A, Oka Y. Leptin induces proliferation of pancreatic cell line MIN6 through activation of mitogen-activated protein kinase. Biochem. Biophys. Res. Comm. 1997; 241: 765-768.

43. Yoshimoto K, Iwahana H, Fukuda A, Sano T, Katsuragi K, Kinoshita M, et al. Ras mutations in endocrine tumors: mutation detection by polymerase chain reaction-single strand conformation polymorphism. Jpn. J. Cancer Res. 1992; 83: 1057-1062.

44. Yashiro T, Fulton N, Hara H, Yasudo K, Montag A, Yashiro N, et al. Comparison of mutations of ras oncogene in human pancreatic exocrine and endocrine tumors. Surgery 1993; 114: 758-763.

45. Perren A, Schmid S, Locher T, Saremaslani P, Bonvin C, Heitz PU, et al. BRAF and endocrine tumors: mutations are frequent in papillary thyroid carcinomas, rare in endocrine tumors of the gastrointestinal tract and not detected in other endocrine tumors. Endocr. Relat. Cancer 2004; 11: 855-860.

46. Tannapfel A, Vomschloss S, Karhoff D, Markwarth A, Hengge UR, Wittekind C, et al. BRAF gene mutations are rare events in gastroenteropancreatic neuroendocrine tumors. Am. J. Clin. Pathol. 2005; 123: $256-260$.

47. Wang XC, Xu SY, Wu XY, Song HD, Mao YF, Fan HY, et al. Gene expression profiling in human insulinoma tissue: genes involved in the insulin secretion pathway and cloning of novel full-length cDNAs. Endocr. Relat. Cancer 2004; 11: 295-303.

48. Landis CA, Masters SB, Spada A, Pace AM, Bourne HR, Vallar L. GTPase inhibiting mutations activate the alpha chain of Gs and stimulate adenylyl cyclase in human pituitary tumors. Nature 1989; 340: 692-696.

49. Lyons J, Landis CA, Harsh G, Vallar L, Grunewald K, Feichtinger H, et al. Two G protein oncogenes in human endocrine tumors. Science 1990; 249: 655-659.

50. Suarez HG, Duvillard JA, Caillu B, Schlumberger M, Parmentier C, Monier R. Gsp mutations in human thyroid tumors. Oncogene 1991; 6: 677-679.

51. Vessey SJR, Jones PM, Wallis SC, Schofield J, Bloom SR. Absence of mutations in the Gsa Gi2a genes in sporadic parathyroid adenomas and insulinomas. Clin. Science 1994; 87: 493-497.

52. Zeiger MA, Norton JA. Gs alpha-identification of a gene highly expressed by insulinoma and other endocrine tumors. Surgery 1993; 114: 458-463.

53. Pavelic K, Hrascan R, Kapitanovic S, Vranes Z, Cabrijan T, Spaventi S, et al. Molecular genetics of malignant insulinoma. Anticancer Res. 1996; 16: 1707-1717.

54. Korc M, Finman JE. Attenuated processing of epidermal growth factor in the face of marked degradation of transforming growth factor-alpha. J. Biol. Chem. 1989; 264: 14990-14999.

55. Hsieh ET, Shepherd FA, Tsao MS. Co-expression of epidermal growth factor and transforming growth factor-alpha is independent of ras mutations in lung adenocarcinoma. Lung cancer 2000; 29: 151157.

56. Papouchado B, Erickson LA, Rohlinger AL, Hobday TJ, Erlichman C, Ames MM, et al. Epidermal growth factor receptor expression in gastrointestinal carcinoids and pancreatic endocrine carcinomas. Mod. Pathol. 2005; 18: 1329-1335.

57. Speel EJM, Scheidweiler AF, Zhao J, Matter C, Saremaslani P, Roth J, et al. Genetic evidence for early divergence of small functioning and nonfunctioning endocrine pancreatic tumours: gain of 9q34 is an early event in insulinomas. Cancer Res. 2001; 61: 5186-5192.

58. Goldman JM, Melo JV. Chronic myeloid leukemia - advances in biology and new approaches to treatment. N. Engl. J. Med. 2003; 349: 1451-1464.

59. DeAizpurua HJ, Cram DS, Naselli G, Devereux L, Dorow DS. Expression of mixed lineage kinase-1 in pancreatic $\beta$-cell lines at different stages of maturation and during embryonic pancreas development. J. Biol. Chem. 1997; 272: 16364-16373. 
60. Iwamura Y, Futagawa T, Kaneko M, Nahagawa K, Kawai K, Yamashita K, et al. Co-deletions of the retinoblastoma gene and Wilms' tumor gene and rearrangement of the Krev-1 gene in a human insulinoma. Jpn. J. Clin. Oncol. 1992; 22: 6-9.

61. Chung DC, Smith AP, Louis DN, Graeme-Cook F, Warshaw AL, Arnold A. Analysis of the retinoblastoma tumor suppressor gene in pancreatic endocrine tumors. Clin. Endocrinol. 1997; 47: 523-528.

62. DeGregory J. The Rb network. J. Cell Science 2004; 117: 3411-3413.

63. Nagano K, Itagaki C, Izumi T, Nunomura K, Soda Y, Tani K, et al. Rb plays a role in survival of Abldependent human tumor cells as a downstream effector of Abl tyrosine kinase. Oncogene 2006; 25; 493-502.

64. Muscarella P, Melvin WS, Fisher WE, Foor J, Ellison EC, Herman JG, et al. Genetic alterations in gastrinomas and nonfunctioning pancreatic neuroendocrine tumors: an analysis of p16/MTS1 tumor suppressor gene inactivation. Cancer Res. 1998; 58: 237-240.

65. Bartsch DK, Kersting M, Wild A, Ramaswamy A, Gerdes B, Schuermann M, et al. Low frequency of p16 (INK4a) alterations in insulinomas. Digestion 2000; 62: 171-177.

66. Tomita T. Cyclin-dependent kinase (cdk6) and p16 in pancreatic endocrine neoplasms. Pathology 2004; 36: 566-570.

67. Lubomierski N, Kersting M, Bert T, Muench K, Wulbrand U, Schuermann M, et al. Tumor suppressor genes in the 9p21 gene cluster are selective targets of inactivation in neuroendocrine gastroenteropancreatic tumors. Cancer Res. 2001; 61: 5905-5910.

68. Cozar-Castellano I, Fiaschi-Taesch N, Bigatel TA, Takane KK, Garcia-Ocana A, Vasavada R, et al. Molecular control of cell cycle progression in the pancreatic $\beta$-cell. Endocrine reviews 2006; 27 : 356370.

69. Canavese G, Azzoni C, Pizzi S, Corleto V, Pasquali C, Davoli C, et al. p27: A potential main inhibitor of cell proliferation in digestive endocrine tumors but not a marker of benign behaviour. Human Pathol. 2001; 32: 1094-1101.

70. Schmitt AM, Anlauf M, Rousson V, Schmid S, Kofler A, Riniker F, et al. WHO 2004 criteria and CK19 are reliable prognostic markers in pancreatic endocrine tumors. Am. J. Surg. Pathol. 2007 In press.

71. Fontaniere S, Casse H, Bertolino P, Zhang CX. Analysis of p27KIP1 expression in insulinomas developed in pancreatic $\beta$-cell specific MEN1 mutant mice. Familial Cancer 2006; 5: 49-54.

72. Zhang L, Fu Z, Binkley C, Giordano T, Burant CF, Logsdon CD, et al. Raf kinase inhibitory protein inhibits $\beta$-cell proliferation. Surgery 2004; 136: 708-715.

73. Stambolic V, Suzuki A, de la Pompa JL, Brothers GM, Mirtsos C, Sasaki T, et al. Negative regulation of PKB/Akt-dependent cell survival by the tumor suppressor PTEN. Cell 1998; 95: 29-39.

74. Nguyen KTT, Tajmir P, Lin CH, Liadis N, Zhu XD, Eweida M, et al. Essential role of PTEN in body size determination and pancreatic $\beta$-cell homeostasis in vivo. Mol. Cell Biol. 2006; 26: 4511-4518.

75. Perren A, Komminoth P, Saremaslani P, Matter C, Feurer S, Lees JA, et al. Mutation and expression analyses reveal differential subcellular compartmentalization of PTEN in endocrine pancreatic tumors compared to normal islet cells. Am. J. Pathol. 2000; 157: 1097-1103.

76. Pelengaris S, Khan M. Oncogenic co-operation in $\beta$-cell tumorigenesis. Endocr. Relat. Cancer 2001; 8: 307-314.

77. Wang DG, Johnston CF, Buchanan KD. Oncogene expression in gastroenteropancreatic neuroendocrine tumors. Implications for pathogenesis. Cancer 1997; 80: 668-675.

78. Hochenbery D, Nunez G, Milliman C, Schreiber RD, Korsmeyer SJ. Bcl-2 is an inner mitochondrial membrane protein that blocks programmed cell death. Nature 1990; 348: 334-336.

79. Grabowski P, Griss S, Arnold CN, Horsch D, Goke R, Arnold R, et al. Nuclear surviving is a powerful novel prognostic marker in gastroenteropancreatic neuroendocrine tumor disease. Neuroendocrinol. 2005; 81: 1-9.

80. Miyashita T, Reed JC. Tumor suppressor p53 is a direct transcriptional activator of the human bax gene. Cell 1995; 80: 293-299. 
81. Owen-Schaub LB, Zhang W, Cusack JC. Wild-type p53 and a temperature-sensitive mutant induce Fas/Apo-1 expression. Mol. Cell. Biol. 1995; 15: 3032-3040.

82. Hermeking H, Eick D. Mediation of c-Myc-induced apoptosis by p53. Science 1994; 265: $2091-2093$.

83. Kaghad M, Bonnet H, Yang A, Creancier L, Biscan JC, Valent A, et al. Monoallelically expressed gene related to p53 at $1 \mathrm{p} 36$, a region frequently deleted in neuroblastoma and other human cancers. Cell 1997; 90: 809-819.

84. Guo SS, Wu AY, Sawicki MP. Deletion of chromosome 1, but not mutation of MEN1 predicts prognosis in sporadic pancreatic endocrine tumors. World J. Surg. 2002; 26: 843-847.

85. Bryan TM, Cech TR. Telomerase and the maintenance of chromosome ends. Curr. Opin. Cell Biol. 1999; 11: 318-324.

86. Tang SJ, Dumot JA, Wang L, Memmesheimer C, Conwell DL, Zuccaro G, et al. Telomerase activity in pancreatic endocrine tumors. Am. J. Gastroenterol. 2002; 97: 1022-1030.

87. Lam KY, Lo CY, Fan ST, Luk JM. Telomerase activity in pancreatic endocrine tumors: a potential marker for malignancy. Mol. Pathol. 2000; 53: 132-136.

88. Lin SY, Elledge SJ. Multiple tumor suppressor pathways negatively regulate telomerase. Cell 2003; 113: $881-889$

89. Marion-Audibert AM, Barel C, Gouysse G, Dumortier J, Pilleul F, Pourreyron C, et al. Low microvessel density is an unfavourable histoprognostic factor in pancreatic endocrine tumors. Gastroenterol. 2003; 125: 1094-1104.

90. Couvelard A, O'Toole D, Turley H, Leek R, Sauvanet A, Degott C, et al. Micro vascular density and hypoxia-inducible factor pathway in pancreatic endocrine tumors: negative correlation of microvascular density and VEGF expression with tumor progression. British J. Cancer 2005; 92: 94-101.

91. Schwarte-Waldhoff I, Volpert OV, Bouck NP, Sipos B, Hahn SA, Klein-Scory S, et al. Smad4/DPC4mediated tumor suppression through suppression of angiogenesis. PNAS 2000; 97: 9624-9629.

92. Bartsch D, Hahn SA, Danichevski KD, Ramaswamy A, Bastian D, Galehdari H, et al. Mutations of the DPC4/Smad4 gene in neuroendocrine pancreatic tumors. Oncogene 1999; 18: 2367-2371.

93. Perren A, Saremaslani P, Schmid S, Bonvin C, Locher T, Roth J, et al. DPC4/SMAD4: no mutations, rare allelic imbalances, and retained protein expression in pancreatic endocrine tumors. Diagn. Mol. Pathol. 2003; 12: 181-186.

94. Johnson JP. Cell adhesion molecules of the immunoglobulin supergene family and their role in malignant transformation and progression to metastatic disease. Cancer metastasis Rev. 1991; 10: 11-22.

95. Kaiser U, Auerbach B, Oldenburg M. The neural cell adhesion molecule NCAM in multiple myeloma. Leuk. Lymphoma 1996; 20: 389-395.

96. Fogar P, Basso D, Pasquali C, De Paoli M, Sperti C, Roveroni G, et al. Neural cell adhesion molecule (N-CAM) in gastrointestinal neoplasias. Anticancer Res. 1997; 17: 1227-1230.

97. Perl AK, Dahl U, Wilgenbus P, Cremer H, Semb H, Christofori G. Reduced expression of neural cell adhesion molecule induces metastatic dissemination of pancreatic $\beta$ tumor cells. Nat. Med. 1999; 5: 286-291.

98. Seelentag WK, Li WP, Schmitz SF, Metzger U, Aeberhard P, Heitz PU, et al. Prognostic value of beta 1,6-branched oligosaccharides in human colorectal carcinoma. Cancer Res. 1998; 58: 5559-5564.

99. Li WP, Komminoth P, Zuber C, Kloppel G, Heitz PU, Roth J. Can malignancy in insulinoma be predicted by the expression of patterns of beta 1,6 branching of aspargine-linked oligosaccharides and polysialic acid of the neural cell adhesion molecule? Virchows Arch. 1996; 429: 197-204.

100. Perl AK, Wilgenbus P, Dahl U, Semb H, Christofori G. A causal role for E-cadherin in the transition from adenoma to carcinoma. Nature 1998; 392: 190-193.

101. Marhaba R, Zoller M. CD44 in cancer progression: adhesion, migration and growth regulation. J. Mol. Histol. 2004; 35: 211-231.

102. Komminoth P, Seelentag WK, Saremaslani P, Heitz PU, Roth J. CD44 isoform expression in the diffuse neuroendocrine system. II Benign and malignant tumors. Histochem. Cell Biol. 1996; 106: 551-562. 
103. Imam H, Eriksson B, Oberg K. Expression of CD44 variant isoforms and association to the benign form of endocrine pancreatic tumors. Ann. Oncol. 2000; 11: 295-300.

104. Morrison H, Sherman LS, Legg J, Banine F, Isacke C, Haipek CA, et al. The NF2 tumor suppressor gene product, merlin, mediates contact inhibition of growth through interactions with CD44. Genes Dev. 2001; 15: 968-980.

105. Nowak MA, Komarova NL, Sengupta A, Jallepalli PV, Shih IM, Vogelstein B, et al. The role of chromosomal instability in tumor initiation. Proc. Natl. Acad. Sci. USA 2002; 99: 16226-16231.

106. Vogelstein B, Kinzler KW. Cancer genes and the pathways they control. Nat. Med. 2004; 10: 789799.

107. Draviam VM, Xie S, Sorger PK. Chromosome segregation and genomic stability. Curr. Opin. Genet. Dev. 2004; 14: 120-125.

108. Perren A, Barghorn A, Schmid S, Saremaslani P, Roth J, Heitz PU, et al. Absence of somatic SDHD mutations in sporadic neuroendocrine tumors and detection of two germline variants in paraganglioma patients. Oncogene 2002; 21: 7605-7608.

109. Wild A, Langer P, Ramaswamy A, Chaloupka B, Bartsch DK. A novel insulinoma tumor suppressor gene locus on chromosome 22q with potential prognostic implications. J. Clin. Endocrinol. Metab. 2001; 86: 5782-5787.

110. Heitz PU, Kasper M, Kloppel G, Polak JM, Vaitukaitis JL. Glycoprotein-hormone alpha-chain production by pancreatic endocrine tumors: a specific marker for malignancy. Immunocytochemical analysis of tumors of 155 patients. Cancer 1983; 51: 277-282.

111. Bordi C, Pilato FP, D'adda T. Comparative study of seven neuroendocrine markers in pancreatic endocrine tumors. Virchows Arch. A Pathol. Anat. Histopathol. 1988; 413: 387-398.

112. Graeme-Cook F, Bell DA, Flotte TJ, Preffer F, Pastel-Levy C, Nardi G, et al. Aneuploidy in pancreatic insulinomas does not predict malignancy. Cancer 1990; 66: 2365-2368.

113. Ohike N, Morohoshi T. Immunohistochemical analysis of cyclooxygenase (COX)-2 expression in pancreatic endocrine tumors: association with tumor progression and proliferation. Pathol. Int. 2001; 51: 770-777.

114. Guo SS, Wu X, Shimoide AT, Wong J, Sawicki MP. Anomalous overexpression of p27(Kip1) in sporadic pancreatic endocrine tumors. J. Surg, Res. 2001; 96: 284-288.

115. Rahman A, Maitra A, Ashfaq R, Yeo CJ, Cameron JL, Hansel DE. Loss of p27 nuclear expression in a prognostically favorable subset of well-differentiated pancreatic endocrine neoplasms. Am. J. Clin. Pathol. 2003; 120: 685-690.

116. Goto A, Niki T, Terado Y, Fukushima J, Fukayama M. Prevalence of CD99 protein expression in pancreatic endocrine tumors (PETs). Histopathol. 2004; 45: 384-392.

117. Ali A, Serra S, Asa SL, Chetty R. The predictive value of CK19 and CD99 in pancreatic endocrine tumors. Am. J. Surg. Pathol. 2006; 30: 1588-1594.

118. Lee CS. Lack of p53 immunoreactivity in pancreatic endocrine tumors. Pathology 1996; 28: 139-141.

119. Kwaspen FHL, Smedts FMM, Broos A, Bulten H, Debie WMH, Ramaekers FCS. Reproducible and highly sensitive detection of the broad spectrum epithelial marker keratin 19 in routine cancer diagnosis. Histopathol. 1997; 31: 503-516.

120. Bouwens L. Cytokeratins and cell differentiation in the pancreas. J. Pathol. 1998; 184: 234-239.

121. Deshpande V, Fernandez-del Castillo, Muzikansky A, Deshpande A, Zukerberg L, Warshaw AL. Cytokeratin 19 is a powerfull predictor of survival in pancreatic endocrine tumors. Am. J. Surg. Pathol. 2004; 28: 1145-1153.

122. La Rosa S, Bianchi V, Rigoli E, Uccella S, Capella C. The prognostic significance of cytokeratin 19 expression in pancreatic endocrine tumors (PETs). Virchows Arch. 2005; 447: 188.

123. Albarello L, Capitanio V, Zerbi A, Di Carlo V, Doglioni C. Cytokeratin 19 expression in pancreatic endocrine tumors. J. Pancreas 2004; 6: 514. 
124. Ward JM, Devor-Henneman DE. Mouse models of human familial cancer syndromes. Toxicol. Pathol. 2004; 32: 90-98.

125. Bertolino P, Tong WM, Herrera PL, Casse H, Zhang CX, Wang ZQ. Pancreatic $\beta$-cell-specific ablation of the multiple endocrine neoplasia type 1 (MEN1) gene causes full penetrance of insulinoma development in mice. Cancer Res. 2003; 63: 4836-4841.

126. Crabtree JS, Scacheri PC, Ward JM, McNally SR, Swain GP, Montagna C, et al. Of mice and MEN1: Insulinomas in a conditional mouse knockout. Mol. Cell. Biol. 2003; 23: 6075-6085.

127. Hanahan D. Heritable formation of pancreatic beta-cell tumors in transgenic mice expressing recombinant insulin / simian virus 40 oncogenes. Nature 1985; 315: 115-122.

128. Evers BM, Ishizuha J, Townsend CM Jr, Thompson JC. The human carcinoid cell line, BON. A model system for the study of carcinoid tumors. Ann. N. Y. Acad. Sci. 1994; 733: 393-406.

129. Igushi $\mathrm{H}$, Hayashi I, Kono A. A somatostatin-secreting cell line established from a human pancreatic islet cell carcinoma (somatostatinoma): release experiment and immunohistochemical study. Cancer Res. 1990; 50: 3691-3693.

130. Baroni MG, Cavallo MG, Mark M, Monetini L, Stoehrer B, Pozzilli P. Beta-cell gene expression and functional characterisation of the human insulinoma cell line CM. J. Endocrinol. 1999; 161: 59-68.

131. Gartner W, Koc F, Nabokikh A, Daneva T, Niederle B, Luger A, et al. Long-term in vitro growth of human insulin-secreting insulinoma cells, Neuroendocrinol. 2006; 83: 123-130.

132. Duran I, Salazar R, Casanovas O, Arrazubi V, Vilar E, Siu LL, et al. New drug development in digestive neuroendocrine tumors. Ann. Oncol. 2007

133. Davoren PM, Epstein MT. Insulinoma complicating tuberous sclerosis. J. Neurol. neurosurg. Psychiatry 1992; 55: 1209.

134. Harvey M, Vogel H, Lee EYHP, Bradley A, Donehower LA. Mice deficient in both p53 and Rb develop tumors primarily of endocrine origin. Cancer Res. 1995; 55: 1146-1151.

135. Broustas CG, Gokhale PC, Rahman A, Dritschilo A, Ahmad I, Kasid U. BRCC2, a novel BH3-like domain-containing protein, induces apoptosis in a caspase-dependent manner. J. Biol. Chem. 2004; 279: 26780-26788.

136. Wang Z, Zhang Y, Li Y, Banerjee S, Liao J, Sarkar FH. Down-regulation of Notch-1 contributes to cell growth inhibition and apoptosis in pancreatic cancer cells. Mol. Cancer Ther. 2006; 5: 483-493. 


\section{CHAPTER 7}

\section{Summary}

Pancreatic cancer can originate from exocrine (duct or acinar) cells, which produce amongst others digestive enzymes, or from endocrine cells, which produce hormones. In insulin-secreting endocrine pancreatic tumors, also called insulinomas, the uncontrolled hormone production can lead to life-threatening symptoms, such as low blood glucose. The only feature that per definition separates benign from malignant disease is organ and/or lymph node infiltration or distant metastases. If only a primary lesion is identified, however, no reliable clinico-pathological parameters are available to indicate their biological behavior. The aim of this thesis was to obtain a better understanding of the molecular processes underlying the development of insulinomas and to identify molecular markers that can reliably discriminate benign from malignant tumors and predict prognosis.

Chapter 1 introduces the basic clinical and molecular characteristics of insulinoma.

In chapter 2 a series of 62 sporadic insulinomas was studied to examine the role of mutations in the multiple endocrine neoplasia type 1 (MEN1) gene and chromosomal alterations in the development and malignant progression of these tumors. Only one tumor with a somatic MEN1 mutation was identified, indicating that mutations in this gene do not play a prominent role. Conventional comparative genomic hybridization $(\mathrm{CGH})$ analysis revealed that the total number of genomic aberrations per tumor differs strongly between benign and malignant tumors, i.e. 4.2 versus 14.1 , respectively $(p<0.0001)$. By using the presence of at least 8 chromosomal aberrations per tumor as a threshold value to define chromosomal instability $(\mathrm{CIN})$, this parameter proved to be a powerful indicator of metastatic disease. Furthermore, we identified chromosome $9 q$ gain as the most frequent aberration in both benign and malignant insulinomas, and a strong association of chromosome $6 q$ losses and 12q, 14q and 17pq gains with metastatic disease.

To improve the resolution of conventional CGH (5-10 Mb) and the reliability in the analysis of DNA copy number changes at chromosomes 1p32-pter, 16p, 19 and 22 , we have applied the CGH technique to microarrays of $3.7 \mathrm{k}$ genomic DNA clones (resolution $\sim 1 \mathrm{Mb}$ ) to study a series of 27 insulinomas (chapter 3). Array $\mathrm{CGH}$ most frequently detected losses of chromosome $11 \mathrm{q}$ and $22 \mathrm{q}$ and gains of chromosome $9 q$ with the chromosomal regions of interest (CRI) being 11q24.1 (56\%), 22q13.1 (67\%), 22q13.31 (56\%), and 9q32 (63\%). Evaluation of the simultaneous occurrence of these aberrations in the individual tumors revealed that gain of chromosome $9 q 32$ and loss of 22q13.1 are early genetic events in insulinoma development, occurring independently of the other alterations. In tumors with an increased genomic complexity, these alterations are often simultaneously detected in the same tumor cells. Losses of $11 \mathrm{q} 24.1$ and $22 \mathrm{q} 13.31$ are also associated 
with these more advanced tumor cases. The identified chromosomal regions most likely harbor crucial candidate genes important in insulinoma tumorigenesis.

In chapter 4, various proposed prognostic markers in endocrine pancreatic tumorigenesis, including proliferative index, tumor size, p53, CK19 status and CIN, have been evaluated to predict metastatic disease in a series of 22 insulinomas. Because only one out of ten malignant tumors showed to harbor a TP53 mutation and p53 immunopositivity, and CK19 immunopositivity was detected in three malignant tumors and one tumor with uncertain behavior, these markers were considered unsuitable for this purpose. Array $\mathrm{CGH}$ analysis revealed that $\geq 20$ chromosomal alterations of at least $10 \mathrm{Mb}$, and $\geq 6$ losses of clones at telomeric ends are the best predictors of malignant progression.

In chapter 5, the value of CIN, tumor size, proliferative index and CK19 status was tested to predict clinical outcome in a series of 47 insulinomas and 24 non-insulinoma EPTs. CIN as well as specific chromosomal alterations, such as $3 p$ and $6 q$ losses and $12 q$ gain, turned out to be the most powerful indicators for poor tumorfree survival ( $p \leq 0.0004)$ and tumor-specific death $(p \leq 0.0113)$ in insulinomas. CIN, chromosome $7 q$ gain, and a proliferative index $\geq 2 \%$ were reliable in predicting a poor tumor-free survival in non-insulinoma EPTs ( $p \leq 0.0181$ ), whereas CK19 expression was the most optimal predictor of tumor-specific death in these tumors. Thus, the DNA copy number status proved to be the most sensitive and efficient marker of adverse outcome in insulinomas and of potential interest in non-insulinoma EPTs. As a consequence, we propose that these markers should be used to refine clinical diagnosis.

Finally, in chapter 6, the progress that has been made in insulinoma research during the past years is discussed together with the results as described in this thesis. The future perspectives are also pointed out, and comprise the development of a simple prognostic test to predict the clinical outcome of insulinomas, as well as the further evaluation of candidate genes in the chromosomal regions of interest. The identified genes will increase our understanding of the molecular pathogenesis of insulinomas and the molecular pathways involved, which will greatly favor the development of future therapeutic strategies. 


\section{CHAPTER 8}

\section{Samenvatting}

Alvleesklierkanker kan ontstaan uit exocriene cellen die onder andere verteringsenzymen produceren, of endocriene cellen die hormonen produceren. In insuline producerende endocriene pancreastumoren (EPTs), zogenaamde insulinomen, kan een ongecontroleerde hormoonproductie leiden tot levensbedreigende symptomen zoals een lage bloedglucose.

Op dit moment zijn er geen goede klinisch bruikbare assays beschikbaar die goedaardige van kwaadaardige tumoren kunnen onderscheiden.

Het doel van dit promotieonderzoek was om een beter inzicht te krijgen in de moleculaire processen die ten grondslag liggen aan het ontstaan van insulinomen. Verder werd gezocht naar moleculaire markers die een betrouwbaar onderscheid kunnen maken tussen goedaardige en kwaadaardige tumoren en de prognose van insulinoma patiënten kunnen voorspellen.

Hoofdstuk 1 introduceert de klinische en moleculaire karakteristieken van insulinomen.

In hoofdstuk 2 is een serie van 62 sporadische insulinomen bestudeerd om de rol van mutaties in het multipele endocriene neoplasie type 1 (MEN1) gen en chromosomale afwijkingen in de ontwikkeling en de maligne progressie van deze tumoren te bestuderen. Er werd slechts 1 tumor met een MEN1 mutatie gevonden, wat impliceert dat mutaties in dit gen geen belangrijke rol spelen in de ontwikkeling van insulinomen. Met behulp van de conventionele "comparative genomic hybridization" (CGH) techniek hebben we gevonden dat het totaal aantal chromosomale afwijkingen per tumor sterk verschilt tussen benigne en maligne tumoren (4.2 versus $14.1, p<0.0001$ ). Door gebruik te maken van de aanwezigheid van tenminste 8 chromosomale afwijkingen per tumor als een grenswaarde voor chromosomale instabiliteit (CIN), bleek deze parameter een sterke indicator voor maligniteit. Verder bleek winst van chromosoom 9q de meest frequente afwijking te zijn in zowel benigne als maligne insulinomen en bleken verlies van chromosoom $6 q$ en winst van chromosoom 12q, 14q en 17pq sterk geassocieerd te zijn met metastasering.

Om de resolutie van de conventionele $\mathrm{CGH}$ techniek $(5-10 \mathrm{Mb})$ te verbeteren en tevens de betrouwbaarheid van de analyse van DNA kopieaantal veranderingen in de repetitieve regio's te verhogen, hebben we gebruik gemaakt van de CGH techniek op microarrays met 3700 genomische DNA klonen (resolutie $\sim 1 \mathrm{Mb}$ ). Met behulp van deze array CGH techniek hebben we een serie van 27 insulinomen bestudeerd (hoofdstuk 3). De meest frequent gedetecteerde afwijkingen met behulp van array $\mathrm{CGH}$ waren verlies van chromosoom $11 \mathrm{q}$ en $22 \mathrm{q}$ en winst van chromosoom 9q met als kritische regio's 11q24.1 (56\%), 22q13.1 (67\%), 22q13.31 (56\%), en 9q32 (63\%). Evaluatie van de aanwezigheid van de verschillende afwijkingen per tumor toonde aan dat winst van chromosoom $9 q 32$ en verlies van 
22q13.1 vroege genetische afwijkingen zijn in de ontwikkeling van insulinomen en onafhankelijk van de andere afwijkingen kunnen voorkomen. In tumoren met een toegenomen genomische complexiteit worden deze afwijkingen vaak samen aangetroffen in dezelfde tumorcellen. Verlies van 11q24.1 en 22q13.31 worden ook geassocieerd met deze verder gevorderde tumoren. De geïdentificeerde chromosomale regio's bevatten hoogstwaarschijnlijk cruciale kandidaatgenen met een belangrijke rol in de tumorigenese van insulinomen.

In hoofdstuk 4 zijn verschillende voorgestelde prognostische markers in de tumorigenese van EPTs, zoals proliferatie index, tumorgrootte, p53, cytokeratine 19 status en CIN, geëvalueerd om metastasering te voorspellen in een serie van 22 insulinomen. Omdat slechts 1 van de 10 maligne tumoren een TP53 mutatie bleek te bezitten en cytokeratine 19 immunopositiviteit gedetecteerd werd in 3 maligne tumoren en 1 tumor met onzeker gedrag, werden deze markers als niet geschikt bevonden. Array $\mathrm{CGH}$ analyse toonde aan dat $\geq 20$ chromosomale afwijkingen van tenminste $10 \mathrm{Mb}$ grootte en $\geq 6$ verliezen van klonen aan de telomeer uiteinden de beste voorspellers zijn van maligne progressie.

In hoofdstuk $\mathbf{5}$ is de waarde van CIN, tumorgrootte, proliferatie index en cytokeratine 19 status getest om de klinische prognose van 47 insulinoma patiënten en 24 patiënten met andere EPTs te voorspellen. Zowel CIN als specifieke chromosomale afwijkingen, zoals verlies van chromosoom $3 p$ en $6 q$ en winst van chromosoom $12 q$, bleken de sterkste indicatoren te zijn voor een slechte tumorvrije overleving ( $p \leq 0.0004)$ en tumorspecifieke dood $(p \leq 0.0113)$ in insulinomen. CIN, chromosoom $7 q$ winst en een proliferatie index $\geq 2 \%$ bleken betrouwbaar in het voorspellen van een slechte tumorvrije overleving in de andere EPTs ( $p \leq 0.0181$ ), terwijl cytokeratine 19 expressie de meest optimale voorspeller was van tumorspecifieke dood in deze tumoren. Dus de DNA kopieaantal status bleek de meest sensitieve en efficiënte prognostische marker te zijn voor insulinomen en tevens een potentiële marker voor de andere EPTs. Deze markers zouden gebruikt moeten worden om de klinische diagnose van deze tumoren te verfijnen.

Tenslotte wordt in hoofdstuk 6 de vooruitgang die geboekt is in het insulinoma onderzoek bediscussieerd samen met de resultaten die beschreven zijn in dit proefschrift. Tevens worden de toekomstplannen beschreven. Deze bestaan uit het ontwikkelen van een eenvoudige test om de klinische prognose van insulinomen te voorspellen, alsmede de verdere evaluatie van kandidaatgenen in de betrokken chromosomale regio's. De geïdentificeerde genen zullen onze kennis van de moleculaire pathogenese van insulinomen vergroten en, uiteindelijk, bijdragen aan de ontwikkeling van nieuwe therapeutische strategieën in de toekomst. 


\section{COLOR FIGURES}

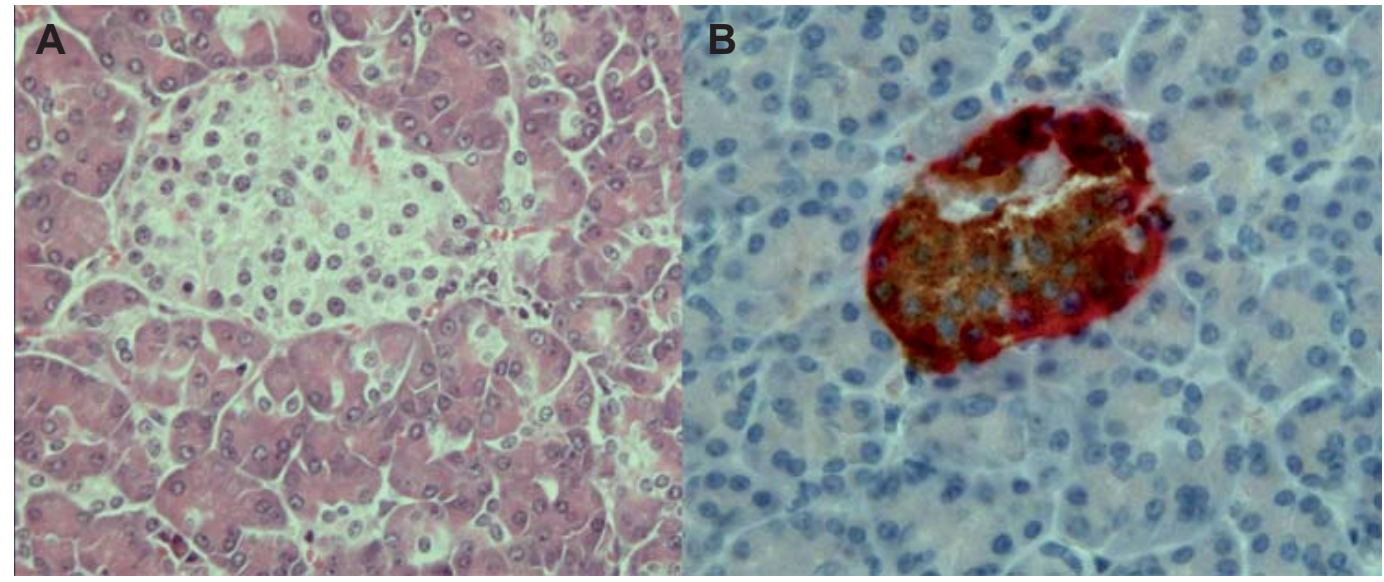

Figure 1.2. Haematoxylin and eosin staining showing a normal pancreatic islet $(A)$, and immunohistochemical staining for insulin (brown) and glucagon (red) in a normal pancreatic islet (B).
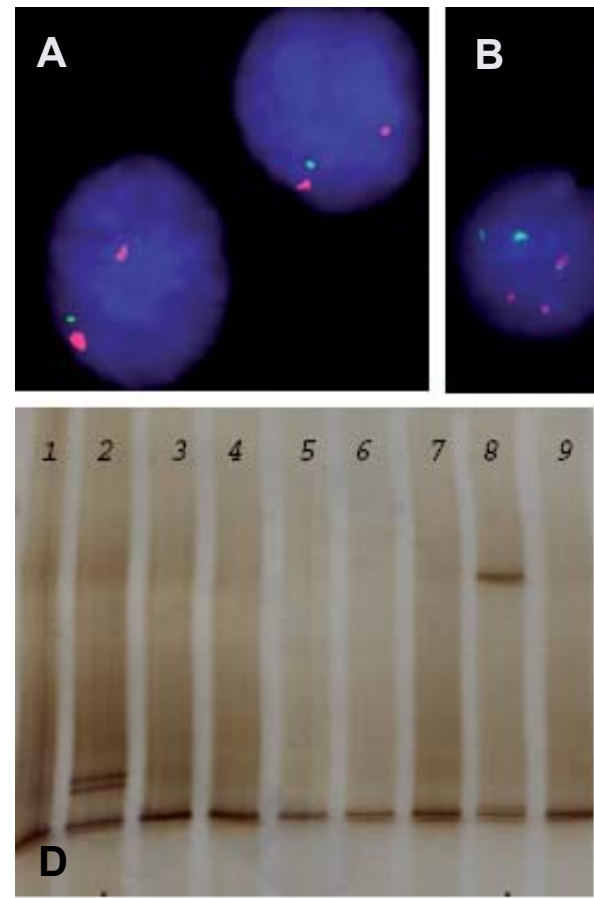

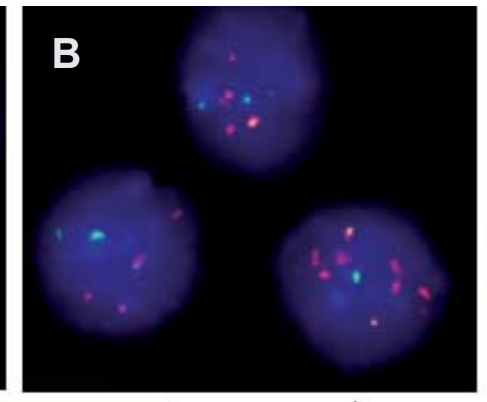

$$
\underset{220}{A C} \mid \operatorname{GTC} G C \text { T G } \mid \begin{array}{ll}
G C A \\
230
\end{array}
$$

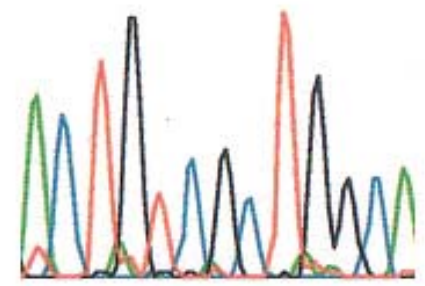

E

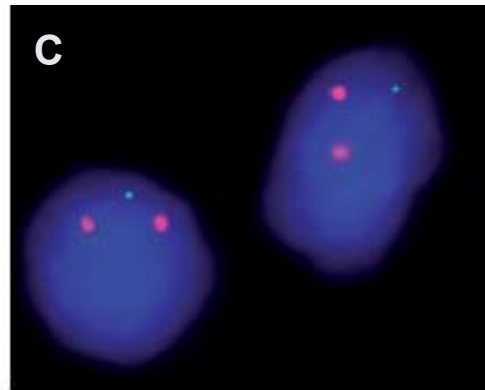

AC T GCA 220

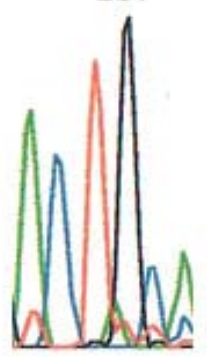

$\mathbf{F}$

Figure 2.2. Results of representative examples of insulinoma cases examined by FISH (see Table 2.2) and MEN1 mutation analysis. (A) Loss of 6q21 (green) with respect to centromere 6 (red) in patient 15. (B) Gain and amplification of $9 q 34$ (red) with respect to centromere 9 (green) in patient 10. (C) Loss of 11q13 (green) with respect to centromere 11 (red) in patient 2. (D) SSCP analysis of exon 10 of the MEN1 gene in seven tumors with a negative control (lane 1) and a positive control (lane 2). Lane 8 represents DNA from patient 14 (Table 2.2) harboring a MEN1 mutation. (E) The normal MEN1 sequence profile of exon 10, with the part deleted in (F) between the vertical lines. $(F)$ sequence profile of patient 14 with the MEN1 mutation, a 7 bp deletion (GTCGCTG) in exon 10. 
A Chromosome 9

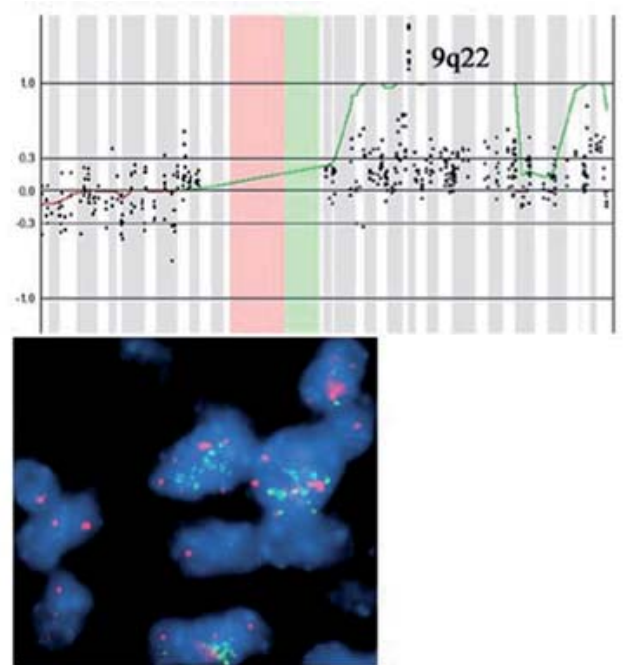

C Chromosome 11

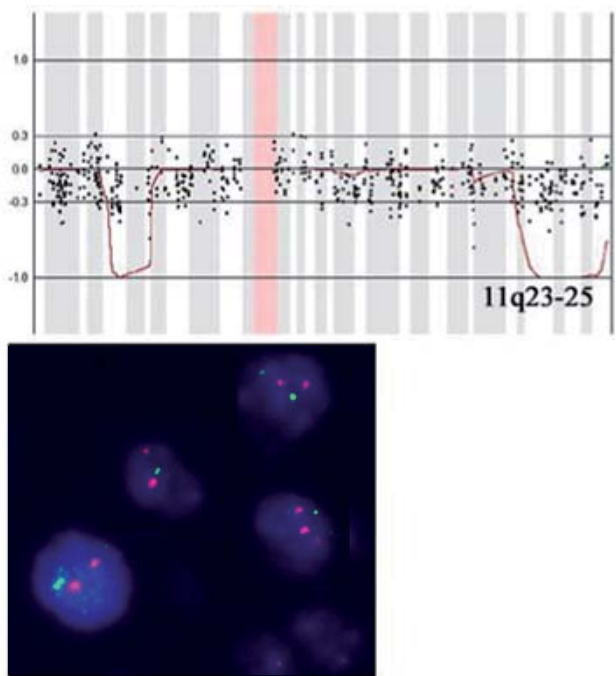

B Chromosome 4

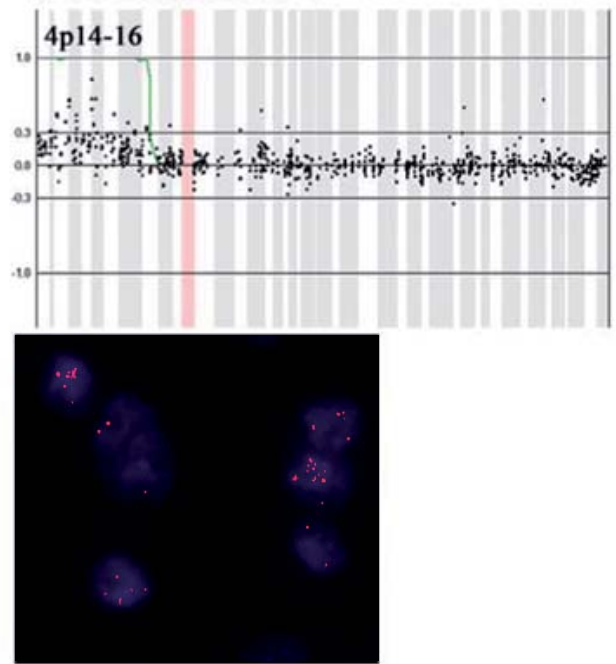

D Chromosome 22

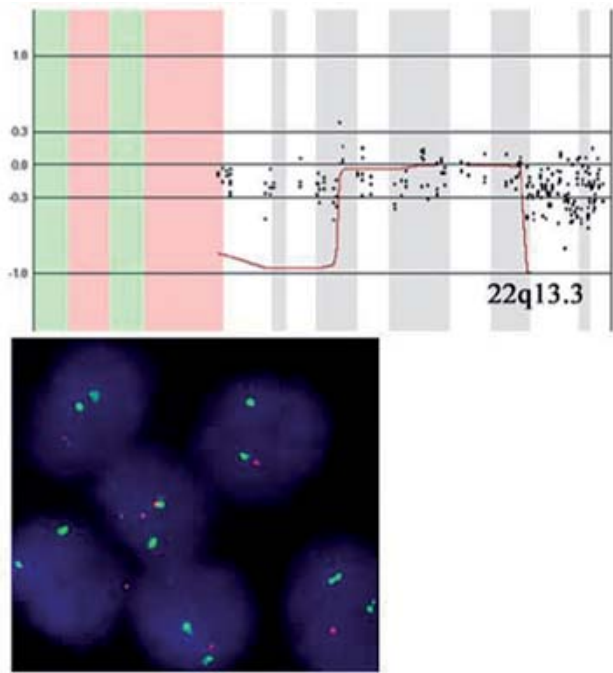

Figure 3.3. FISH validation of array $\mathrm{CGH}$ analysis showing $(\mathrm{A})$ amplification of $9 \mathrm{q} 22$ (green) with respect to centromere 9 (red) in tumor 1 (Table 3.2), (B) high-level gain of chromosome 4p15 (red) in tumor 2, (C) loss of chromosome 11q23 (green) with respect to centromere 11 (red) in tumor 6, and (D) loss of 22q13 (red) with respect to centromere 22 (green) in tumor 9.

A

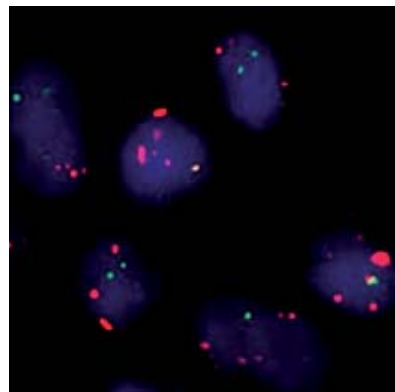

B

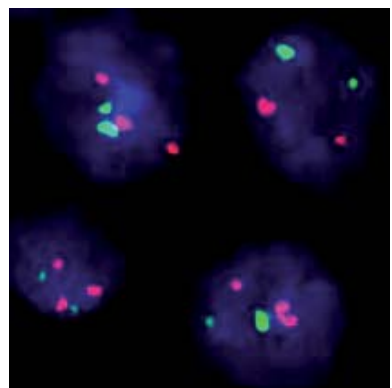

Figure 3.4. FISH analysis of patient 10 (Table 3.3) with both $9 q 32$ gain (red) and 22q13.1 loss (green) detected in the same cell (A), and compared to centromeres 1 (green) and 7 (red) (B). 
A

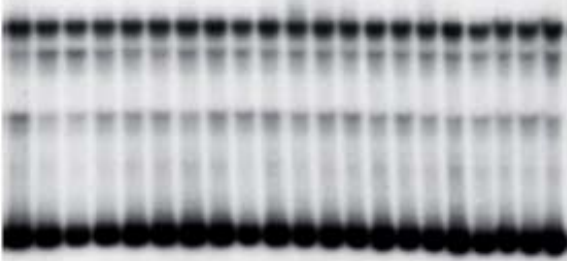

B
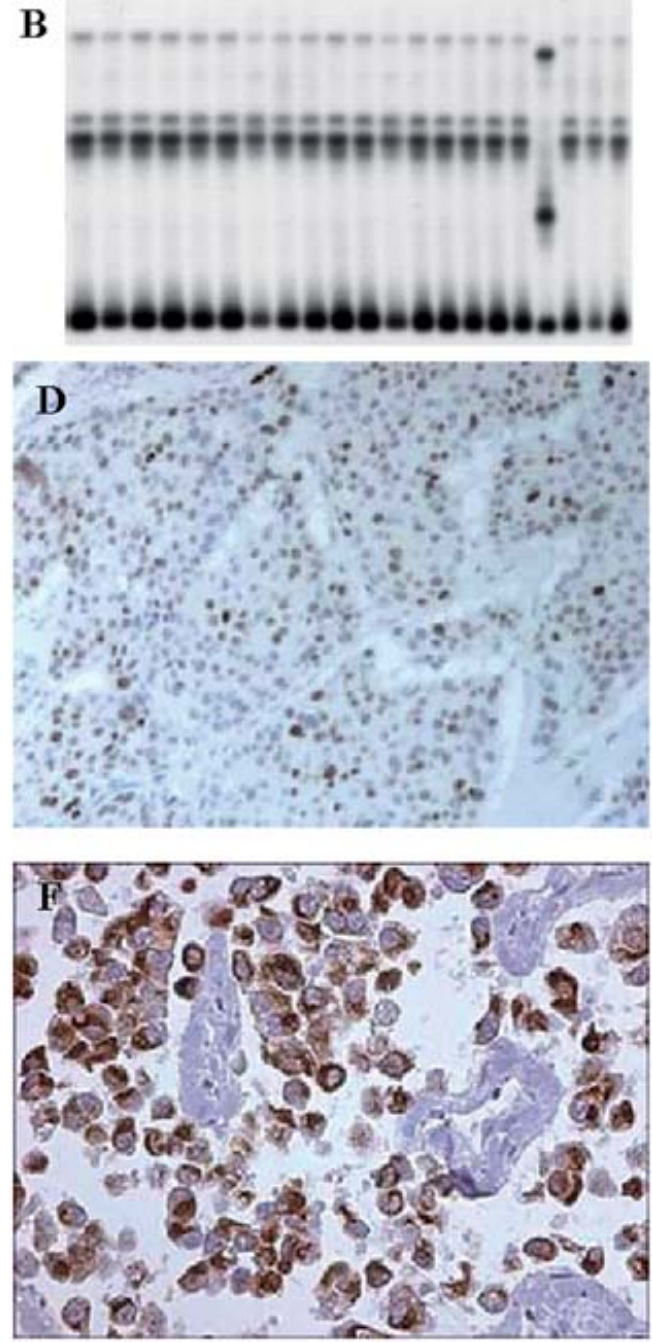

\section{R273S}

\section{CGT $\rightarrow$ AGT}

T $\quad \mathrm{G} \underset{\mathrm{C}}{\mathrm{A}} \mathrm{G} \quad \mathrm{T} \quad \mathrm{G}$
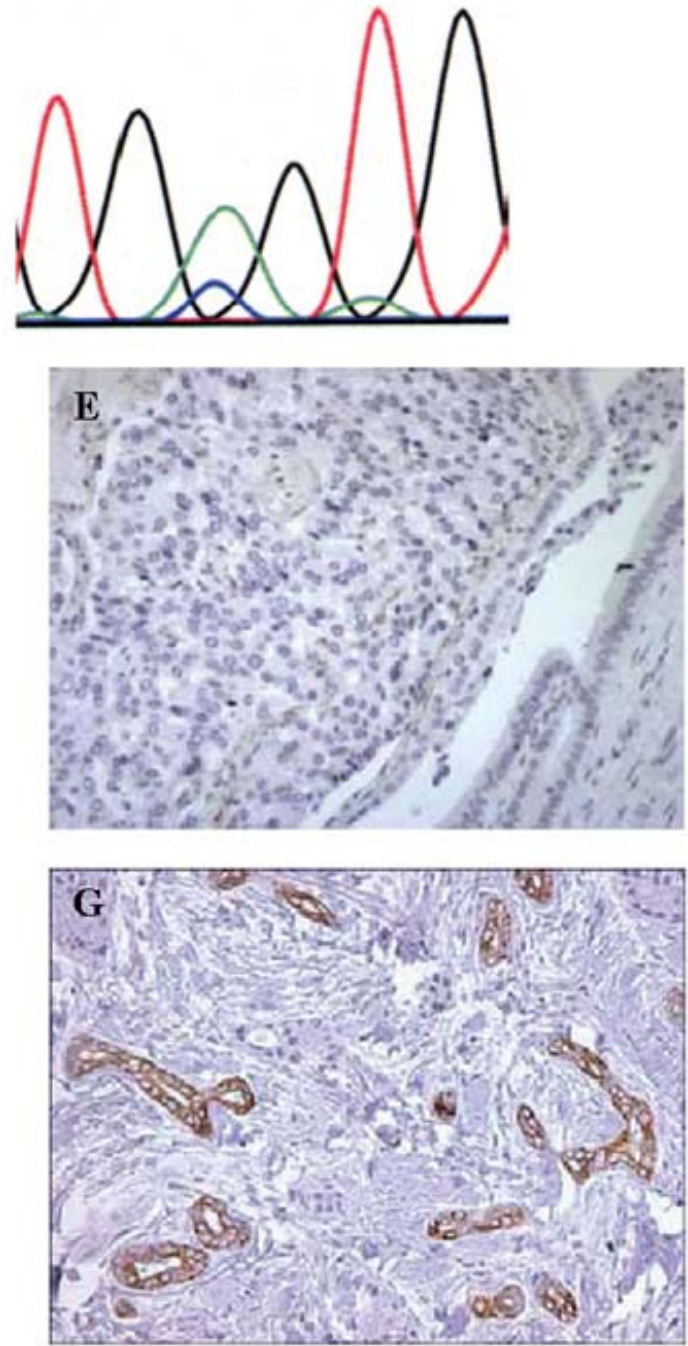

Figure 4.2. Mutation analysis of TP53, showing (A) SSCP analysis of exon $7 / 1$, showing no aberrations, (B) SSCP analysis of exon $8 / 1$, showing one tumor with an aberrant SSCP pattern (tumor 20 , table 4.3), and (C) sequence profile of tumor 20 with the TP53 mutation, arginine 273 serine. Immunohistochemistry for nuclear p53 and cytoplasmic CK19 expression, showing (D) a p53 positive insulinoma (tumor 20), (E) a p53 negative insulinoma (tumor 16), (F) a CK19 positive insulinoma (tumor 19), and (G) a CK19 negative insulinoma with positive staining in ductal cells (tumor 2). 


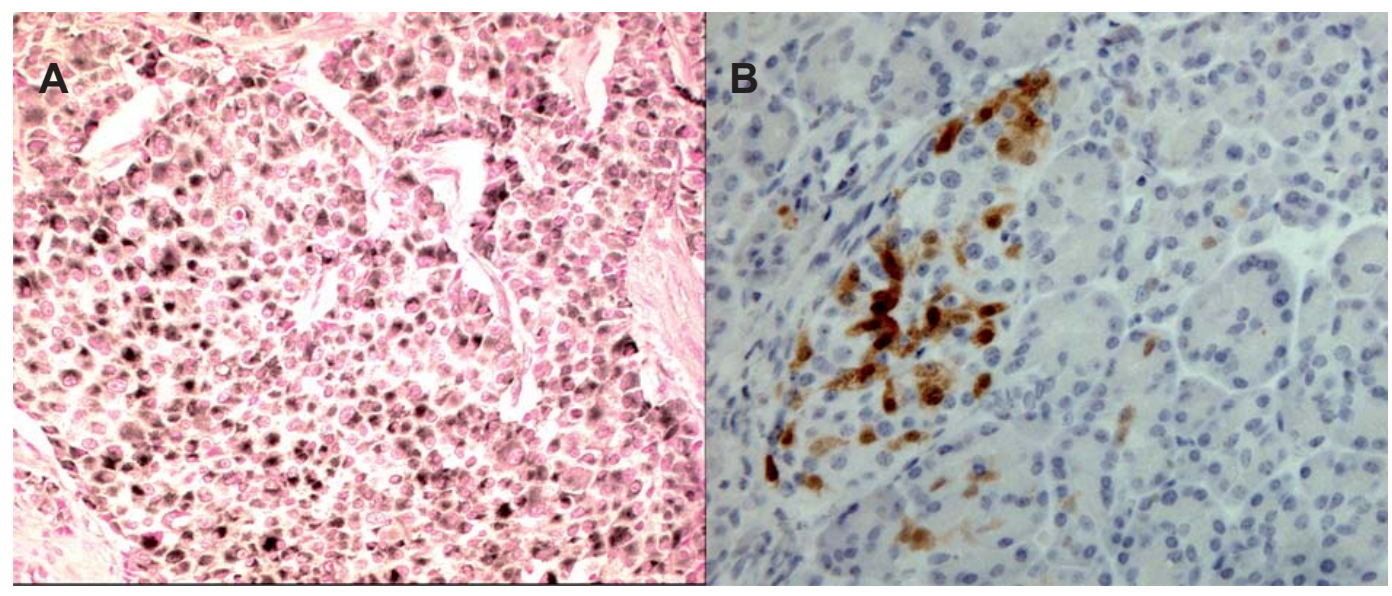

Figure 6.2. Positive immunostaining of the $c A b l$ protein in a malignant insulinoma (A), and positive immunostaining of $\mathrm{p} 16$ in the normal pancreatic islet (B). 


\section{LIST OF ABBREVIATIONS}

$\begin{array}{ll}\text { AW } & \text { Alive without disease } \\ \text { AWD } & \text { Alive with disease } \\ \text { BAC } & \text { Bacterial artificial chromosome } \\ \text { BSA } & \text { Bovine serum albumin } \\ \text { CDK } & \text { Cyclin-dependent kinase } \\ \text { CGH } & \text { Comparative genomic hybridization } \\ \text { CI } & \text { Confidence interval } \\ \text { CIN } & \text { Chromosomal instability } \\ \text { CK19 } & \text { Cytokeratin 19 } \\ \text { CRI } & \text { Chromosomal region of interest } \\ \text { CT } & \text { Computed tomography } \\ \text { DAB } & \text { diaminobenzidine } \\ \text { DAPI } & \text { 4',6-diamidino-2-phenylindole } \\ \text { DGGE } & \text { Denaturing gradient gel electrophoresis } \\ \text { DOC } & \text { Dead other cause } \\ \text { DOD } & \text { Dead of disease } \\ \text { EPT } & \text { Endocrine pancreatic tumor } \\ \text { ER } & \text { Endoplasmic reticulum } \\ \text { FISH } & \text { Fluorescence in situ hybridization } \\ \text { HCG } & \text { a-chain of human chorionic gonadotropin } \\ \text { HMM } & \text { Hidden markov models } \\ \text { LOH } & \text { Loss of heterozygosity } \\ \text { MEN1 } & \text { Multiple endocrine neoplasia type 1 } \\ \text { MRI } & \text { Magnetic resonance imaging } \\ \text { NF } & \text { Neurofibromatosis } \\ \text { NIPHS } & \text { non-insulinoma pancreatogenic hypoglycemia syndrome } \\ \text { OR } & \text { Odds ratio } \\ \text { PCR } & \text { Polymerase chain reaction } \\ \text { RT-PCR } & \text { Reverse transcriptase-polymerase chain reaction } \\ \text { SRI } & \text { Smallest region of interest } \\ \text { SSC } & \text { Saline sodium citrate } \\ \text { SSCP } & \text { Single-strand confirmation polymorphism } \\ \text { SSTR } & \text { somatostatin receptor subtype } \\ \text { TSC } & \text { Tuberosclerosis } \\ \text { VHL } & \text { Von Hippel Lindau } \\ \text { WHO } & \text { World Health Organisation } \\ & \end{array}$




\section{DANKWOORD}

Graag wil ik hier een kort woord van dank richten aan hen die mij hebben geholpen bij het tot stand komen van dit proefschrift.

Ten eerste, mijn promotor, Frans Ramaekers voor alle goede tips en het stellen van prioriteiten. Mijn co-promotor, Ernst-Jan Speel, die mij de gelegenheid gegeven heeft dit project te beginnen. Bedankt voor je hulp en voor alle ideeën, al waren het er vaak veel te veel.

Sandra voor alle hulp met de experimenten, je vriendschap en je rol als paranimf. Adriaan de Bruïne voor het bekijken van de coupes wanneer ik niet meer wist waar ik de tumor moest zoeken en voor het voorzitterschap bij de beoordelingscommissie.

Aurel Perren, thank you for the opportunity to work in your lab and your hospitality. Also for the important collaboration and the interesting discussions. Paul Komminoth, thank you for the helpful discussions, the good advices and the wonderful dinners at your house. Sonja Schmid, thank you for your help in the lab and the good time that I had in Zurich.

Britt Skogseid and Margaretha Halin, thank you for the good collaboration.

Albert Verhofstad, Leo Hofland, Ronald de Krijger en Piet Slootweg voor de mooie verzameling insulinomen. Winand Dinjens, Hein Sleddens, en Johannes Uytdewilligen voor de p53 mutatie analyse.

Joris Veltman voor alle hulp met het array CGH verhaal. Ad Geurts van Kessel, bedankt dat u me destijds voorgedragen hebt voor deze functie en voor de goede samenwerking. Ton Feuth voor de hulp met de analyse van de array CGH data. Karoly Szuhai, Jeroen Knijnenburg, Erik van Beers en Simon Joosse voor de hulp met het opzetten van de array CGH techniek in Maastricht.

Wouter de Herder, Ad Hermus, Alain Kummer, Anja Schmitt en Marco Volante voor de hulp bij het verzamelen van de patiënten data en Adri Voogd voor de statistische ondersteuning.

Verder iedereen van de afdeling Moleculaire Celbiologie voor de goede werksfeer. Annick voor het snijden van de paraffine coupes, de gezelligheid op de kamer en omdat je mijn paranimf wil zijn. Ton voor de nuttige discussies en Jeroen bedankt dat je dat ene glaasje nog even mee wou kleuren.

Natuurlijk wil ik ook pap en mam bedanken voor de onvoorwaardelijke steun, de fijne opbeurende gesprekken wanneer het nodig was en alle afleiding.

Opa voor uw enthousiasme en medeleven. En omdat u me telkens weer herinnerde aan de deadlines. Marjo en Piet omdat jullie altijd voor me klaarstaan.

Silvie voor het ontwerpen van de kaft van dit proefschrift en John voor de hulp met de lay-out. Peter bedankt! Waarvoor ik je moet bedanken weet ik nog steeds niet, maar omdat je er graag instaat: bedankt dat je mijn broertje bent!

Wodan voor de afleiding als (en waardoor) het me even niet meer lukte met schrijven. En tenslotte Guido, omdat jij er altijd voor me bent. 


\section{PUBLICATIONS}

\section{Original papers}

Bodmer D, Janssen I, Jonkers YMH, van den Berg E, Dijkhuizen T, Debiec-Rychter M, Schoenmakers E, Geurts van Kessel A. Molecular cytogenetic analysis of clustered sporadic and familial renal cell carcinoma-associated 3q13 approximately q22 breakpoints. Cancer Genet. Cytogenet. 2002; 136: 95-100.

Veltman JA, Jonkers YMH, Nuijten I, Janssen I, van der Vliet W, Huys E, Vermeesch J, Van Buggenhout G, Fryns JP, Admiraal R, Terhal P, Lacombe D, Geurts van Kessel A, Smeets D, Schoenmakers EF, van Ravenswaaij-Arts CM. Definition of a critical region on chromosome 18 for congenital aural atresia by arrayCGH. Am. J. Hum. Genet. 2003; 72: 1578-84.

Jonkers YMH, Claessen SMH, Perren A, Schmid S, Komminoth P, Verhofstad AA, Hofland LJ, de Krijger RR, Slootweg PJ, Ramaekers FCS, Speel EJM. Chromosomal instability predicts metastatic disease in patients with insulinomas. Endocr. Relat. Cancer 2005; 12: 435-47.

Jonkers YMH, Claessen SMH, Veltman JA, Geurts van Kessel A, Dinjens WNM, Skogseid B, Ramaekers FCS, Speel EJM. Molecular parameters associated with insulinoma progression: chromosomal instability versus p53 and CK19 status. Cytogenet. Genome Res. 2006; 115: 289-297.

Jonkers YMH, Claessen SMH, Feuth T, Geurts van Kessel A, Ramaekers FCS, Veltman JA, Speel EJM. Novel candidate tumor suppressor gene loci on chromosomes 11q23-24 and 22q13 involved in human insulinoma tumorigenesis. J. Pathol. 2006, 210: 450-458.

Jonkers YMH, Ramaekers FCS, Speel EJM. Moleculaire veranderingen tijdens de progressie van insulinomen. Kanker, in press.

Jonkers YMH, Ramaekers FCS, Speel EJM. Molecular alterations during insulinoma tumorigenesis. Accepted for publication in BBA Reviews on Cancer

Jonkers YMH, Claessen SMH, Perren A, Schmitt AM, Hofland LJ, de Herder WW, de Krijger RR, Verhofstad AAJ, Hermus AR, Kummer JA, Skogseid B, Volante M, Voogd AC, Ramaekers FCS, Speel EJM. DNA copy number status is a powerful predictor of poor survival in insulinoma patients. Submitted for publication 


\section{Abstracts}

Speel EJM, Jonkers YMH, Claessen SMH, Perren A, Komminoth P, Ramaekers FCS. MEN 1 mutations and genomic alterations in sporadic benign and malignant insulinomas. J. Int. Med. 2004; 255: 723-724 (abstract \#8003)

Jonkers YMH, Claessen SMH, Komminoth P, Perren A, Verhofstad AA, Hofland LJ, De Krijger RR, Slootweg PJ, Veltman JA, Ramaekers FCS, Speel EJM. Genomic alterations in benign and malignant insulinomas as revealed by conventional and array $\mathrm{CGH}$. Proc. Amer. Assoc. Cancer Res. 2004; 45: 654 (abstract \#2837)

Speel EJM, Jonkers YMH, Claessen SMH, Perren A, Schmid S, Komminoth P, Verhofstad AA, Hofland LJ, de Krijger RR, Slootweg PJ, Ramaekers FCS. Chromosomal instability predicts the malignant phenotype in sporadic insulinomas. Virchows Arch. 2005; 447: 188 (abstract \#O-160)

Jonkers YMH, Claessen SMH, Feuth T, Geurts van Kessel A, Ramaekers FCS, Veltman JA, Speel EJM. Frequent loss of chromosome $1 p$ and $22 q$ loci in insulinomas. Eur. J. Med. Genet. 2005; 48: 501 (abstract \#P35)

Jonkers YMH, Claessen SMH, Feuth T, Geurts van Kessel A, Ramaekers FCS, Veltman JA, Speel EJM. Novel tumor suppressor gene loci on chromosomes 1p, 11q and 22q in insulinomas. Proc. Amer. Assoc. Cancer Res. 2006; 47: 99 (abstract \#423)

Jonkers YMH, Claessen SMH, Feuth T, Geurts van Kessel A, Ramaekers F, Veltman JA, Speel EJM. Frequent loss of chromosome 11q and 22q loci in insulinomas. Neuroendocrinol. 2006; 83: 58 (abstract \#B13) 


\section{CURRICULUM VITAE}

Yvonne Margaretha Hendrika Jonkers werd geboren op 15 januari 1979 te Tegelen. In 1997 behaalde zij het VWO diploma aan het College den Hulster te Venlo. In datzelfde jaar begon zij met de studie Biomedische Gezondheidswetenschappen aan de Katholieke Universiteit Nijmegen. Tijdens haar studie heeft zij stages gelopen bij de afdelingen Interne Geneeskunde (Dr. B.J. Kullberg), Biomaterialen (Prof. Dr. J.A. Jansen) en Antropogenetica (Prof. Dr. A. Geurts van Kessel) van het UMC St. Radboud te Nijmegen. Na haar afstuderen in 2001 tot januari 2003 was zij werkzaam als onderzoeksassistent bij de microarray faciliteit van het UMC St. Radboud (Dr. J.A. Veltman, Prof. Dr. A. Geurts van Kessel). In januari 2003 tradt zij in dienst als assistent in opleiding bij de afdeling Moleculaire Celbiologie van de Universiteit Maastricht (Dr. E.J.M. Speel, Prof. Dr. F.C.S. Ramaekers). Gedurende haar promotieonderzoek is zij 1,5 maand werkzaam geweest op het laboratorium van Dr. A. Perren bij de afdeling Pathologie van het Universiteitsziekenhuis te Zürich, Zwitserland. In 2005 ontving zij de René Vogels oncologie beurs. In 2006 ontving zij een prijs voor beste abstract gedurende de ENETS meeting in Praag. Sinds mei 2007 is zij werkzaam als postdoc op de afdeling Moleculaire Celbiologie van de Universiteit Maastricht. 
